Portland State University

PDXScholar

$12-20-2021$

\title{
Characterization and Interpretation of Feldspathic Chromite Assemblages (FCAs) in Four Ordinary Chondrites: an Electron Backscatter Diffraction (EBSD) Study
}

Kimberly Louisa Maccini Portland State University

Follow this and additional works at: https://pdxscholar.library.pdx.edu/open_access_etds

Part of the Geology Commons Let us know how access to this document benefits you.

\section{Recommended Citation}

Maccini, Kimberly Louisa, "Characterization and Interpretation of Feldspathic Chromite Assemblages (FCAs) in Four Ordinary Chondrites: an Electron Backscatter Diffraction (EBSD) Study" (2021). Dissertations and Theses. Paper 5878.

https://doi.org/10.15760/etd.7749

This Thesis is brought to you for free and open access. It has been accepted for inclusion in Dissertations and Theses by an authorized administrator of PDXScholar. Please contact us if we can make this document more accessible: pdxscholar@pdx.edu. 
Characterization and Interpretation of Feldspathic Chromite Assemblages (FCAs) in Four Ordinary Chondrites: An Electron Backscatter Diffraction (EBSD) Study

\title{
by
}

Kimberly Louisa Maccini

A thesis submitted in partial fulfillment of the requirements for the degree of

\author{
Master of Science \\ in \\ Geology
}

Thesis Committee:

Alexander Ruzicka, Chair

Richard Hugo

Melinda Hutson

Portland State University

2021 


\begin{abstract}
Feldspathic Chromite Assemblages (FCAs) are chemically distinctive assemblages rich in $\mathrm{Na}, \mathrm{Al}$, and $\mathrm{Cr}$ that are found in a variety of chondrites. They consist of concentrations of chromite associated mainly with feldspathic material, either feldspar or the glassy material known as maskelynite. Professor Alan Rubin (2003) has proposed that some FCAs formed by shock melting, but the origin of different types of feldspathic chromite assemblages are unclear and have not been studied with more modern techniques such as Electron Backscatter Electron Diffraction (EBSD).

Here EBSD was used to study FCAs in four metamorphosed ordinary chondrites of different shock stages, including Estacado (H6, S1), Spade (H6, S4), NWA 13533 (L6, S4), and Alfianello (L6, S5). EBSD results indicate that FCAs can be grouped into three different assemblages, including Coarse Clumped Chromite (CCC), Fine Clumped Chromite (FCC), and Chromite Poor (CP) assemblages. CCCs are compact assemblages that contain chromite crystals often larger than $5 \mu \mathrm{m}$ in diameter size with little physical distance between adjacent chromite grains. FCCs are compact assemblages that contain numerous chromite grains less than $5 \mu \mathrm{m}$ in diameter that have physical space between the chromite grains. CPs are assemblages that contains chromite congregated in one area but with less chromite grains than the FCC or CCC assemblages.

The four meteorites used in this study are a mix of high and low shock stage. Out of the three assemblage types, it was found that CCCs were present in both high and low shocked meteorites. FCCs were also found in both high and low shock meteorites, but had a noticeable absence in Spade. The two CP assemblages were present only in higher
\end{abstract}


shocked meteorites (Spade and NWA 13533). Quantitative characteristics (grain sizes of chromite, grain number density of chromite, grain lattice preferred orientation of chromite, and grain orientation spread (or GOS)) of these assemblages and their minerals do not appear to be different between high and low shock meteorites other than differences in the grain orientation spread. These GOS characteristics appear more related to the host meteorite. We postulate that the origins of the FCCs are an end product of exsolution of a previous grain, while the CCCs origins are more likely to be aggregates of pre-existing grains or grain-clumps that have been crystallized from a melt. The CPs found in this study do not particularly fit either model.

My findings support those of Rubin (2003) in terms of Estacado being annealed but support only some of the findings of Rubin and Jones (2003) for Spade, namely that Spade is a melt breccia with the plagioclase having been melted. 


\section{Acknowledgements}

First and foremost, I would like to give a heart-felt thank you to Dr. Alexander Ruzicka, for putting up with my nonsense and constant connections made between meteorites and food. Your enthusiasm for meteoritics opened my eyes to a field of study I had not previously given much consideration to, and for that I will be endlessly grateful. Additionally, I would like to thank my committee members, Richard Hugo, and Melinda Hutson, for your guidance and assistance in crafting this thesis.

I would also like to thank my fellow graduate students, who were helpful and inspiring and held me up when I was down. My time at Portland State University will forever be a cherished memory that you all helped create.

A huge thanks you must also be given to Landon, who sat through so many demonstrations of my presentation, and listened to endless drafts of my thesis that I did not know I was speaking out loud. You are the rock that got me through it all and I can only hope to one day repay the love and encouragement you showed during this process.

Lastly, the largest thank you goes out to my parents and siblings. Dad, Mom, Jessica, Joey, and Mikey, your support during this journey kept me going, thank you, thank you, thank you for believing in me and my dreams. 


\section{Table Of Contents}

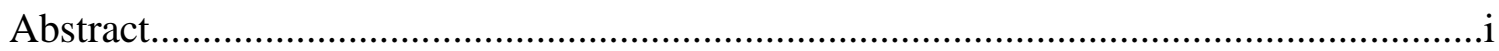

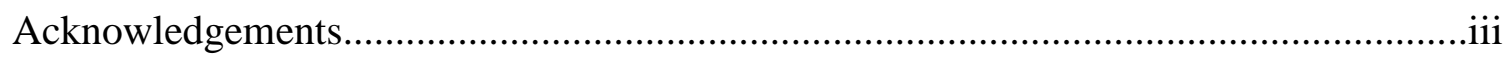

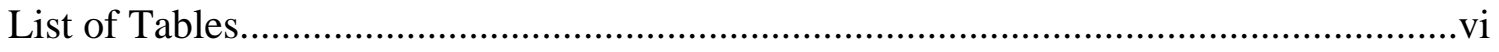

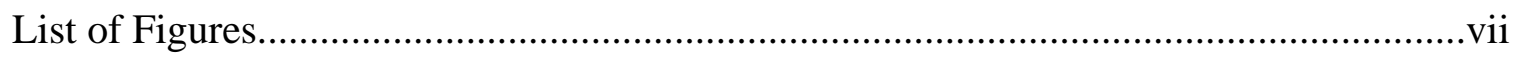

List of Abbreviations \& Symbols............................................................................ii

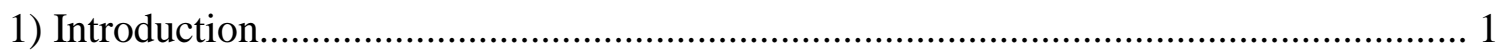

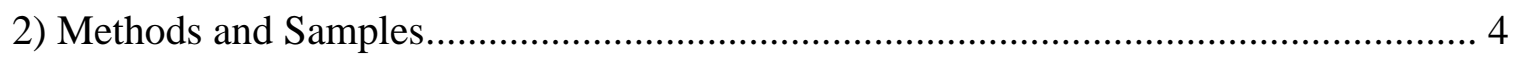

2.1 Methodology ................................................................................... 4

2.2 Shock Classification..................................................................... 4

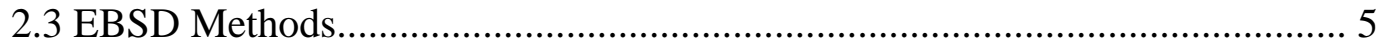

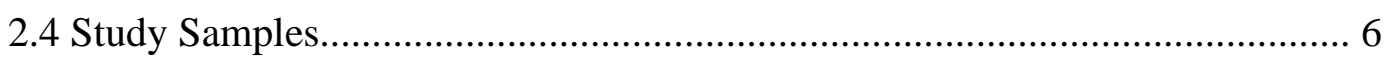

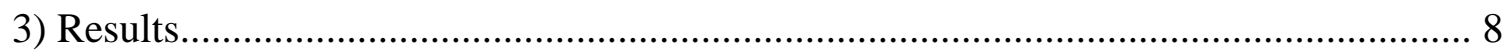

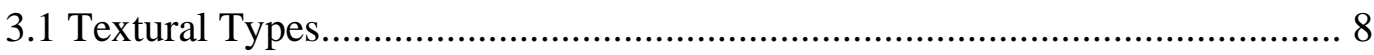

3.2 Characterization of Assemblages........................................................ 11

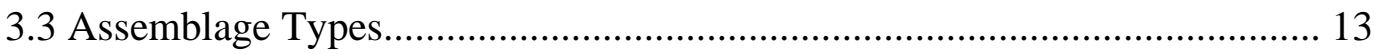

3.4 A Quantitative EBSD Parameters for FCA Groups.................................. 15

3.5 Orientation and Deformation Data for Example FCA Assemblages............. 25

3.6 LAM \& Mini-LAM Data........................................................................ 39

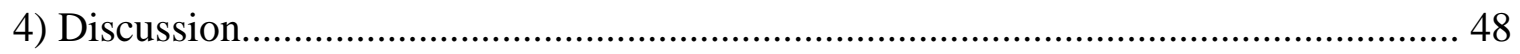

4.1 General Meteorites (Deformation-Thermal History)................................ 48

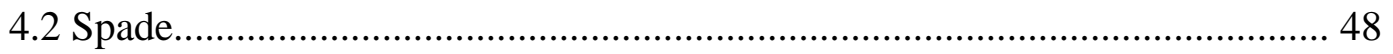

4.3 NWA 13533 \& Alfianello..................................................................... 49 
4.6 What is the Bigger Picture?.................................................................... 56

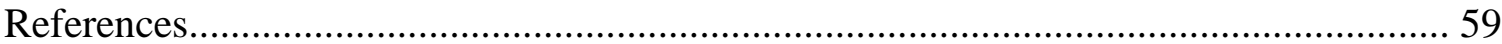

Appendix A

Optical Microscopy.

Appendix B

EDS-EBSD

Appendix C

Subsets and other data. 
List of Tables

\begin{tabular}{|c|c|c|}
\hline Table 1 & Meteorites used in this study for EBSD work & Pg. 7 \\
\hline Table 2 & $\begin{array}{l}\text { Listing of all Targeted Maps, including metadata and } \\
\text { basic data for assemblages }\end{array}$ & Pg. 12 \\
\hline Table 3 & $\begin{array}{l}\text { Chromite data for assemblages in this study that have } \\
\text { been classified as Fine Clumped Chromite (FCC). } \\
\text { These assemblages have generally the smallest } \\
\text { Chromite Coarseness Ratio among FCAs in this } \\
\text { study. }\end{array}$ & Pg. 13 \\
\hline Table 4 & $\begin{array}{l}\text { Chromite data for assemblages in this study that have } \\
\text { been classified as Coarse Clumped Chromite (CCC). } \\
\text { These assemblages have generally the largest } \\
\text { Chromite Coarseness Ratio of FCAs in this study. }\end{array}$ & Pg. 14 \\
\hline Table 5 & $\begin{array}{l}\text { Chromite data for assemblages in this study that have } \\
\text { been classified as Chromite Poor (CP). Note these } \\
\text { assemblages have the lowest Area Fraction of } \\
\text { Chromite of all the Targeted Maps in this study. }\end{array}$ & Pg. 14 \\
\hline Table 6 & $\begin{array}{l}\text { Plagioclase details for the Targeted Maps acquired } \\
\text { for this study }\end{array}$ & Pg. 14 \\
\hline Table 7 & $\begin{array}{l}\text { Olivine data including shock stage (weighted and } \\
\text { conventional), and the EBSD parameters } \mathrm{R}_{2-10} \text { and } \\
\mathrm{Sk}_{\mathrm{d}}>50 \text { based on Large Area Maps. The implied } \\
\text { thermal history based on the EBSD parameters is } \\
\text { shown following Ruzicka and Hugo (2018). Shock } \\
\text { stage data for Spade, Estacado, and Alfianello after } \\
\text { Friedrich et al. (2017). }\end{array}$ & Pg. 40 \\
\hline Table 8 & $\begin{array}{l}\text { Mean Grain Orientation Spread (GOS) values for } \\
\text { equivalent grain sizes greater than } 50 \mu \mathrm{m} \text { and for } \\
\text { equivalent grain sizes of } 5-15 \mu \mathrm{m} \text { for olivine and } \\
\text { chromite, based on LAM and mini-LAM data. }\end{array}$ & Pg. 42 \\
\hline Table 9 & $\begin{array}{l}\text { Mean GOS table for all Targeted Maps and Large } \\
\text { Area Maps. Shows the grain size }(\mathrm{d}>50 \& \mathrm{~d} 5-15) \\
\text { and standard deviation of GOS for Olivine, Chromite, } \\
\text { and Plagioclase. }\end{array}$ & Pg. 44 \\
\hline
\end{tabular}


List of Figures

\begin{tabular}{|c|c|c|}
\hline Figure 1 & An example of Fine Clumped Chromite (FCC) in NWA 13533 & Pg. 9 \\
\hline Figure 2 & An example of Coarse Clumped Chromite (CCC) in Estacado & Pg. 10 \\
\hline Figure 3 & An example of a Chromite Poor (CP) assemblage in Spade & Pg. 11 \\
\hline Figure 4 & Chromite Coarseness Ratio (grain size) vs. Clump density & Pg. 15 \\
\hline Figure 5 & Chromite Coarseness Ratio (grain size) vs. LPO \# & Pg. 16 \\
\hline Figure 6 & $\begin{array}{l}\text { Chromite Coarseness Ratio (grain size) vs. Area Fraction of } \\
\text { Chromite }\end{array}$ & Pg. 17 \\
\hline Figure 7 & $\begin{array}{l}\text { Chromite Coarseness Ratio (grain size) vs. Mean GOS of } \\
\text { chromite, all d }\end{array}$ & Pg. 18 \\
\hline Figure 8 & Clump Density vs. Mean GOS of chromite, all d & Pg. 18 \\
\hline Figure 9 & Clump Density vs. LPO \# & Pg. 19 \\
\hline Figure 10 & Area Fraction of Chromite vs. Clump Density & Pg. 20 \\
\hline Figure 11 & Area Fraction of Chromite vs. LPO\# & Pg. 21 \\
\hline Figure 12 & Area Fraction of Chromite vs. Mean GOS of chromite, all d & Pg. 21 \\
\hline Figure 13 & Mean Grain Orientation Spread (GOS) for all d & Pg. 22 \\
\hline Figure 14 & $\begin{array}{l}\text { Mean Grain Orientation Spread (GOS) for all } \mathrm{d} \text { for chromite } \\
\text { on the } \mathrm{x} \text {-axis, versus Chromite } \mathrm{d} \text { 5-15 on the } \mathrm{y} \text {-axis }\end{array}$ & Pg. 23 \\
\hline Figure 15 & $\begin{array}{l}\text { Mean Grain Orientation Spread (GOS) for all } \mathrm{d} \text { for chromite } \\
\text { on the } \mathrm{x} \text {-axis, versus Chromite } \mathrm{d}<5 \text { on the } \mathrm{y} \text {-axis }\end{array}$ & Pg. 24 \\
\hline Figure 16 & FCC example 1 & Pg. 29 \\
\hline Figure 17 & FCC example 2 & Pg. 30 \\
\hline Figure 18 & CCC example 1 & Pg. 31 \\
\hline Figure 19 & CCC example 2 & Pg. 32 \\
\hline Figure 20 & CP example 1 & Pg. 33-34 \\
\hline Figure 21 & CP example 2 & Pg. 35-36 \\
\hline Figure 22 & Recrystallization map, Spade 1 & Pg. 37 \\
\hline Figure 23 & Recrystallization map, Spade 2 & Pg. 38 \\
\hline Figure 24 & $\begin{array}{l}\text { Temperature (R2-10 parameter) vs. Annealing Parameter } \\
(\mathrm{skd}>50 \text { parameter) }\end{array}$ & Pg. 40 \\
\hline Figure 25 & $\begin{array}{l}\text { Mean Grain Orientation Spread (GOS) of grain sizes (d) } \\
\text { greater than } 50 \text { for olivine versus chromite in all four samples } \\
\text { Large Area Maps (LAM) }\end{array}$ & Pg. 42 \\
\hline Figure 26 & $\begin{array}{l}\text { Mean Grain Orientation Spread (GOS) of grain sizes (d) 5-15 } \\
\text { for olivine verses chromite in all four samples Large Area } \\
\text { Maps (LAM) }\end{array}$ & Pg. 43 \\
\hline Figure 27 & Spade mini-LAM GOS15 map & Pg. 45 \\
\hline Figure 28 & Estacado LAM GOS15 map & Pg. 45 \\
\hline Figure 29 & Alfianello LAM GOS15 map & Pg. 46 \\
\hline Figure 30 & NWA 13533 LAM GOS15 map for olivine & Pg. 47 \\
\hline Figure 31 & LPO \# vs. Mean GOS of chromite, all d & Pg. 54 \\
\hline
\end{tabular}


List of Abbreviations \& Symbols

\begin{tabular}{|c|c|c|}
\hline Abbreviation & Definition & Page \# \\
\hline SEM & Scanning Electron Microscope & 3 \\
\hline EBSD & Electron Backscatter Diffraction & 3 \\
\hline EDS & $\begin{array}{l}\text { Energy Dispersive Spectrometer (or Energy Dispersive } \\
\text { Spectrometry) }\end{array}$ & 5 \\
\hline $\mathrm{OM}$ & Optical Microscopy & 4 \\
\hline FCA & Feldspathic Chromite Assemblage & 1 \\
\hline FCC & Fine Clumped Chromite assemblage & 8 \\
\hline $\mathrm{CCC}$ & Coarse Clumped Chromite assemblage & 10 \\
\hline $\mathrm{CP}$ & Chromite Poor assemblage & 11 \\
\hline $\mathrm{d}$ & $\begin{array}{l}\text { Grain Size (equivalent diameter of a grain with the measured } \\
\text { area, in units of microns) }\end{array}$ & 15 \\
\hline LAM & EBSD Large Area Map & 4 \\
\hline TM & EBSD Targeted Map & 4 \\
\hline GOS & $\begin{array}{l}\text { Grain Orientation Spread, an EBSD metric of the average } \\
\text { misorientation within a grain, given in degrees }\end{array}$ & 5 \\
\hline MOS & $\begin{array}{l}\text { Maximum Orientation Spread, an EBSD metric of the } \\
\text { maximum misorientation within a grain, given in degrees }\end{array}$ & viii \\
\hline GROD angle & $\begin{array}{l}\text { Grain Reference Orientation Deviation angle, an EBSD } \\
\text { metric of the misorientation of a given pixel within a grain } \\
\text { from the average misorientation of the grain, in degrees }\end{array}$ & 5 \\
\hline IPF & $\begin{array}{l}\text { Inverse Pole Figure, an EBSD pole figure that displays the } \\
\text { orientation of a grain (crystal direction or plane) relative to a } \\
\text { sample } \mathrm{x}, \mathrm{y}, \mathrm{z} \text { coordinate system; IPF orientations can also } \\
\text { be displayed in maps using false color schemes }\end{array}$ & 5 \\
\hline LPO & Lattice Preferred Orientation & 6 \\
\hline $\mathrm{LPO} \# \Delta_{<100\rangle}$ & $\begin{array}{l}\text { LPO strength for chromite, given as the difference between } \\
\text { maximum MUD and minimum MUD values in a }<100>\text { pole } \\
\text { figure plot for chromite, based on 15-degree half-width } \\
\text { contouring }\end{array}$ & 13 \\
\hline$\% \mathrm{~d}>5 />1$ & $\begin{array}{l}\text { A measure of overall grain coarseness, given by the } \\
\text { percentage of grains with } d>5 \text { relative to grains with } d>1\end{array}$ & 15 \\
\hline $\mathrm{n}_{\mathrm{g}}$ & number of grains & 12 \\
\hline CRA & $\begin{array}{l}\text { Crystal Rotation Axis plot, an EBSD plot showing } \\
\text { misorientation rotation axis directions in a crystal reference } \\
\text { frame }\end{array}$ & viii \\
\hline MUD & $\begin{array}{l}\text { Multiples of Uniform Distribution, a measure of the } \\
\text { deviation of a spatial distribution from a totally random } \\
\text { spatial distribution in a pole figure or CRA plot, with MUD } \\
>1 \text { indicating an excess relative to a random spatial } \\
\text { distribution (MUD }=1 \text { ), and MUD }<1 \text { indicating a deficit } \\
\text { relative to a random spatial distribution }\end{array}$ & viii \\
\hline
\end{tabular}




\section{1) INTRODUCTION}

Felspathic Chromite Assemblages (FCAs) are chemically distinctive assemblages rich in $\mathrm{Na}, \mathrm{Al}, \mathrm{Si}$, and $\mathrm{Cr}$ (as well as other various elements) that are found in a variety of chondrites. Composed chiefly of Cr-spinel (chromite) and feldspathic material (plagioclase or feldspathic glass), they are widely present in ordinary chondrites, where they take on a variety of textural forms, both inside and outside of chondrules (Ramdohr, 1967; Bischoff and Keil, 1984; Krot and Ivanova, 1992; Krot and Rubin, 1993; Rubin, 2003, 2004). Previously called aggregate (or heap) chromite, pseudomorphous (or decomposition) chromite (among other types; Ramdohr, 1967, 1973), or chromite plagioclase assemblages (Rubin, 2003), they are here called feldspathic chromite assemblages (FCAs) instead, to acknowledge that feldspathic glass sometimes occurs instead of plagioclase (Ramdohr, 1967, 1973; Rubin, 2003). This feldspathic glass corresponds to the shock-produced material known as maskelynite (e.g., Chen and El Goresy, 2000; Rubin, 2003; Fritz et al., 2005). Rubin (2003) found FCAs in every equilibrated ordinary chondrite in which he looked, suggesting they could be important to understanding the thermal histories of these chondrites and their parent asteroids. It has been proposed that at least some FCAs formed at high temperatures (Ramdohr, 1967, 1973) by shock melting (Krot and Rubin, 1993; Rubin, 2003), but whether all textural varieties formed by shock melting, and how their compositions, mineralogies, and textural variety were established, has not been adequately explained in detail.

Chromite assemblages can occur both within and outside chondrules. Chondrules are rounded beads of rock that have textures indicating they cooled from melt, possibly as free-floating melt droplets. In some chondrules, chromite is a major component together 
with albitic plagioclase (Ramdohr, 1967; Krot and Rubin, 1993; Krot et al., 1993). Ramdohr $(1967,1973)$ noted that some chromite-rich chondrules in chondrites are firmly intergrown with the meteorite matrix and are bound by feldspar (or feldspathic glass) at the chondrule-matrix contact, as if they had been welded to the meteorite. Other assemblages form inclusions, which are irregularly shaped, and which could have formed in situ (Rubin 2003, 2004). FCAs of the inclusion type range in size from 200-300 $\mu \mathrm{m}$ across, with $0.2-20 \mu \mathrm{m}$ size euhedral, subhedral, anhedral, and rounded chromite grains surrounded by plagioclase or glass of plagioclase composition (Rubin 2003).

If FCAs did form by shock processes, one might expect other evidence for shock deformation in the chondrites. Petrographic criteria for shock deformation in olivine and feldspar, utilizing an optical microscope, can be used to assign chondrites to one of six shock stages (S1 through S6) representing increasing shock pressure (Stöffler et al., 1991, 2018, 2019). These petrographic criteria include the formation of planar microfractures and undulose-mosaic extinction in olivine, and undulose-mosaic extinction or the formation of a feldspathic glass (maskelynite) for plagioclase (Stöffler et al., 1991, 2019). However, many of the chondrites that contain FCAs also have low-shock stages (S1 or S2) (Rubin, 2003, 2004). This has been interpreted as indicating early shock deformation to produce the FCAs, followed by annealing to obliterate deformation effects (Rubin, 2003, 2004). If a shock melt origin for all FCAs is correct, for a FCA to appear in an unshocked (S1) meteorite would mean that it would have had to have been shocked, and then annealed to remove the obvious effects of shock, with the notable exception of the FCAs themselves (Rubin, 2003, 2004). Rubin (2003, 2004) has suggested that regardless of shock stage, the FCAs can be used as shock indicators. 
More recently, electron backscatter diffraction (EBSD) techniques have been used to evaluate shock deformation in chondrites (e.g., Ruzicka and Hugo, 2018; Hugo et al., 2019). These techniques utilize an EBSD detector attached to a scanning electron microscope (SEM) to identify mineral structures and quantify crystal orientations. Such data can be used to study crystal fabrics and deformation (Prior et al., 2009). Ruzicka and Hugo (2018) and Hugo et al. (2019) developed additional EBSD metrics to evaluate the extent of shock deformation, post-shock annealing, and pre-shock deformation temperature, which are important variables for understanding the shock histories of chondrites (Ruzicka et al., 2015).

The purpose of this study is to 1) identify the characteristics of the different assemblages by quantitative EBSD metrics, 2) use the characteristics of these assemblages to determine whether there are any differences between low and high shock stage meteorites, 3) interpret how these assemblages may have formed, and 4) test the model of shock followed by annealing of Rubin (2003).

What was investigated in this study were FCAs found as inclusions within the meteorite samples, notably they presented as irregular shapes, as opposed to chondrules which are spherical. These inclusions contain multiple chromite grains that are associated with feldspathic material (mostly appearing as plagioclase, and maskelynite). This study focused on the FCAs that have been described as "chromite plagioclase assemblages" by Rubin (2003) and "pseudomorphic" or "aggregated chromite assemblages" by Ramdohr $(1967,1973)$. 


\section{2) METHODS AND SAMPLES}

\subsection{Methodology:}

Thin sections of meteorites in the Cascadia Meteorite Laboratory (CML) collection were surveyed using Optical Microscopy (OM) with a Leica DM2500 petrographic microscope with intent to locate FCAs. Many thin sections were surveyed (Annex Table A-1). Samples were selected for further study based on having well-formed feldspathic-chromite assemblages with a variety of textural types in generally unweathered meteorites of differing shock stages. Samples were then prepped and mapped using EBSD, gathering both Large Area Maps (LAMs), as well as Targeted Maps (TMs) from each sample. Assemblage data were then individually analyzed using Oxford Instruments AZtec 4.3, AZtecCrystal 1.1, and Channel 5 software to create various maps, plots, and tables from which other data were extracted.

\subsection{Shock Classification:}

Olivine shock character data were gathered from each thin section for the purpose of evaluating the shock history of these meteorites. Shock stage was determined for samples that had not previously been classified using a Leica DM2500 petrographic microscope. Based on olivine grains within the samples, conventional shock stage was determined using the criteria of Stöffler et al. $(1991,2019)$ as the highest shock stage containing at least $25 \%$ of the grains observed. Petrographic criteria include the extent of undulatory or mosaic extinction, the number of planar fractures within the grain, and whether the olivine shows recrystallization. Table A-1 shows the conventional shock stage for all meteorites that were studied with optical microscopy. The weighted shock stage was then determined using the methods of Jamsja and Ruzicka (2010). In the 
Jamjsa and Ruzicka (2010) method, extinction angles and the number of planar fractures sets together with any evidence for recrystallization are the primary criteria for assigning shock stage to an individual grain. Weighted shock stage is determined by the mean of all assigned olivine shock stage characters for each individual grain, displayed with the standard deviation of the population (Jamsja and Ruzicka, 2010). Olivine grains used for analysis have minimal weathering and alteration, with the key criterion being that they are of sufficient recommended size ( $\geq 50 \mu \mathrm{m}$ in one dimension).

\subsection{EBSD Methods:}

The SEM-EBSD system used for this work was a Zeiss Sigma Variable PressureField Emission Gun-Scanning Electron Microscope (VP-FEG-SEM), with an Oxford Instruments ULTIM MAX 65 energy dispersive spectrometer (EDS) with silicon-drift detector, and an Oxford Instruments NordlysNano Symmetry Electron Backscatter Detector (EBSD) with 5-diode forward scattered electron detectors. The SEM was used to obtain high resolution Backscatter Electron (BSE) images, chemical maps, and chemical point data of the specific areas of interest within each sample. EBSD data including band contrast and crystal identities and orientations were obtained in map format. Band contrast images represent the intensity differences in Kikuchi images of diffraction data and are typically related to the quality of diffraction patterns. Crystal orientations are commonly portrayed as inverse pole figure (IPF) (x, y, z) maps, which show the orientation of principal crystal axes relative to the $\mathrm{x}, \mathrm{y}$, and $\mathrm{z}$ sample directions. EBSD data were analyzed with Oxford Instruments AZtec 4.3, Channel5, and AZtecCrystal 1.1 software to determine various metrics including grain orientation spread (GOS), grain reference orientation deviation (GROD) angle, and lattice preferred 
orientation (LPO) maps and metrics for olivine, chromite, and plagioclase grains. Additionally, grain size data were collected. GOS metrics derived from Large Area Maps were used to evaluate deformation temperature and annealing in the samples according to the methods of Ruzicka and Hugo (2018) and Hugo et al. (2019). These methods include an assessment of temperature at the time of deformation, given by the EBSD parameter $\mathrm{R}_{2-10}$ for olivine, which is related to the fraction of misorientation rotation directions in the $<010>$ and $<001>$ crystal directions of olivine compared to the total rotation directions in the $\langle 100\rangle,\langle 010\rangle$, and $\langle 001\rangle$ directions, for misorientation angles between 2 and $10^{\circ}$ (Ruzicka and Hugo, 2018). They also include an assessment of annealing (recovery) following deformation, given by the $\mathrm{Sk}_{\mathrm{d}>50}$ parameter for olivine, which is related to the skewness of GOS values (=mean/median GOS) in olivine grains larger than 50 $\mu \mathrm{m}$ across (Ruzicka and Hugo, 2018).

For EBSD work, the SEM accelerating voltage was set to $20 \mathrm{keV}$, with mapping step sizes ranging from $0.11 \mu \mathrm{m}$ to $0.83 \mu \mathrm{m}$ for the Targeted Maps, and between 2.5$4.5 \mu \mathrm{m}$ for the Large Area Maps. The minimum grain size criterion for all maps was 5 contiguous pixels. All maps (LAM and TM) were gathered in less than 24 hours.

\subsection{Study Samples:}

Meteorites used in this study for EBSD analysis are: Spade (H6), Estacado (H6), Alfianello (L6), and NWA 13533 (L6) (Table 1). Spade, Estacado, and Alfianello were previously shock-classified (Friedrich et al. 2017), whereas NWA 13533 was classified (group, type) and the shock stage was determined for this study. 
Table 1: Meteorites used in this study for EBSD work.

Name

Spade Classification

Conventional Shock Stage

Estacado

H6

S4

Alfianello

H6

$\mathrm{S} 1$

NWA 13533

L6

S5

S4 


\section{3) RESULTS}

\subsection{Textural Types}

For this study, we focus on three main textural types of FCAs, Fine Clumped Chromite, Coarse Clumped Chromite, and Chromite Poor. These classifications have been created for this study and are based on quantitative EBSD data as discussed below. The primary criteria used to distinguish textural types are 1) grain sizes of chromite in an assemblage, 2) the number of chromite grains in each area of an assemblage ("clump number density" or simply "clump density"), and 3) the area fraction of chromite pixels in an assemblage. Before discussing quantitative data in detail, examples of the different textural types are first given below.

Fine Clumped Chromite (FCC) - These are assemblages found in compact regions that contain numerous chromite grains less than $5 \mu \mathrm{m}$ in diameter (Fig. 1). Although in clumps, some physical distance occurs between adjacent chromite grains. In these clumps individual chromite grains can be roughly equant or elongate, and elongate grains are typically parallel to other elongate grains (Fig. 1). Some of the assemblage clumps have apparent crystal outlines, and these outlines have been proposed to be the remnant edges of a parent crystal that has since exsolved to form chromite (Ramdohr, 1967, 1973). 


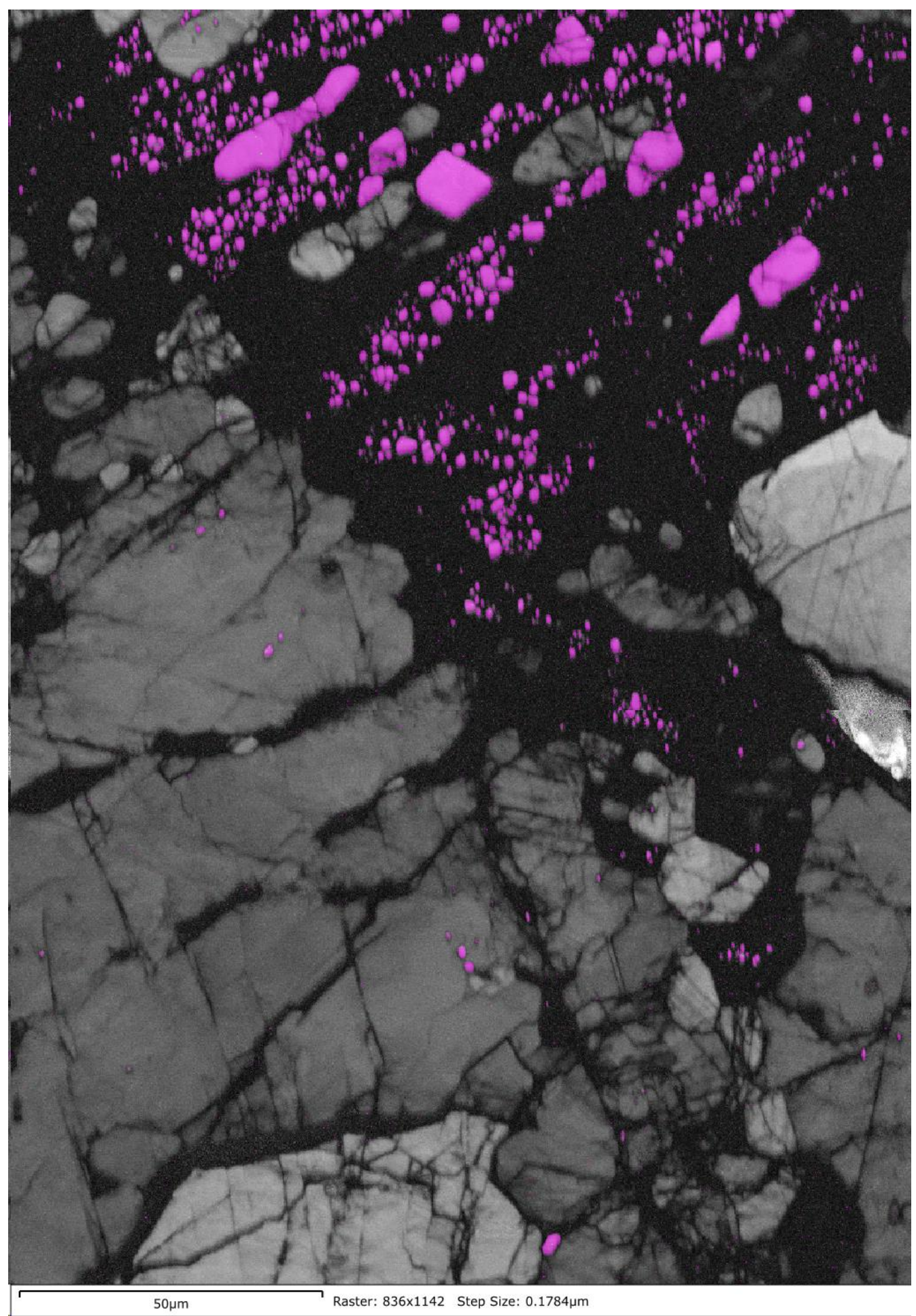

Figure 1: An example of Fine Clumped Chromite (FCC) in NWA 13533. Image: monochrome $=$ band contrast, pink $=$ pixels indexed as chromite. Black areas associated with chromite are maskelynite. Medium grey areas outside the assemblage consist of olivine and pyroxene; the lighter grey area to the middle right consists of metal. EBSD map: 0995-TM4D 
Coarse Clumped Chromite (CCC) - This type of assemblage contains chromite crystals often larger than $5 \mu \mathrm{m}$ in diameter size that form compact assemblages with little if any physical distance between adjacent chromite grains (Fig. 2). They could have started as broken or fractured chromite grains that have since, potentially through shock, been cobbled back together to form a clumped pile of chromite surrounded by feldspar (Ramdohr, 1967, 1973). While chromite is a brittle mineral (Ramdohr, 1967), not all chromites in chondrites or FCAs have been found to be heavily fractured. The CCC chromite in Figure 2, for example, is not especially fractured. (Faint lines crossing the interiors of chromite grains are polishing scratches-A. Ruzicka, personal communication).

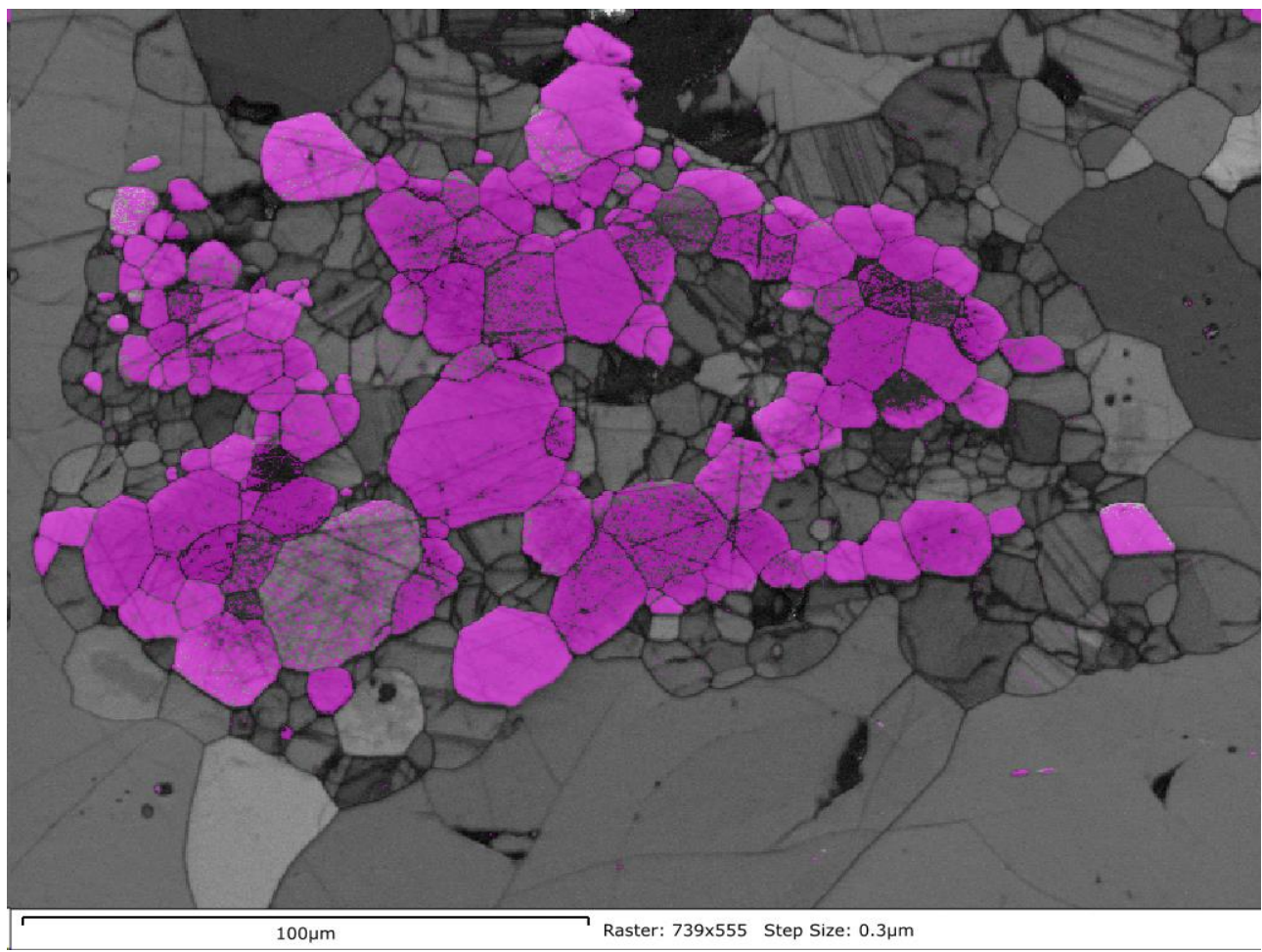

Figure 2: An example of Coarse Clumped Chromite (CCC) in Estacado. Image: monochrome = band contrast, pink $=$ pixels indexed as chromite. Grey areas intergrown with chromite are largely grains indexed as plagioclase; grey areas outside the assemblage consist chiefly of olivine. EBSD map: 0295-TM2B 
Chromite Poor (CP) - This assemblage type contains chromite congregated in one area but has more distance between chromite grains, with visibly less chromite than the FCC or CCC assemblages (Fig. 3). This designation can be fitted into the FCC or the $\mathrm{CCC}$ category in some instances for some parameters, but $\mathrm{CP}$ assemblages are set apart as their own grouping due to the relatively low proportion of chromite.

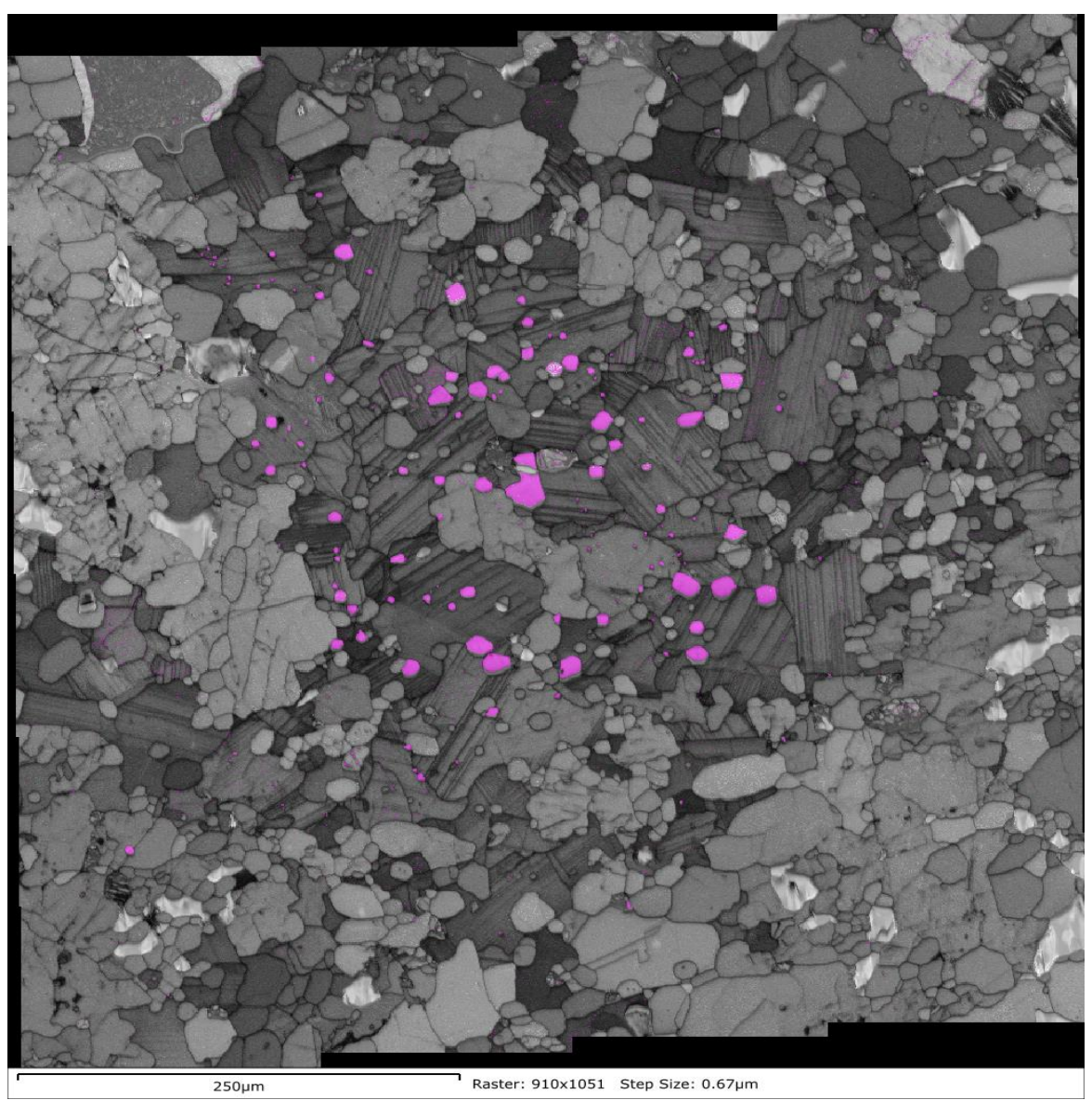

Figure 3: An example of a Chromite Poor (CP) assemblage in Spade. Image: monochrome = band contrast, pink $=$ pixels indexed as chromite. Grains intergrown with chromite consist largely of grains indexed as plagioclase. Grey areas outside the assemblage consist mainly of olivine and pyroxene. EBSD map: 0269TM1A

\subsection{Characterization of Assemblages}

Multiple Targeted Maps were taken from each of the four meteorites analyzed with EBSD (Table 2). Each Targeted Map was chosen for containing an FCA. These 
FCAs vary slightly in texture and make-up. Some maps only had one assemblage, whereas others had multiple nearby assemblages that were grouped into subsets (Table 2). An assemblage was determined by having a concentration of chromite with feldspathic material surrounding it. Within Alfianello and NWA 13533, feldspar in FCAs is largely maskelynized, but there were some relict plagioclase crystals found within maskelynite (Table 2). These relict plagioclase grains appear cracked in BSE or forescattered diode (FSD) images, in contrast to a smooth appearance for maskelynite. In Spade and Estacado, crystalline plagioclase is present in the FCAs (Table 2), and it is observed to be twinned. The presence of maskelynite (feldspathic glass) as opposed to plagioclase, is indicative of a more highly shocked meteorite.

Table 2: Listing of all Targeted Maps, including metadata and basic data for assemblages.

\begin{tabular}{|c|c|c|c|c|c|c|c|c|}
\hline $\begin{array}{l}\text { Meteorite } \\
\text { (thin } \\
\text { section) }\end{array}$ & $\begin{array}{c}\text { Targeted } \\
\text { Map }\end{array}$ & $\begin{array}{c}\text { Whole } \\
\text { Map Area } \\
\left(\mathbf{m m}^{2}\right)\end{array}$ & $\begin{array}{l}\text { Assemblage } \\
\text { Area }\left(\mathbf{m m}^{2}\right)\end{array}$ & $\begin{array}{l}\text { Step } \\
\text { Size } \\
(\mu \mathrm{m}) \\
\end{array}$ & $\begin{array}{c}\mathbf{n}_{\mathrm{g}} \\
\text { plag* }\end{array}$ & $\begin{array}{c}\mathbf{n}_{\mathrm{g}} \\
\text { chr* }^{*}\end{array}$ & $\begin{array}{c}\text { \# of } \\
\text { assemblage } \\
\text { subsets }\end{array}$ & $\begin{array}{l}\text { Assemblage } \\
\text { Mineralogy* }\end{array}$ \\
\hline \multirow{3}{*}{$\begin{array}{c}\text { Spade } \\
(0269-1 A)\end{array}$} & TM1A & 0.4293 & 0.2579 & $0.67 \mu \mathrm{m}$ & 2318 & 126 & 1 & chr + plag \\
\hline & TM2A & 0.3781 & 0.1195 & $0.83 \mu \mathrm{m}$ & 832 & 77 & 2 & chr + plag \\
\hline & TM3A & 0.5697 & 0.1042 & $0.83 \mu \mathrm{m}$ & 832 & 159 & 1 & chr + plag \\
\hline \multirow{5}{*}{$\begin{array}{l}\text { Estacado } \\
(0295-3 C)\end{array}$} & TM1B & 0.0142 & 0.0114 & $0.13 \mu \mathrm{m}$ & 670 & 332 & 6 & chr + plag \\
\hline & TM2B & 0.0369 & 0.0328 & $0.30 \mu \mathrm{m}$ & 600 & 350 & 1 & chr + plag \\
\hline & TM3B & 0.3129 & 0.0128 & $0.28 \mu \mathrm{m}$ & 82 & 168 & 1 & chr + plag \\
\hline & TM4B & 0.0051 & 0.0051 & $0.11 \mu \mathrm{m}$ & 1214 & 232 & 7 & chr + plag \\
\hline & TM5B & 0.0164 & 0.0123 & $0.15 \mu \mathrm{m}$ & 673 & 351 & 6 & chr + plag \\
\hline \multirow{6}{*}{$\begin{array}{r}\text { Alfianello } \\
(\text { (0496-1A) }\end{array}$} & TM1C & 0.8343 & 0.0568 & $0.45 \mu \mathrm{m}$ & -- & 196 & 4 & chr + mask \\
\hline & TM2C & 0.0411 & 0.0341 & $0.25 \mu \mathrm{m}$ & 12 & 2015 & 13 & $\begin{array}{c}\text { chr }+ \text { mask w/ } \\
\text { plag }\end{array}$ \\
\hline & TM3C & 0.0058 & 0.0035 & $0.12 \mu \mathrm{m}$ & 36 & 227 & 2 & chr + mask \\
\hline & TM4C & 0.0123 & 0.0066 & $0.18 \mu \mathrm{m}$ & 66 & 336 & 9 & $\begin{array}{c}\text { chr }+ \text { mask w/ } \\
\text { plag }\end{array}$ \\
\hline & TM5C & 0.0111 & 0.0069 & $0.17 \mu \mathrm{m}$ & 206 & 528 & 5 & $\begin{array}{c}\text { chr + mask w/ } \\
\text { plag }\end{array}$ \\
\hline & TM6C & 0.0203 & 0.0133 & $0.22 \mu \mathrm{m}$ & 13 & 224 & 7 & chr + mask \\
\hline \multirow{4}{*}{$\begin{array}{c}\text { NWA } \\
13533 \\
(0995-1)\end{array}$} & TM1D & 0.1472 & 0.1472 & $0.38 \mu \mathrm{m}$ & -- & 1824 & 23 & chr + mask \\
\hline & TM4D & 0.0304 & 0.0231 & $0.18 \mu \mathrm{m}$ & -- & 614 & 17 & chr + mask \\
\hline & TM5D & 0.0286 & 0.0231 & $0.18 \mu \mathrm{m}$ & -- & 539 & 4 & chr + mask \\
\hline & TM6D & 0.1546 & 0.1055 & $0.18 \mu \mathrm{m}$ & 203 & 1848 & 2 & chr + mask \\
\hline
\end{tabular}

$* \mathrm{Chr}=$ chromite, plag $=$ plagioclase, mask $=$ maskelynite, $\mathrm{n}_{\mathrm{g}}=$ number of grains 


\subsection{Assemblage Types}

In this study, we have found there to be two main groups of FCAs, Fine Clumped

Chromite, and Coarse Clumped Chromite. There is an additional group, Chromite Poor, that does not quite fit into the two main groups. Tables 3, 4, and 5 show data for the three groups that help to characterize these assemblage types. Table 6 shows the plagioclase data for each targeted map. In maps containing multiple assemblages and subsets (Table 2), data in these tables are averaged values for the assemblages in each map.

\section{FCC:}

Table 3: Chromite data for assemblages in this study that have been classified as Fine Clumped Chromite (FCC). These assemblages have generally the smallest Chromite Coarseness Ratio among FCAs in this study.

\begin{tabular}{|c|c|c|c|c|c|c|}
\hline Meteorite & $\begin{array}{c}\text { Targeted } \\
\text { Maps }\end{array}$ & $\begin{array}{c}\text { Assemblage } \\
\text { Type }\end{array}$ & $\begin{array}{c}\text { Chromite } \\
\text { Coarseness Ratio } \\
(\% \mathrm{~d}>5 / \mathrm{d}>1)\end{array}$ & $\begin{array}{c}\text { Area } \\
\text { Fraction of } \\
\text { Chromite } \\
\text { (pixel fraction) }\end{array}$ & $\begin{array}{c}\text { Clump } \\
\text { Density } \\
\text { (grains per } \mathrm{mm}^{2} \text { ) }\end{array}$ & $\begin{array}{l}\text { LPO \# } \\
\Delta<100>\end{array}$ \\
\hline \multirow{4}{*}{$\begin{array}{l}\text { Estacado } \\
(0295-3 C)\end{array}$} & TM1B & FCC & 0 & 0.21 & 29049.4 & 9.51 \\
\hline & TM3B & FCC & 0 & 0.12 & 13100.7 & 6.27 \\
\hline & TM4B & FCC & 0 & 0.17 & 45250.6 & 5.18 \\
\hline & TM5B & FCC & 0.741 & 0.21 & 28515.7 & 10.86 \\
\hline \multirow{5}{*}{$\begin{array}{l}\text { Alfianello } \\
\text { (0496-1A) }\end{array}$} & TM2C & FCC & 1.46 & 0.27 & 59039.0 & 6.34 \\
\hline & TM3C & FCC & 0 & 0.29 & 65117.6 & 8.17 \\
\hline & TM4C & FCC & 1.10 & 0.33 & 50978.6 & 9.74 \\
\hline & TM5C & FCC & 0.529 & 0.39 & 76733.0 & 7.81 \\
\hline & TM6C & FCC & 3.75 & 0.25 & 16815.6 & 4.45 \\
\hline \multirow{2}{*}{$\begin{array}{c}\text { NWA } 13533 \\
(0995-1)\end{array}$} & TM1D & FCC & 1.54 & 0.12 & 12391.4 & 3.39 \\
\hline & TM4D & FCC & 1.69 & 0.16 & 26527.3 & 5.82 \\
\hline
\end{tabular}




\section{CCC:}

Table 4: Chromite data for assemblages in this study that have been classified as Coarse Clumped Chromite (CCC). These assemblages have generally the largest Chromite Coarseness Ratio of FCAs in this study.

\begin{tabular}{|c|c|c|c|c|c|c|}
\hline Meteorite & $\begin{array}{c}\text { Targeted } \\
\text { Maps }\end{array}$ & $\begin{array}{c}\text { Assemblage } \\
\text { Type }\end{array}$ & $\begin{array}{c}\text { Chromite } \\
\text { Coarseness Ratio } \\
(\% \mathrm{~d}>5 / \mathrm{d}>1)\end{array}$ & $\begin{array}{c}\text { Area Fraction } \\
\text { of Chromite } \\
\text { (pixel fraction) }\end{array}$ & $\begin{array}{c}\text { Clump } \\
\text { Density } \\
\left(\text { grains per mm }{ }^{2}\right)\end{array}$ & $\begin{array}{c}\text { LPO \# } \\
\Delta_{<100>}\end{array}$ \\
\hline Spade & TM2A & CCC & 44.16 & 0.23 & 644.5 & 4.56 \\
\cline { 2 - 7 } (0269-1A) & TM3A & CCC & 37.50 & 0.45 & 1525.9 & 4.14 \\
\hline Estacado & TM2B & CCC & 61.96 & 0.55 & 10674.4 & 7.48 \\
\hline Alfianello & TM1C & CCC & 17.39 & 0.27 & 3452.3 & 3.53 \\
\hline NWA 13533 & TM6D & CCC & 29.67 & 0.41 & 17513.6 & 1.40 \\
\hline
\end{tabular}

\section{CP:}

Table 5: Chromite data for assemblages in this study that have been classified as Chromite Poor (CP). Note these assemblages have the lowest Area Fraction of Chromite of all the Targeted Maps in this study.

\begin{tabular}{|c|c|c|c|c|c|c|}
\hline Meteorite & $\begin{array}{c}\text { Targeted } \\
\text { Maps }\end{array}$ & $\begin{array}{c}\text { Assemblage } \\
\text { Type }\end{array}$ & $\begin{array}{c}\text { Chromite } \\
\text { Coarseness Ratio } \\
(\% \mathrm{~d}>5 / \mathrm{d}>1)\end{array}$ & $\begin{array}{c}\text { Area Fraction } \\
\text { of Chromite } \\
\text { (pixel fraction) }\end{array}$ & $\begin{array}{c}\text { Clump Density } \\
\left.\text { (grains per mm }{ }^{2}\right)\end{array}$ & $\begin{array}{c}\text { LPO \# } \\
\Delta_{<100>}\end{array}$ \\
\hline Spade & TM1A & CP & 36.51 & 0.054 & 488.5 & 1.58 \\
\hline NWA 13533 & TM5D & CP & 2.01 & 0.09 & 23361.7 & 0.88 \\
\hline
\end{tabular}

Table 6: Plagioclase details for the Targeted Maps acquired for this study.

\begin{tabular}{|c|c|c|c|c|c|c|c|c|}
\hline \multirow{2}{*}{\multicolumn{3}{|c|}{ get }} & \multirow{2}{*}{\multicolumn{3}{|c|}{ Grain Size $(\mu \mathrm{m})$}} & \multirow{2}{*}{\multicolumn{3}{|c|}{ GOS values (degrees)(All d) }} \\
\hline & & & & & & & & \\
\hline Meteorite & $\begin{array}{c}\text { Targeted } \\
\text { Map }\end{array}$ & $\begin{array}{c}\text { \# of } \\
\text { Grains }\end{array}$ & Mean & Max,Min & Median & Mean & $\begin{array}{l}\text { Standard } \\
\text { Deviation }\end{array}$ & $\begin{array}{c}\text { mean/median } \\
\text { ratio (All) }\end{array}$ \\
\hline \multirow{3}{*}{$\begin{array}{c}\text { Spade } \\
(0269-1 A)\end{array}$} & TM1A & 2318 & 3.44 & $63.5,1.69$ & 2.13 & 0.66 & 0.49 & 1.25 \\
\hline & TM2A & 832 & 5.12 & $55,2.10$ & 2.96 & 0.78 & 0.59 & 1.26 \\
\hline & TM3A & 832 & 5.06 & $76.9,2.09$ & 2.81 & 0.73 & 0.63 & 1.38 \\
\hline \multirow{5}{*}{$\begin{array}{l}\text { Estacado } \\
(0295-3 C)\end{array}$} & TM1B & 670 & 1.20 & $\begin{array}{c}18.22 \\
0.33\end{array}$ & 0.78 & 0.62 & 0.20 & 1.05 \\
\hline & TM2B & 600 & 2.38 & $\begin{array}{c}19.27 \\
0.76\end{array}$ & 1.27 & 0.68 & 0.40 & 1.19 \\
\hline & TM3B & 82 & 2.10 & $42.3,0.7$ & 0.82 & 0.97 & 0.66 & 1.30 \\
\hline & TM4B & 1214 & 0.53 & $9.92,0.28$ & 0.36 & 0.59 & 0.36 & 1.13 \\
\hline & TM5B & 673 & 1.01 & $51,0.38$ & 0.48 & 0.51 & 0.33 & 1.21 \\
\hline \multirow{6}{*}{$\begin{array}{l}\text { Alfianello } \\
\text { (0496-1A) }\end{array}$} & TM1C & 25 & 1.25 & $2.34,0.97$ & 1.15 & 0.95 & 0.47 & 1.20 \\
\hline & TM2C & 12 & 1.51 & $4.49,0.63$ & 1.12 & 1.12 & 0.60 & 1.20 \\
\hline & TM3C & 36 & 0.47 & $1.59,0.3$ & 0.37 & 0.88 & 0.32 & 1.02 \\
\hline & TM4C & 66 & 0.93 & $6.33,0.44$ & 0.56 & 0.86 & 0.55 & 1.17 \\
\hline & TM5C & 206 & 0.63 & $5.94,0.42$ & 0.49 & 0.70 & 0.32 & 1.12 \\
\hline & TM6C & 13 & 0.87 & $2.58,0.56$ & 0.76 & 1.06 & 0.57 & 1.38 \\
\hline \multirow{4}{*}{$\begin{array}{c}\text { NWA } \\
13533 \\
(0995-1)\end{array}$} & TM1D & 8 & 2.32 & $6.83,1.14$ & 1.48 & 1.16 & 0.51 & 1.14 \\
\hline & TM4D & 28 & 0.85 & $2.87,0.45$ & 0.60 & 0.78 & 0.25 & 1.01 \\
\hline & TM5D & 70 & 0.67 & $2.69,0.45$ & 0.53 & 0.99 & 0.67 & 1.17 \\
\hline & TM6D & 203 & 1.31 & $8.17,0.64$ & 0.89 & 0.93 & 0.33 & 1.06 \\
\hline
\end{tabular}


As seen in the above tables $(3,4,5)$, the FCC category appears to have a very small chromite coarseness ratio, whereas the CCC group has a very large value. Chromite Poor sets itself apart with a lower area fraction of chromite than either the FCC or the CCC group.

\subsection{Quantitative EBSD Parameters for FCA Groups}

The plots below show the two distinct groups, FCC and $\mathrm{CCC}$, according to various quantitative parameters. Although there is some overlap between the two main groups in some of the plots, they have different ranges of parameters. The Chromite Poor assemblages can be seen to line up with either the CCC or FCC groups for some parameters, but they do not consistently fall into one of the other two groups.

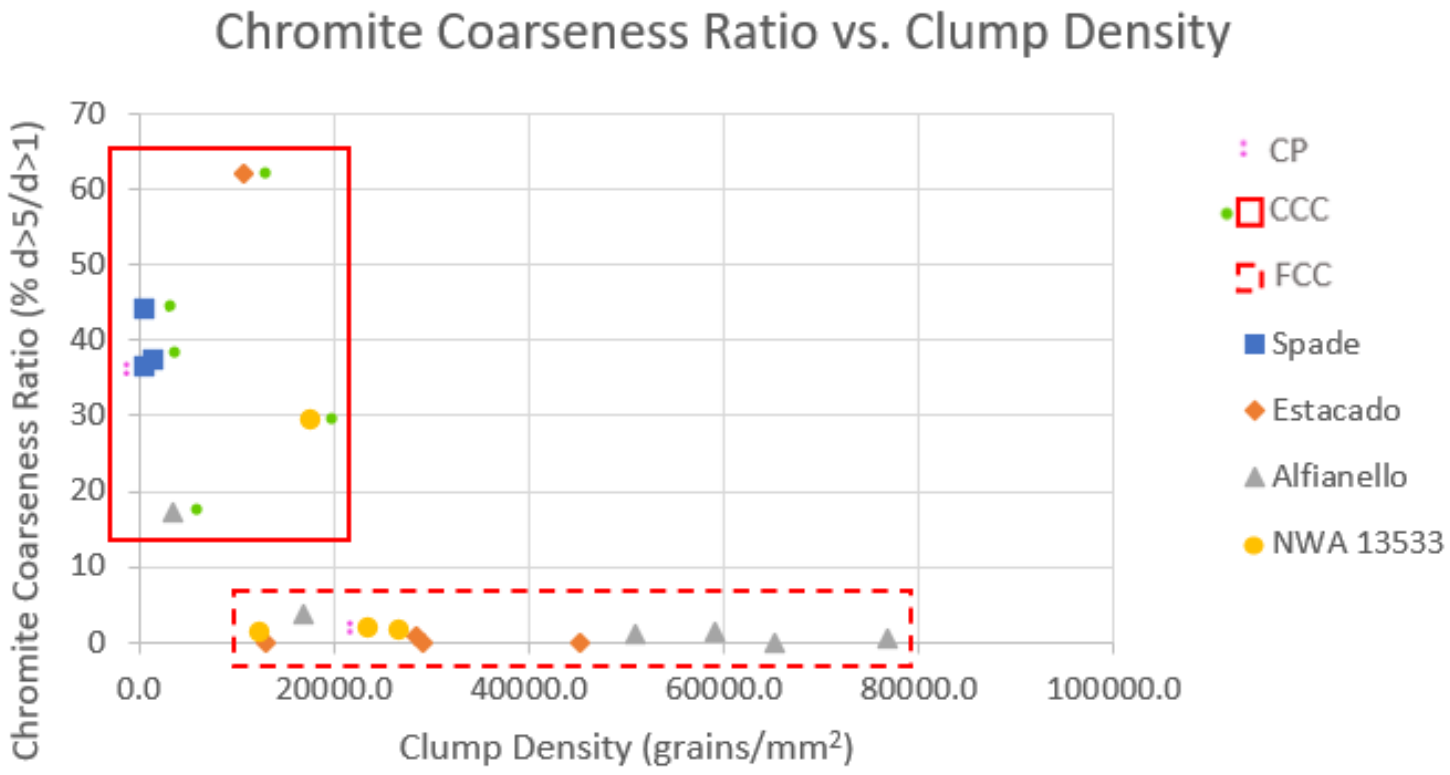

Figure 4: Chromite Coarseness Ratio (grain size) vs. Clump density. $\mathrm{d}=$ equivalent grain diameter in microns $(\mu), \% d>5 / d>1$ is the percentage of grains with $d>5$ compared to all grains with $d>1$. Green dots next to symbol for meteorite denote CCC, pink double dots denote CP, lack of dots denote FCC. Solid line box shows CCC trend, while dotted line box shows FCC trend. 
Grain size and clump density show the distinct difference in the FCC and CCC groups (Fig. 4). CCCs tend to be less 'clumped' (have lower number grain densities) than FCCs, but they overlap some FCCs with the lowest clump density. Figure 4 shows that for these two parameters, the Spade $\mathrm{CP}$ assemblage fits into the CCC group, whereas the NWA $13533 \mathrm{CP}$ assemblage fits into the FCC group. In the case of this figure, we see that both of our $\mathrm{CP}$ data points have a lower clump density but are varied in their grain size.

\section{Chromite Coarseness Ratio vs. LPO \#}

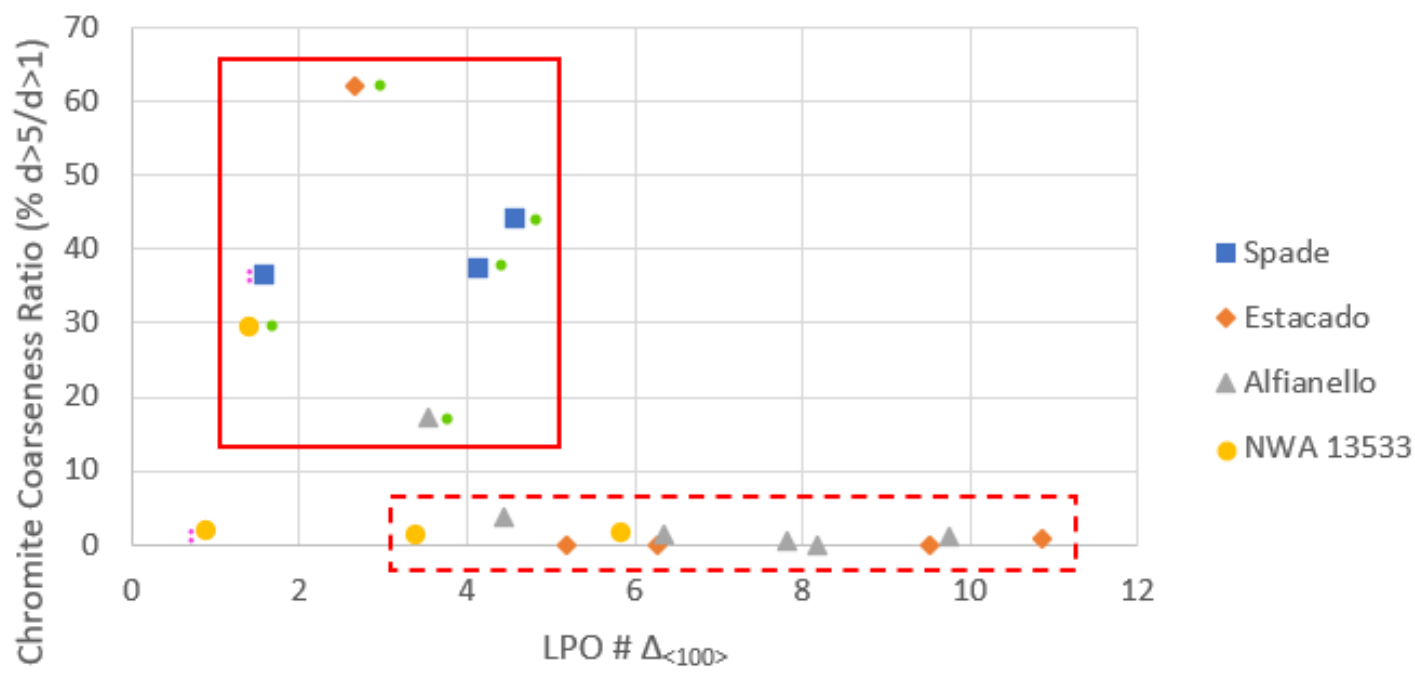

Figure 5: Chromite Coarseness Ratio (grain size) vs. LPO \#. Green dots next to symbol for meteorite denote CCC, pink double dots denote CP, lack of dots denote FCC. Solid line box shows CCC trend, while dotted line box shows FCC trend.

Figure 5 shows that there tends to be a higher LPO number (higher degree of chromite lattice preferred orientation) for the FCC group, as opposed to the CCC group. The Spade CP assemblage again fits within the CCC group in terms of chromite LPO and grain size, but the NWA $13533 \mathrm{CP}$ assemblage falls far outside of either the FCC or CCC groups in terms of having weak LPO together with low grain size. 


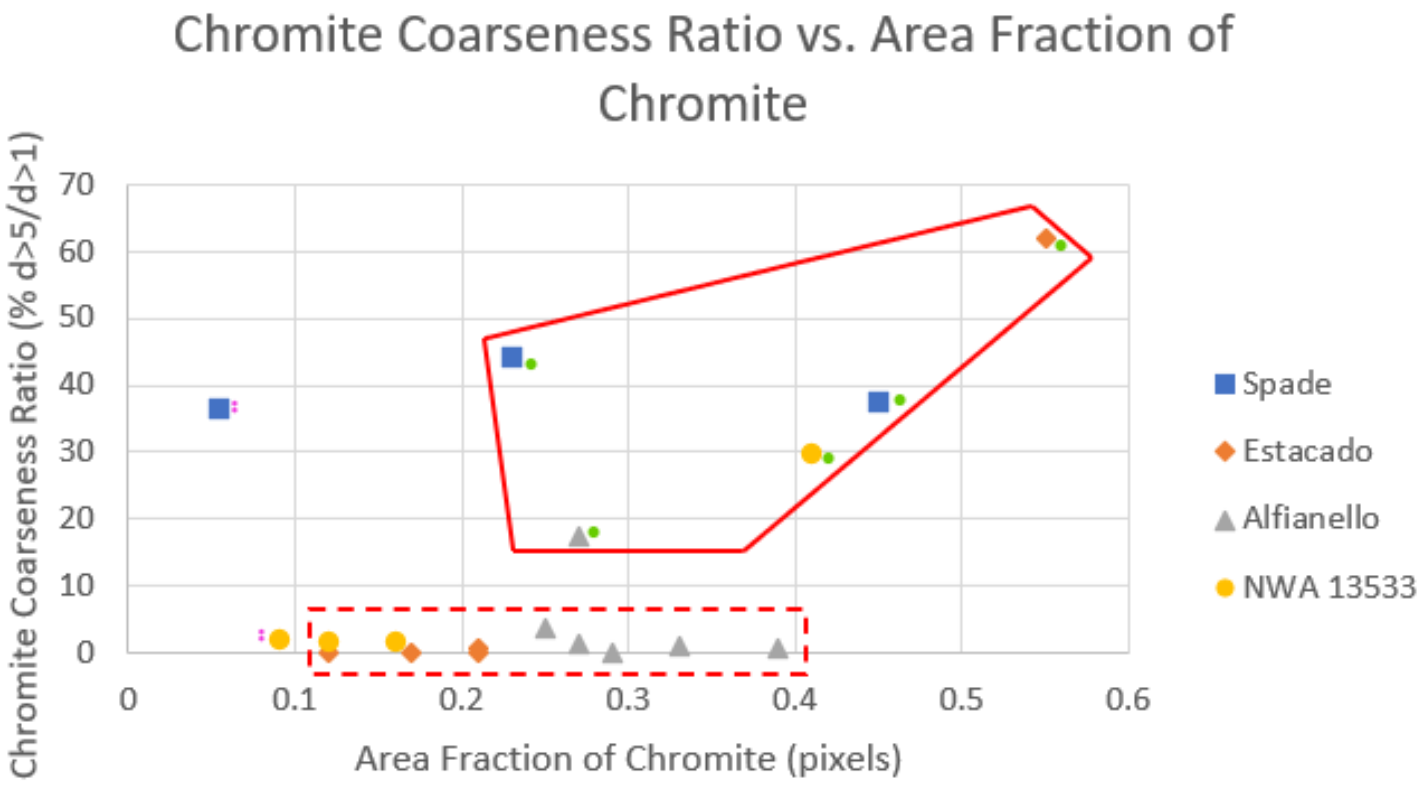

Figure 6: Chromite Coarseness Ratio (grain size) vs. Area Fraction of Chromite. Green dots next to symbol for meteorite denote CCC, pink double dots denote CP, lack of dots denote FCC. Solid line box shows CCC trend, while dotted line box shows FCC trend.

Figure 6 shows both CCC and FCC to have a large and overlapping spread in chromite area fraction, although FCC assemblages tend to have a lower chromite area fraction than CCC. The $\mathrm{CP}$ assemblages are set slightly apart from either the $\mathrm{CCC}$ or FCC fields, as they have the lowest amount of chromite.

In Figure 7 and plots to immediately follow, GOS is shown for all grain sizes ("all d"). Although GOS is dependent on grain size (Ruzicka and Hugo, 2018), we will see later that for the chromite grains in FCAs, GOS all d is a good measure of the overall deformation extent of chromite. 


\section{Chromite Coarseness Ratio vs. Mean GOS}

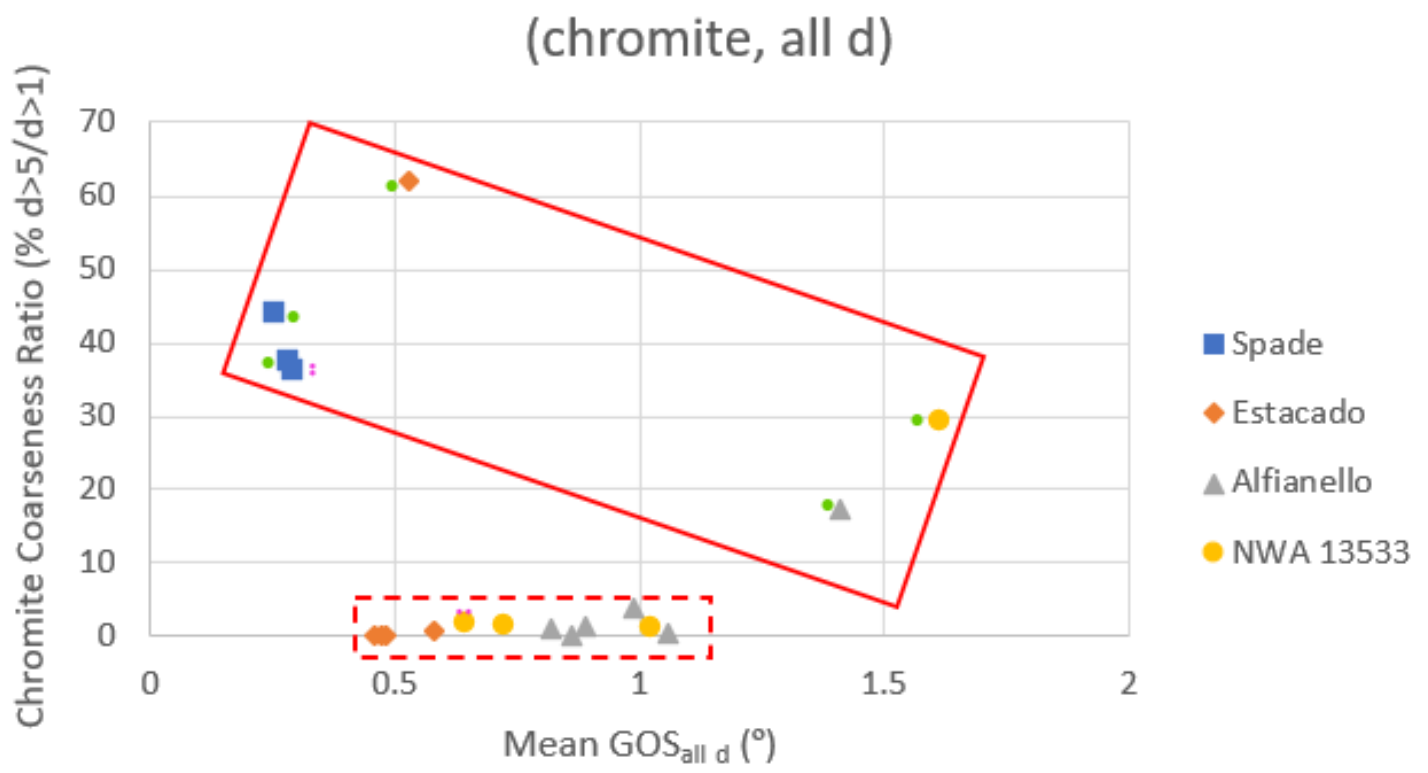

Figure 7: Chromite Coarseness Ratio (grain size) vs. Mean GOS of chromite, all d. $d=$ equivalent grain diameter in microns $(\mu)$. Green dots next to symbol for meteorite denote CCC, pink double dots denote $\mathrm{CP}$, lack of dots denote FCC. Solid line box shows CCC trend, while dotted line box shows FCC trend.

\section{Clump Density vs. Mean GOS (chromite, all d)}



Figure 8: Clump Density vs. Mean GOS of chromite, all d. $d=$ equivalent grain diameter in microns $(\mu)$. Green dots next to symbol for meteorite denote CCC, pink double dots denote CP, lack of dots denote FCC. Solid line box shows CCC trend, while dotted line box shows FCC trend. 
Figure 8 depicts the clump density of each assemblage verses the mean $\mathrm{GOS}_{\text {all }} \mathrm{d}$ showing that there is some overlap in our assemblage groupings. Despite this overlap in the FCC and CCC groups in Figure 8, we can see a distinct difference in average chromite GOS $_{\text {all d }}$ between our meteorites. Spade and Estacado have a low average GOS all d in chromite $\left(\sim 0.25-0.6^{\circ}\right)$ compared to Alfianello and NWA $13533\left(\sim 0.7-1.6^{\circ}\right)$.

\section{Clump Density vs. LPO \#}

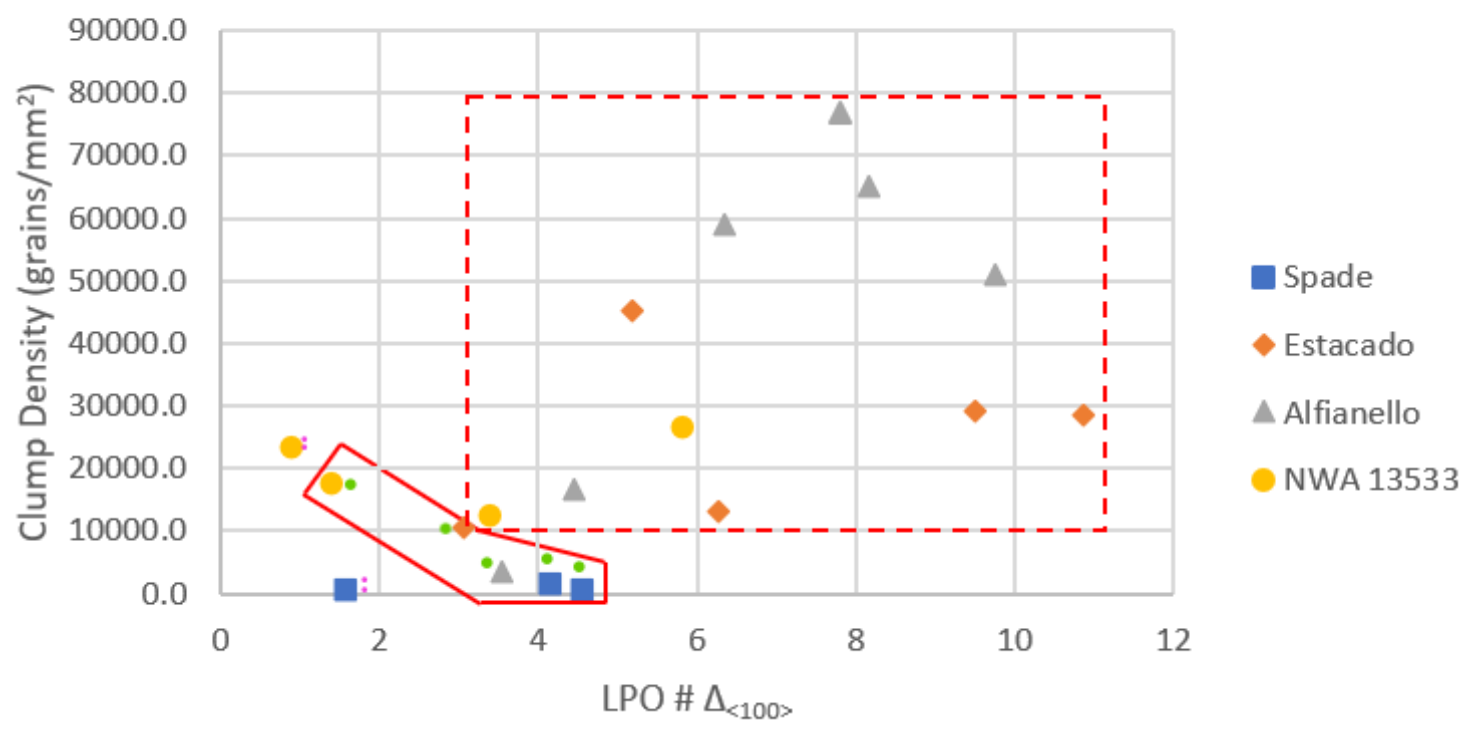

Figure 9: Clump Density vs. LPO \#. Green dots next to symbol for meteorite denote CCC, pink double dots denote CP, lack of dots denote FCC. Solid line box shows CCC trend, while dotted line box shows FCC trend.

Figure 9 shows that there is some distinction in the FCC and CCC groups, as well as showing our CPs as outliers. FCCs tend to have the high clump density as well as the higher LPO number. Whereas our CCCs trend on the lower end for both LPO and clump density.

Figures 10, 11, and 12 show the Area Fraction data for each Targeted Map. They show that there is some distinction between the separate assemblage groups, however it's 
more muddled than other parameters. This points to area fraction not being a large factor in the creation of the assemblages.

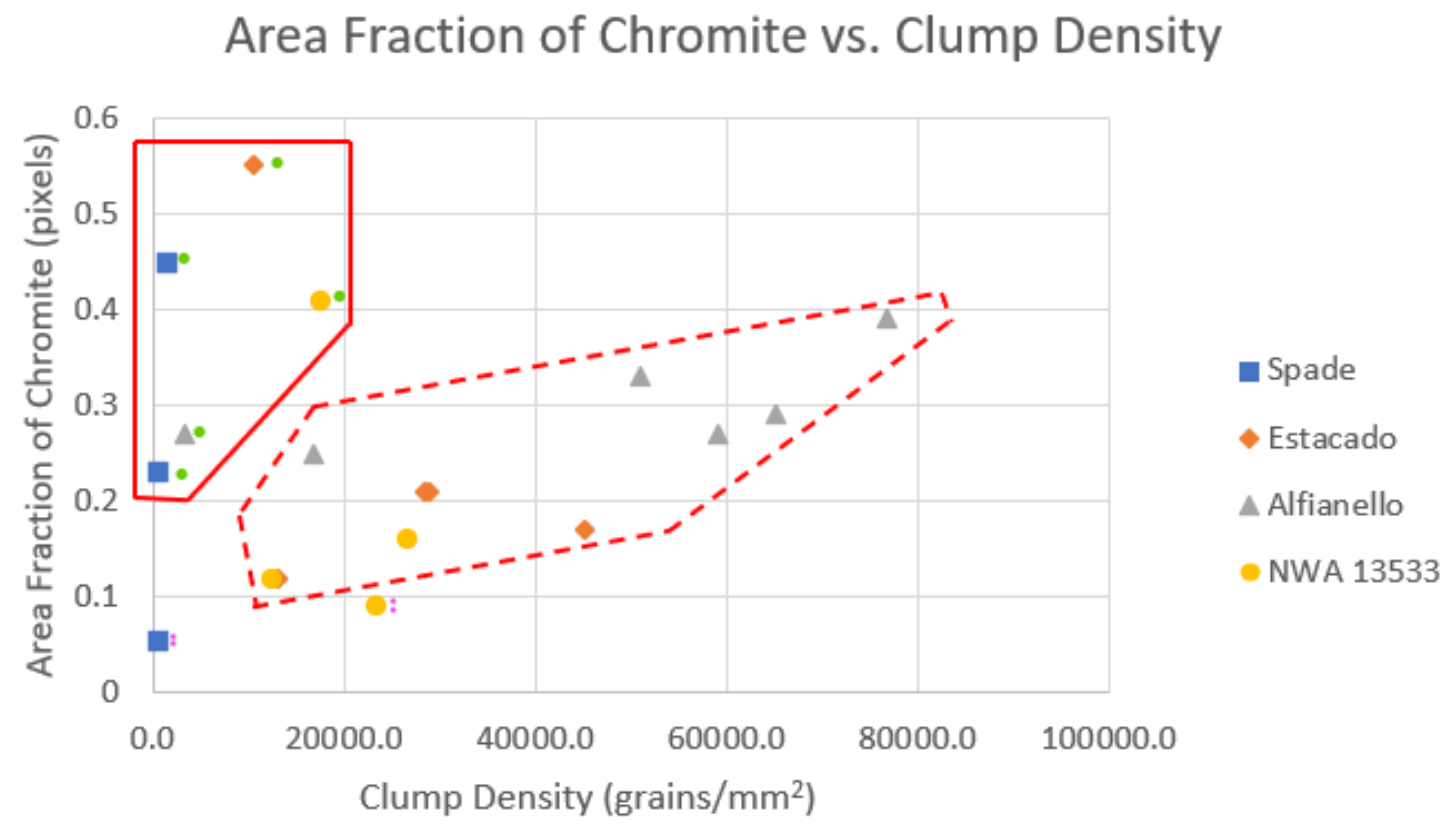

Figure 10: Area Fraction of Chromite vs. Clump Density. Green dots next to symbol for meteorite denote CCC, pink double dots denote CP, lack of dots denote FCC. Solid line box shows CCC trend, while dotted line box shows FCC trend. 


\section{Area Fraction of Chromite vs. LPO \#}

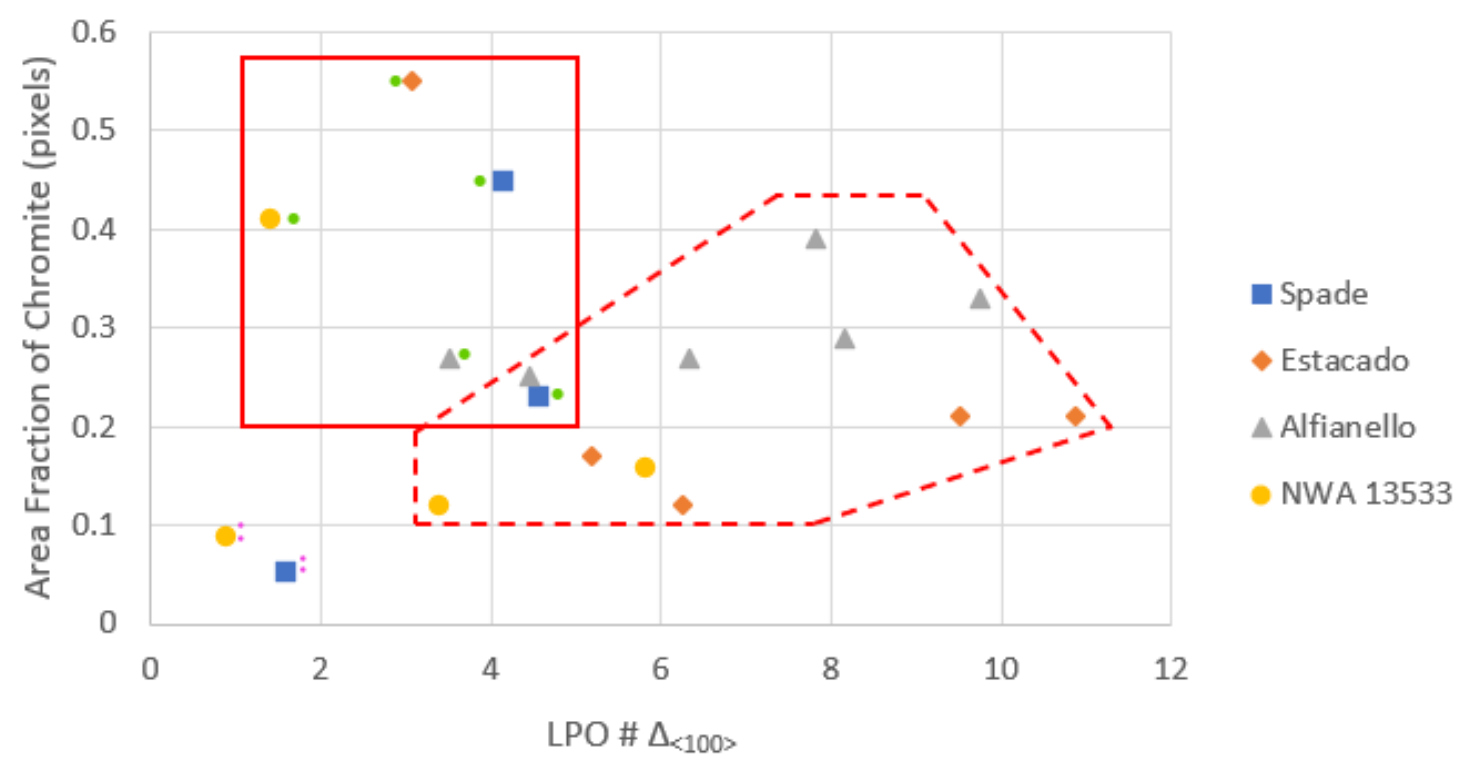

Figure 11: Area Fraction of Chromite vs. LPO\#. Green dots next to symbol for meteorite denote CCC, pink double dots denote $\mathrm{CP}$, lack of dots denote FCC. Solid line box shows CCC trend, while dotted line box shows FCC trend.

\section{Area Fraction of Chromite vs. Mean GOS (chromite, all d)}

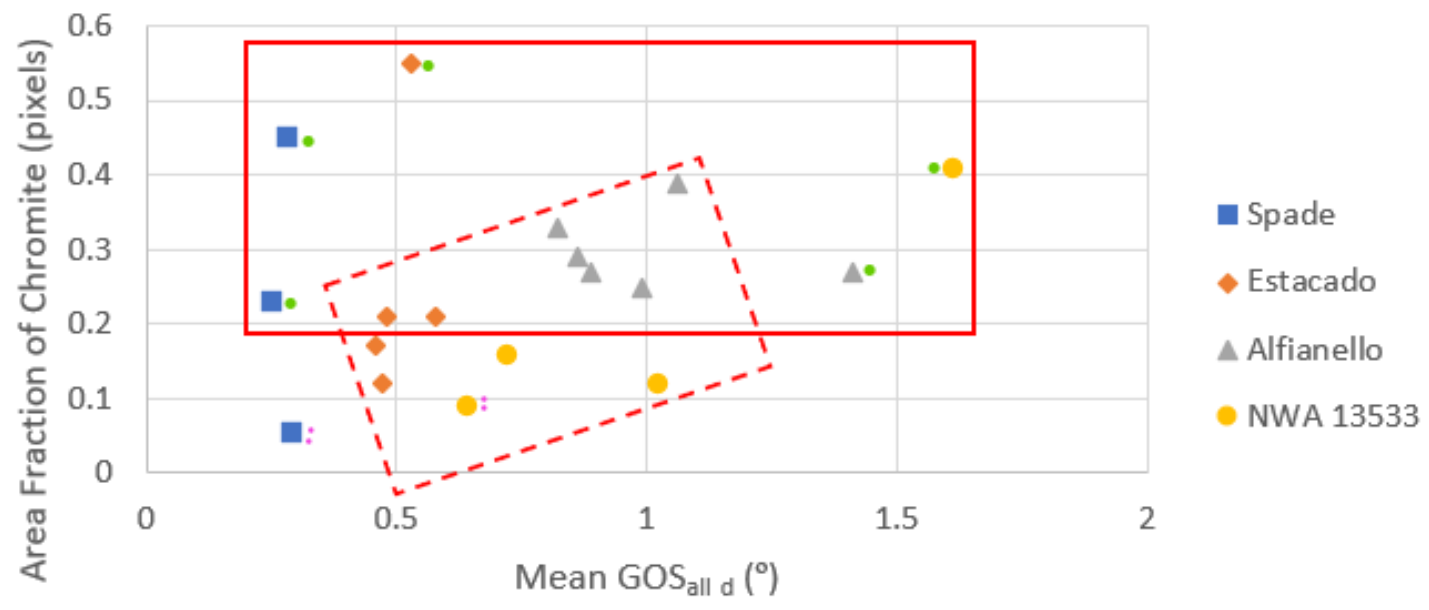

Figure 12: Area Fraction of Chromite vs. Mean GOS of chromite, all d. $d=$ equivalent grain diameter in microns $(\mu)$. Green dots next to symbol for meteorite denote CCC, pink double dots denote CP, lack of dots denote FCC. Solid line box shows CCC trend, while dotted line box shows FCC trend. 


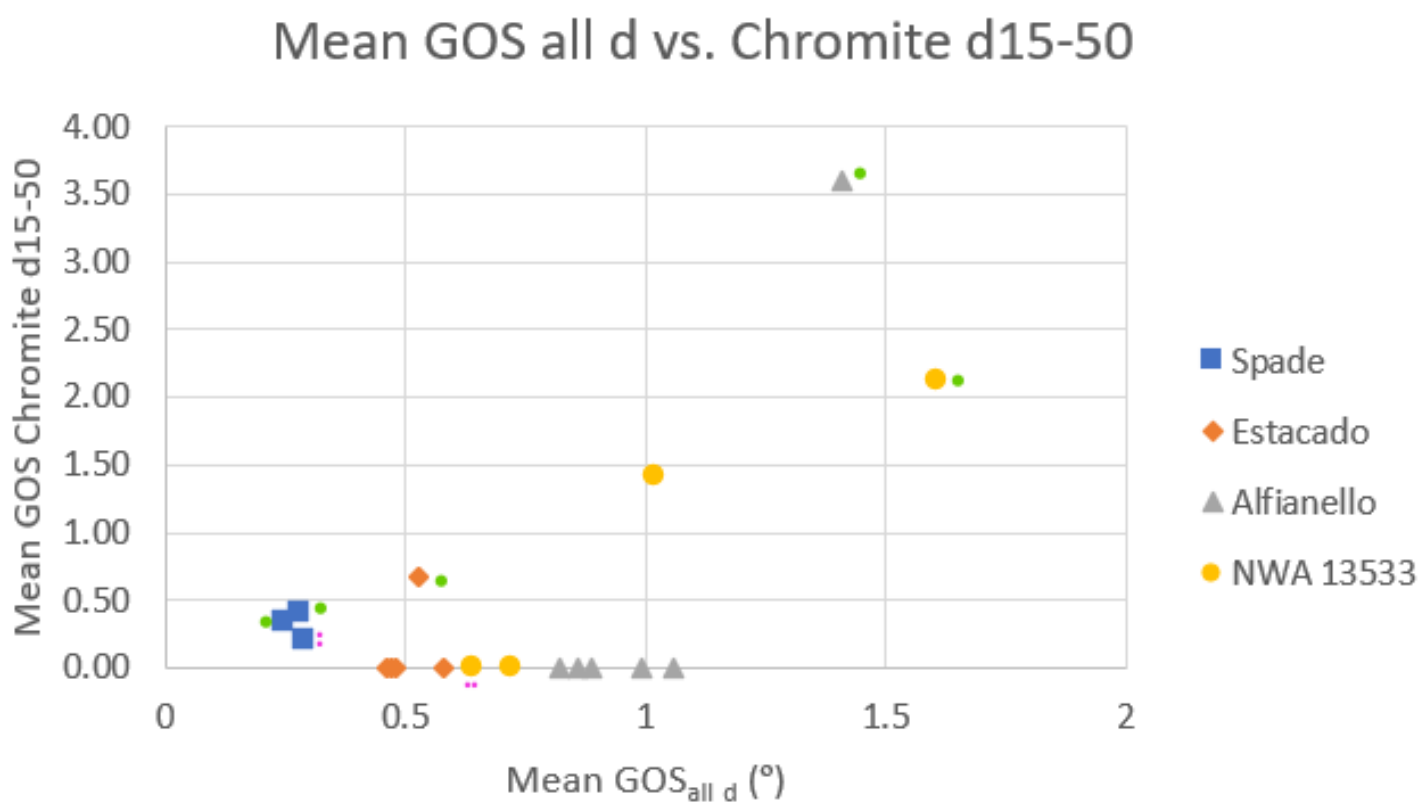

Figure 13: Mean Grain Orientation Spread (GOS) for all d for chromite on the $\mathrm{x}$-axis, versus Chromite $\mathrm{d}$ 15-50 on the y-axis. Data points on the x-axis with zero values are artifacts of not having any d15-50 grains. Green dots next to symbol for meteorite denote CCC, pink double dots denote CP, lack of dots denote FCC.

In Figure 13, mean GOS in chromite for $\mathrm{d}=15-50$ grains $\left(\mathrm{GOS}_{\mathrm{d} 15-50}\right)$ is plotted against mean GOS in grains of all sizes $\left(\mathrm{GOS}_{\text {all }} \mathrm{d}\right)$. It is seen that not all targeted maps featured chromite grains between $15-50 \mu \mathrm{m}$ size range, which is not surprising given the diminutive size of grains in some of the FCC assemblages. Aside from such assemblages, Figure 13 shows that there is a general correlation between chromite $\operatorname{GOS}_{\mathrm{d} 15-50}$ and $\mathrm{GOS}_{\text {all d. }}$ 
Mean GOS vs. Chromite d5-15

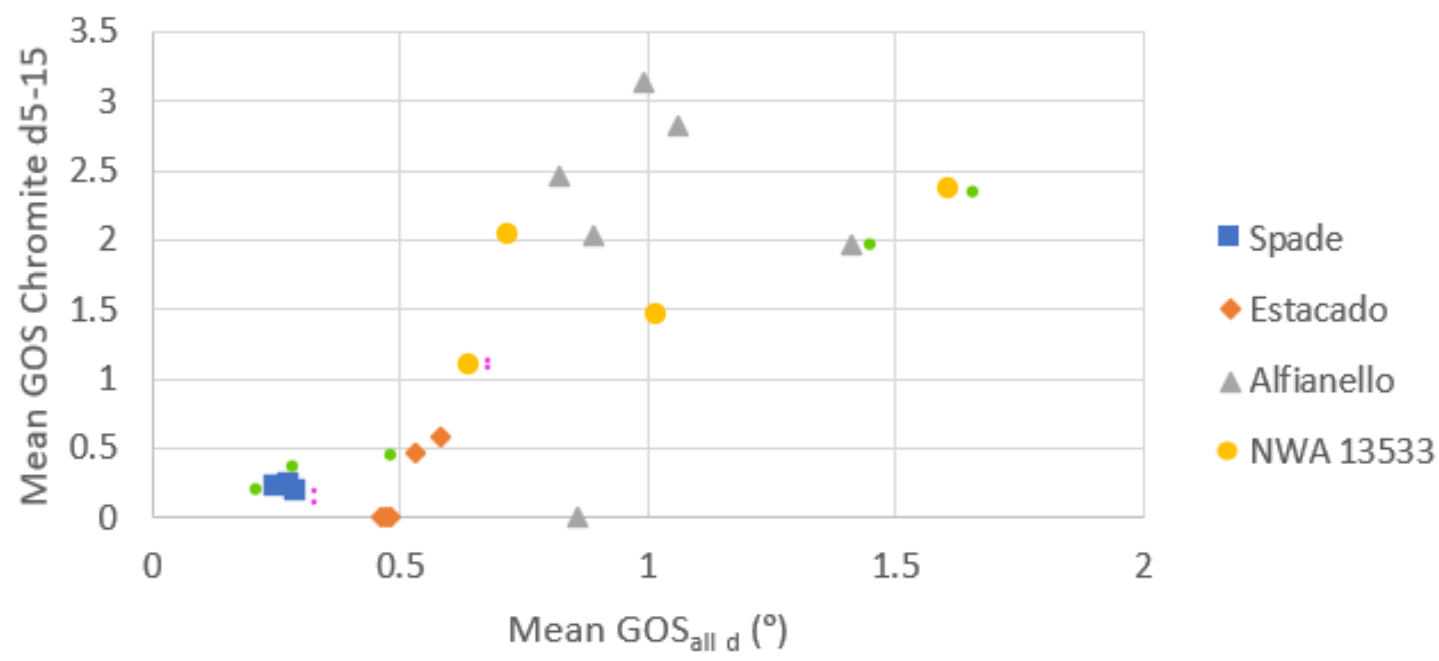

Figure 14: Mean Grain Orientation Spread (GOS) for all d for chromite on the $\mathrm{x}$-axis, versus Chromite $\mathrm{d}$ 515 on the y-axis. Data points on the x-axis with zero values are artifacts of not having any d5-15 grains.

Green dots next to symbol for meteorite denote $\mathrm{CCC}$, pink double dots denote $\mathrm{CP}$, lack of dots denote FCC.

Figure 14 shows mean GOS in chromite for $\mathrm{d}=5-15$ grains $\left(\mathrm{GOS}_{\mathrm{d} 5-15}\right)$ against mean GOS in grains of all sizes $\left(\operatorname{GOS}_{\text {all d }}\right)$. There is now a more obvious positive trend, as more assemblages have grains at the $5-15 \mu \mathrm{m}$ size, with only three targeted maps sitting on the x-axis. The positive trend occurs both for FCC and CCC assemblages, but they may have different slopes (less steep for CCCs, steeper for FCCs). 


\section{Mean GOS all d vs. Chromite $d<5$}



Figure 15: Mean Grain Orientation Spread (GOS) for all d for chromite on the $\mathrm{x}$-axis, versus Chromite $\mathrm{d}<5$ on the y-axis. Green dots next to symbol for meteorite denote CCC, pink double dots denote CP, lack of dots denote FCC.

In Figure 15, mean GOS in chromite for $\mathrm{d}<5$ grains $\left(\mathrm{GOS}_{\mathrm{d}<5}\right)$ is plotted against mean GOS in grains of all sizes. This linear correlation can be taken as evidence that the GOS all d parameter largely reflects the smallest $(\mathrm{d}<5)$ grains. This is true for FCC as well as CCC. Two CCC assemblages, one each from Alfianello and NWA 13533, have the largest chromite GOS values among the FCAs studied, whereas two other CCC assemblages, both from Spade, have the lowest GOS values. There is no obvious difference in chromite GOS between CCC and FCC assemblages. Instead, assemblages in the Alfianello and NWA 13533 tend to have higher chromite GOS than assemblages in Spade and Estacado.

The plagioclase data (Table 6) shows the relative coarseness of the feldspathic grains in Spade and Estacado, in comparison to the very small grains found in Alfianello 
and NWA 13533. The small grains in the high shock meteorites are due to relict plagioclase grains that were not fully maskelynized. Alfianello and NWA 13533 were shocked hard enough that the feldspathic material was transformed to a glass, but not entirely, leaving behind a few grains.

\subsection{Orientation and Deformation Data for Example FCA Assemblages}

Figures 16-21 show orientation and deformation data for chromite in particular assemblages of different types. Inverse Pole Figure (IPF) maps show the crystal orientations of each chromite grain using a false color scheme, together with a monochrome band contrast image. In these maps the orientation of the $<100>$ direction in chromite is shown relative to a sample coordinate system ( $\mathrm{x}=$ left-right in the plane of the section, $\mathrm{y}=\mathrm{up}$-down in the plane of the section, $\mathrm{z}=$ normal to the section). Two types of pole figure plots are shown. One plots the orientation of each pixel with the corresponding color in the associated IPF map (pole figure plot with IPF colors). The other is a density plot based on $15^{\circ}$ halfwidth contouring assuming one point per grain (contoured pole figure plot). The contoured pole figures especially highlight whether there is a lattice preferred orientation (LPO) of chromite grains. As chromite is a cubic mineral, there are three crystallographically equivalent $<100>$ directions, so a single orientation will show as three distinct spots in a contoured $<100>$ pole figure.

Grain Orientation Spread (GOS) and Grain Reference Orientation Deviation (GROD) angle maps show deformation of each chromite grain using a false color scheme together with a monochrome band contrast image. GOS indicates the average misorientation, whereas GROD angle shows the deviation in orientation within a crystal relative to the average orientation. GOS maps are shown with maximum values set to 
$15^{\circ}$, whereas GROD angle maps are shown with maximum values set to $20^{\circ}$. In these maps blue corresponds to minimum values, green to intermediate values, and red to maximum values.

Data for two example FCC assemblages are shown in Figure 16 and 17. The assemblages in NWA 13533 (TM1) (Fig. 16) and Alfianello (TM2) (Fig. 17) both consist of chromite groupings with sharp edges, all set in maskelynite. In NWA 13533, the chromite groupings form lath-like shapes. In Alfianello, the groupings have various polyhedral outlines. Both assemblages are dominated by small chromite crystallites, although there are some larger grains in the Alfianello assemblage that tend to be aligned.

Within each grouping of the two FCC assemblages, IPF colors are similar but vary somewhat, indicating a high degree but not perfect LPO. The pole figure plots for Alfianello indicate that there is one dominant orientation of chromite (a set of three spots), indicating a dominant LPO approaching a single orientation for all chromite groupings in this map (Fig. 17). The contoured pole figure plot for NWA 13533 indicates a somewhat more complex situation, characterized by a girdle of two $<100>$ directions around a third dominant $\langle 100\rangle$ direction (Fig. 18). This suggests rotation of a cube around a single axis that is fixed in direction. This could be related to the spread of chromite clumps in Figure 16, as there are more clumped groups that are going in many directions, as opposed to one large clump of chromite in the assemblage in Figure 17. The fan shape for clumps seen in Figure 16 is one that implies crystallization from a single point, analogous to the radiating pattern seen in radial pyroxene chondrules in chondrites (A. Ruzicka, Personal Communication). 
Both of the FCC assemblages feature chromite crystals with low overall GOS values (Fig. 16, 17). A few crystallites, especially in the Alfianello assemblage, are more deformed (Fig. 17). In the latter, this includes most obviously the larger grains, but also some of the smaller crystallites.

Data for two CCC assemblages are shown in Figures 18 and 19. Both assemblages, in NWA 13533 (TM6) (Fig. 18) and in Estacado (TM2) (Fig. 19), consist of chromite grain groupings in chain-like patterns. These chains have irregular edges, marked by the edges of chromite crystals. The chromite grains are adjacent to maskelynite in NWA 13533 and within plagioclase in Estacado. In the Estacado assemblage, chromite grains are granular and often meet in triple junctions (Fig. 19). In the NWA 13533 assemblage, chromite grains also tend to be equant, though less granular, and often meet in triple junctions. A large difference from Estacado is that the CCC grains in NWA 13533 are more highly fractured, with some parts of the assemblage appearing to be brecciated (Fig. 18).

In contrast to the FCCs, the CCCs in NWA 13533 and Estacado do not show a strong chromite LPO, as indicated by a variety of IPF colors and a spatially random distribution in the pole figure plots (Fig. 18, 19). However, the LPO is higher for the Estacado assemblage (Fig. 19) than for the NWA 13533 assemblage (Fig. 18). Generally low LPO is typical of this assemblage type (Fig. 5, 9, 11).

The two CCC assemblages differ significantly in chromite deformation. In figure 18, the GROD angle 20 map for the CCC in NWA 13533 shows that there are many grains within the clump that have seen deformation (shown as blue grains with green to red in and around them). Conversely, Figure 17 for the CCC in Estacado is almost solidly 
blue, with only one solid green grain, and very few blue grains showing some green around the edges (see scale bar).

Data for the two CP assemblages found in this study are shown in Figures 20 and 21. Both assemblages tend to have generally low LPO strength for chromite and low GOS for chromite. They also differ from one another, one being a larger map (Fig. 21), that tends to align itself closer with the CCC group, while the smaller map aligns more with the FCC group. The CP group also differs texturally, with the Spade TM showing plagioclase surrounding the chromite, while the NWA 13533 TM has maskelynite enclosing the chromite. 


\section{FCC}

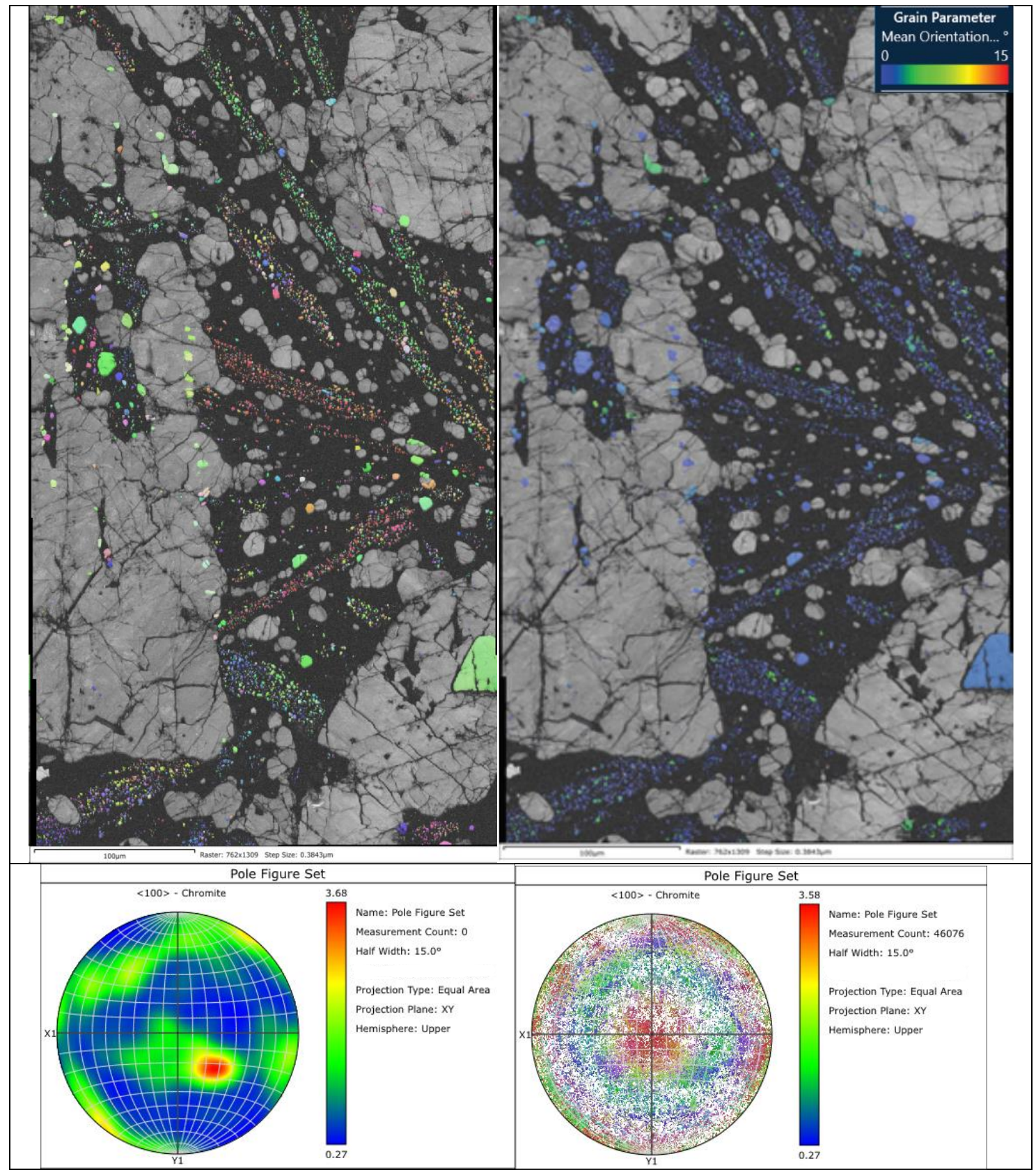

Figure 16: FCC example 1. NWA 13533 (TM1), IPFx (top left) and GOS15 (top right) maps (colors) together with band contrast (monochrome), with contoured pole figure plot (bottom left), as well as scattered pole figure plot in IPFx colors (bottom right). 


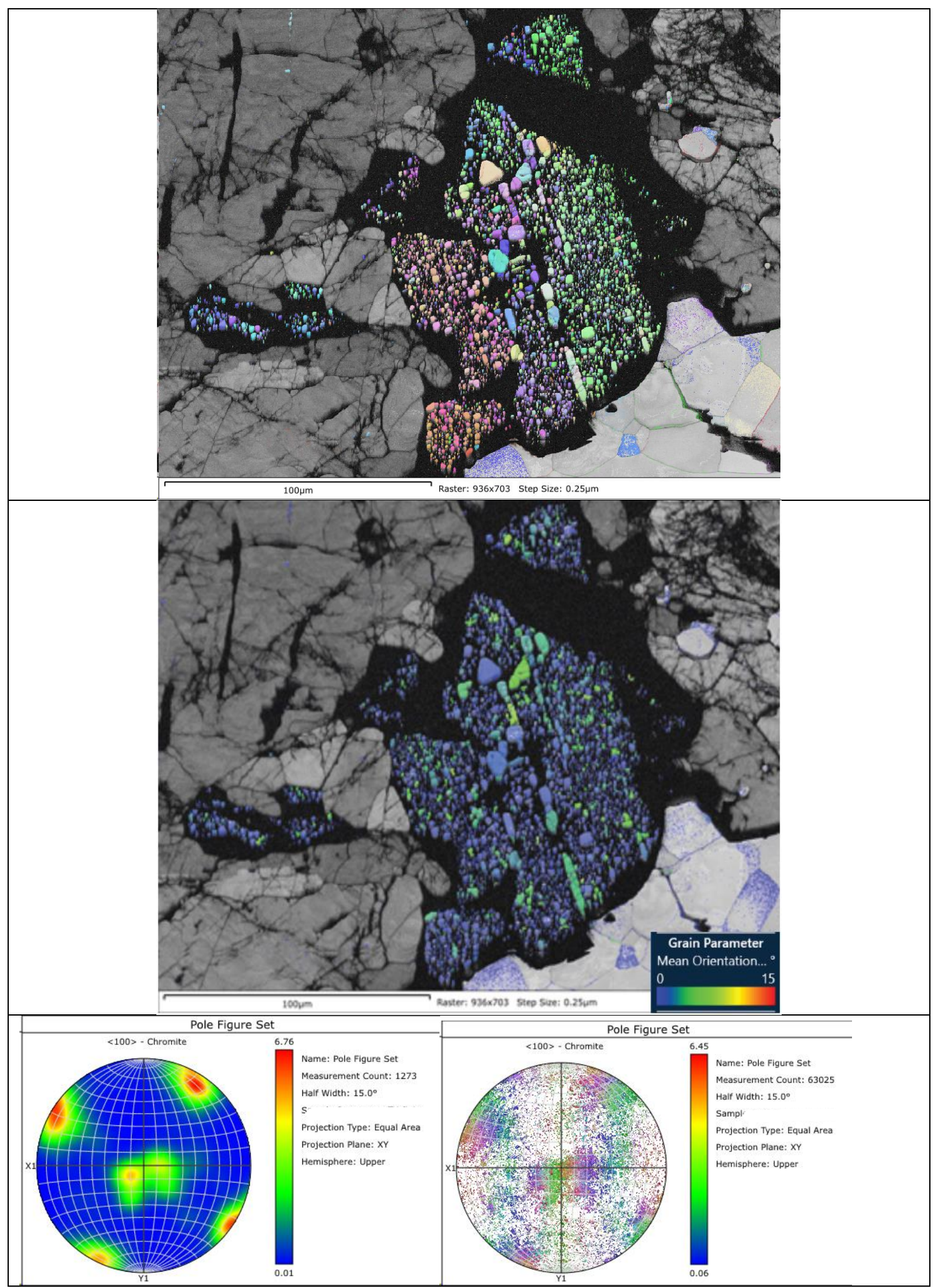

Figure 17: FCC example 2. Alfianello (TM2), IPFx (top left) and GOS15 (top right) maps (colors) together with band contrast (monochrome), with contoured pole figure plot (lower left) and scattered pole figure plot in IPFx colors (lower right). 


\section{CCC}

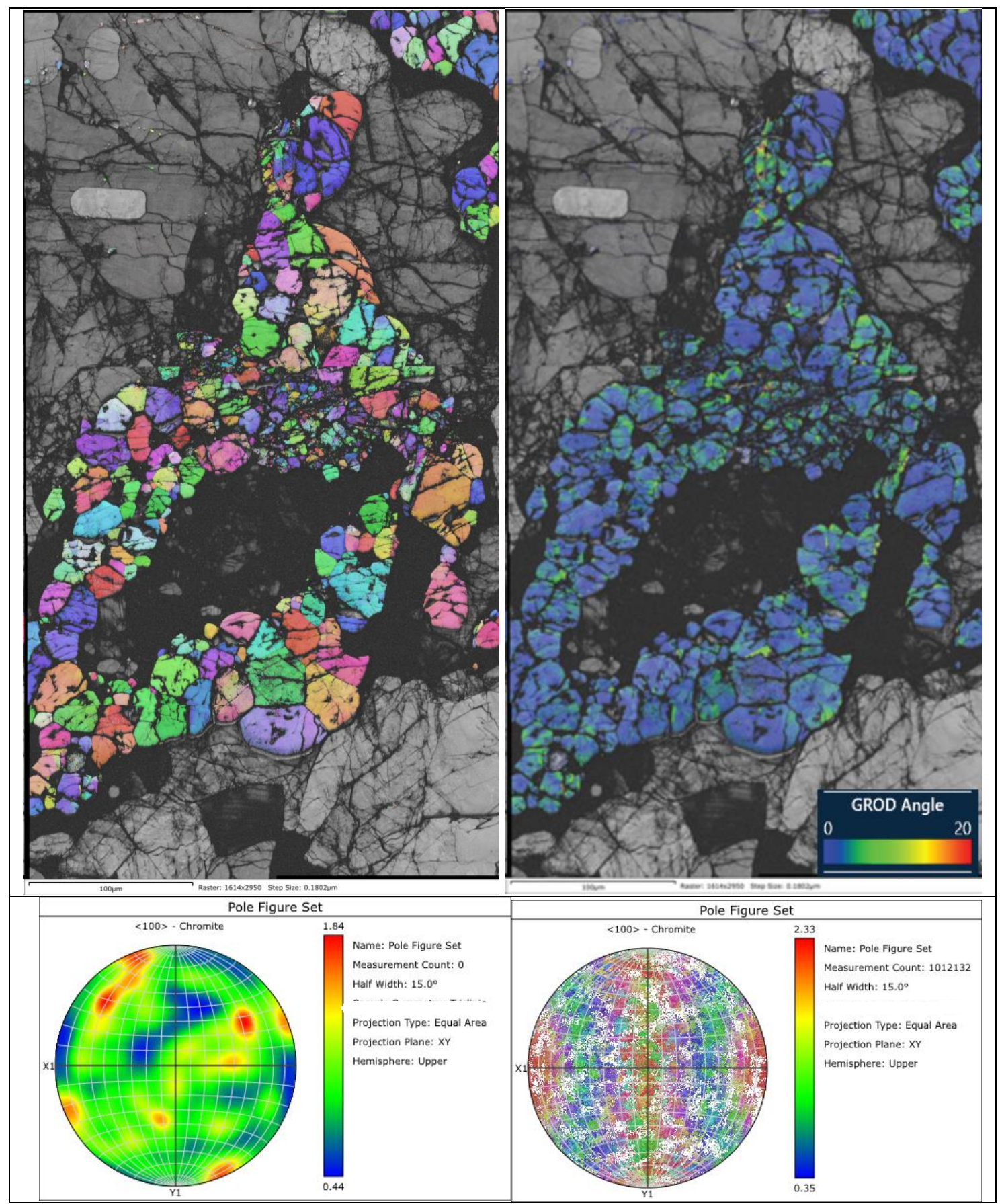

Figure 18: CCC example 1. NWA 13533 (TM6), IPFx (top left) and GROD angle20 (top right) maps together with band contrast (monochrome), with contoured pole figure plot (lower left), as well as scattered pole figure plot in IPFx colors (lower right). 


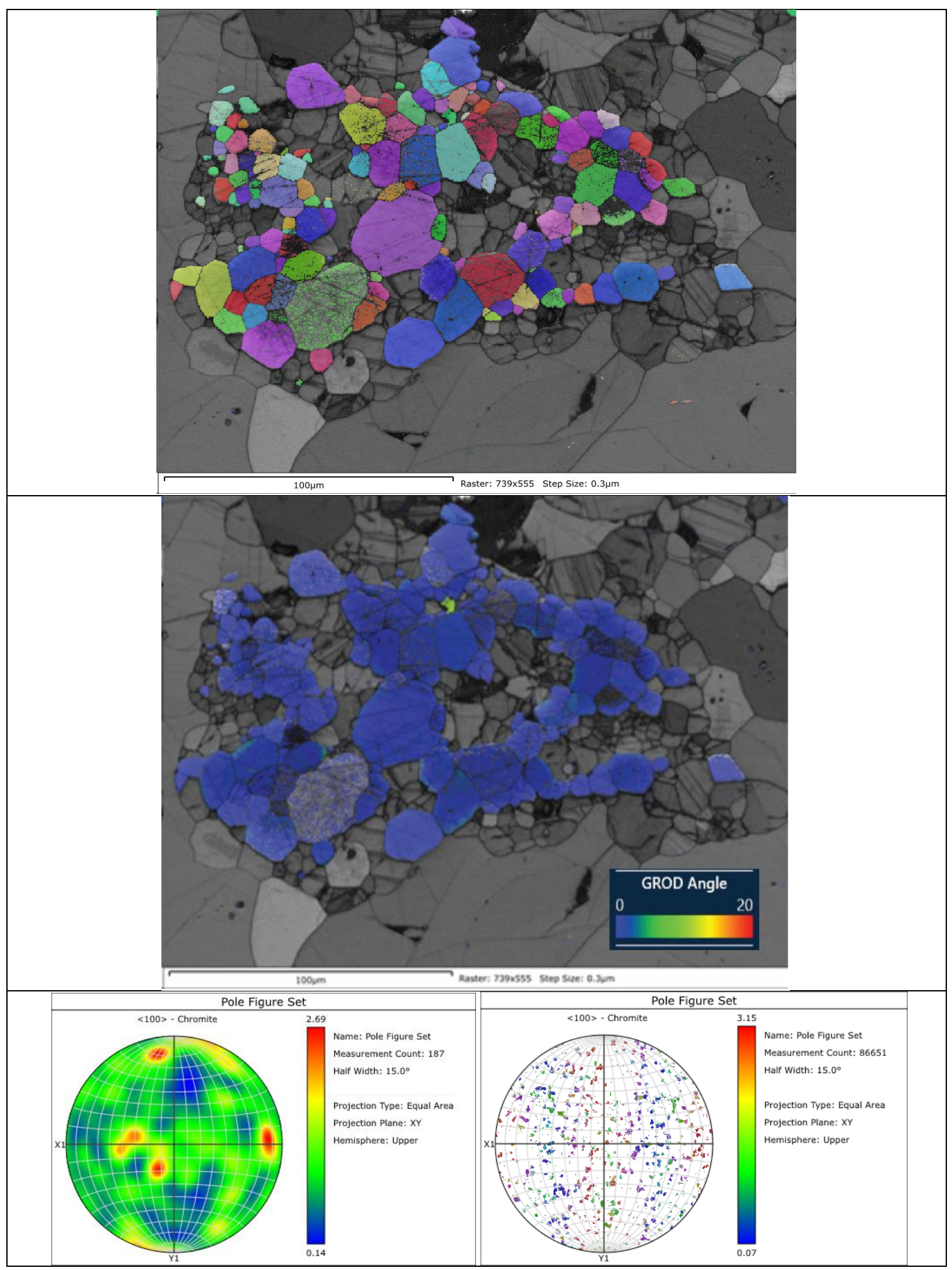

Figure 19: CCC example 2. Estacado (TM2), IPFx (top) and GROD angle20 (middle) maps together with band contrast (monochrome), with contoured pole figure plot (lower left) and scattered pole figure plot in IPFx colors (lower right). Some artifacts were removed from the pole figures as to give accurate numbers. 


\section{CP}

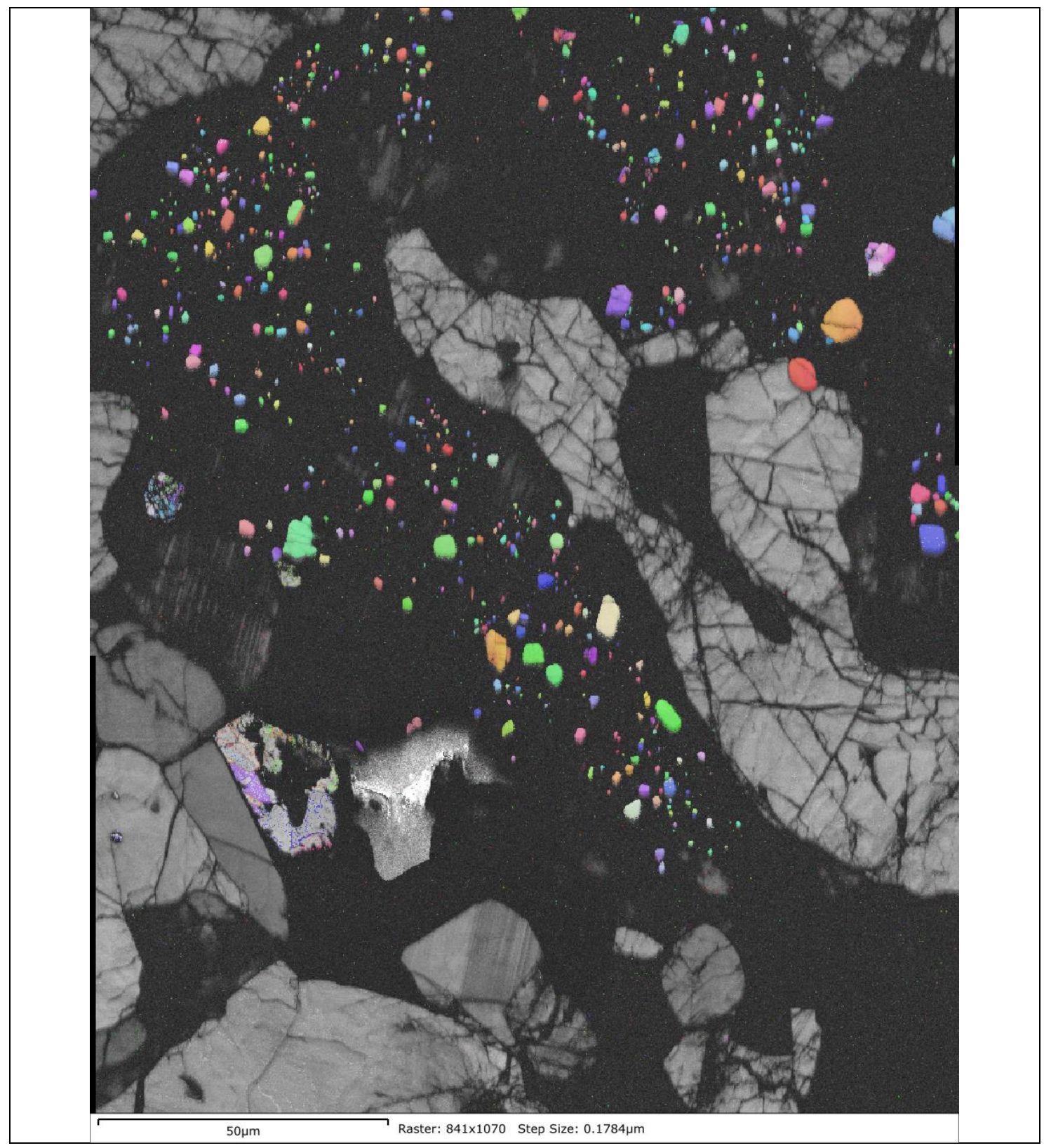




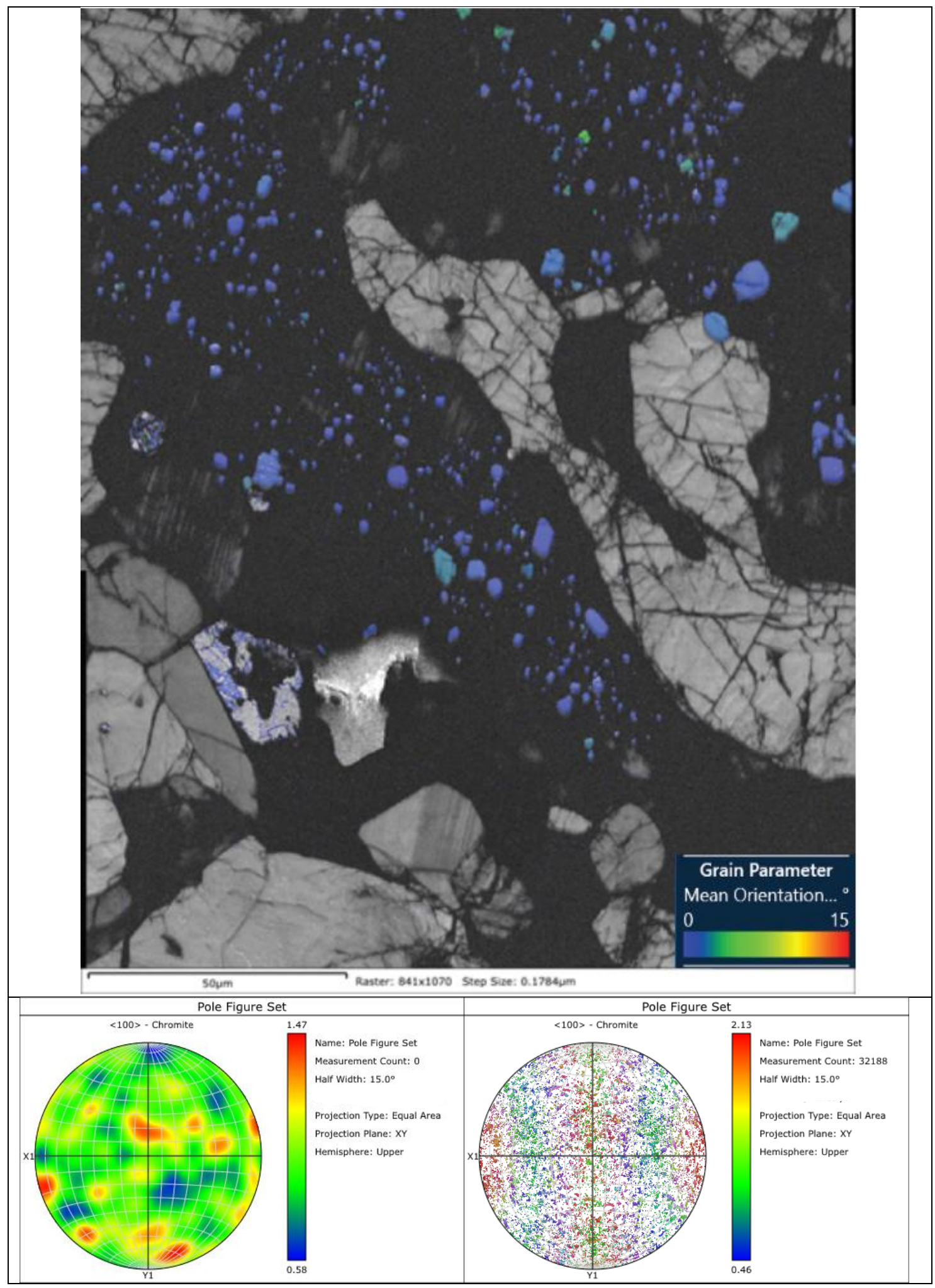

Figure 20: CP example 1. NWA 13533 (TM5), IPFx (top) and GOS15 (middle) maps together with band contrast (monochrome), with a 1 point-per-grain contoured pole figure plot (lower left) and all-pixels scattered pole figure plot in IPFx colors (lower right). 


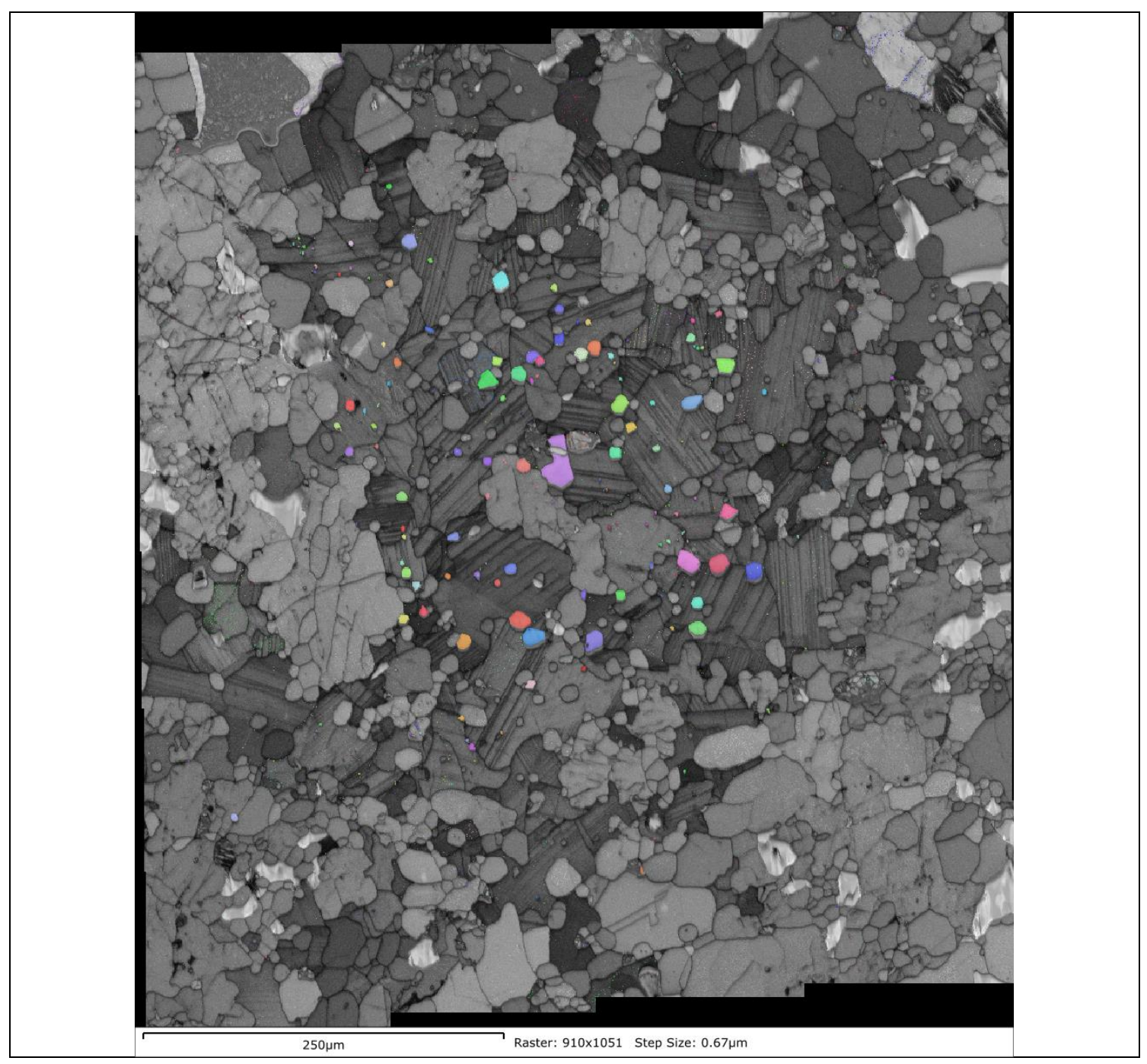




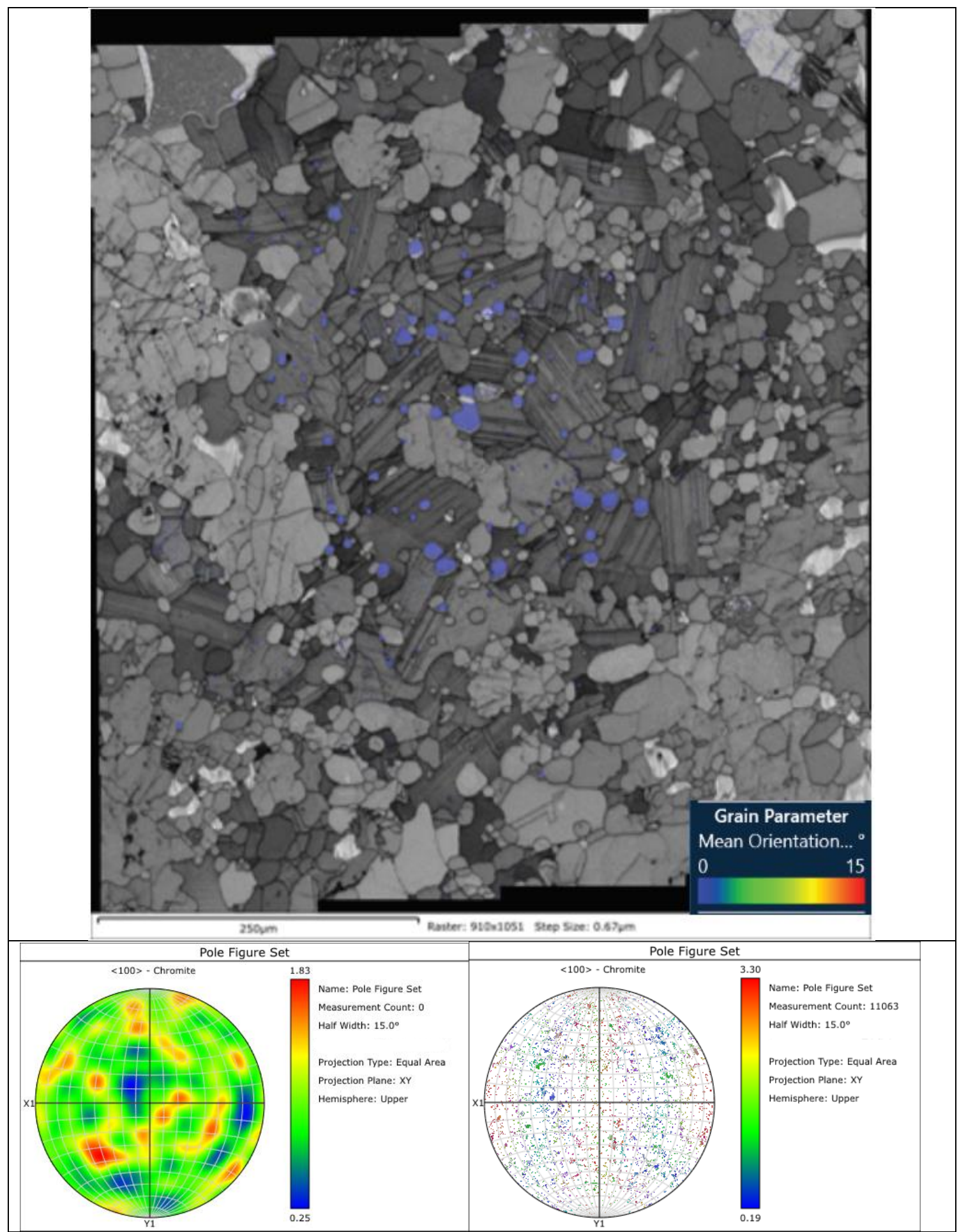

Figure 21: CP example 2. Spade (TM1), IPFx (top) and GOS15 (middle) maps together with band contrast (monochrome), with contoured pole figure plot (lower left) and scattered pole figure plot in IPFx colors (lower right). 


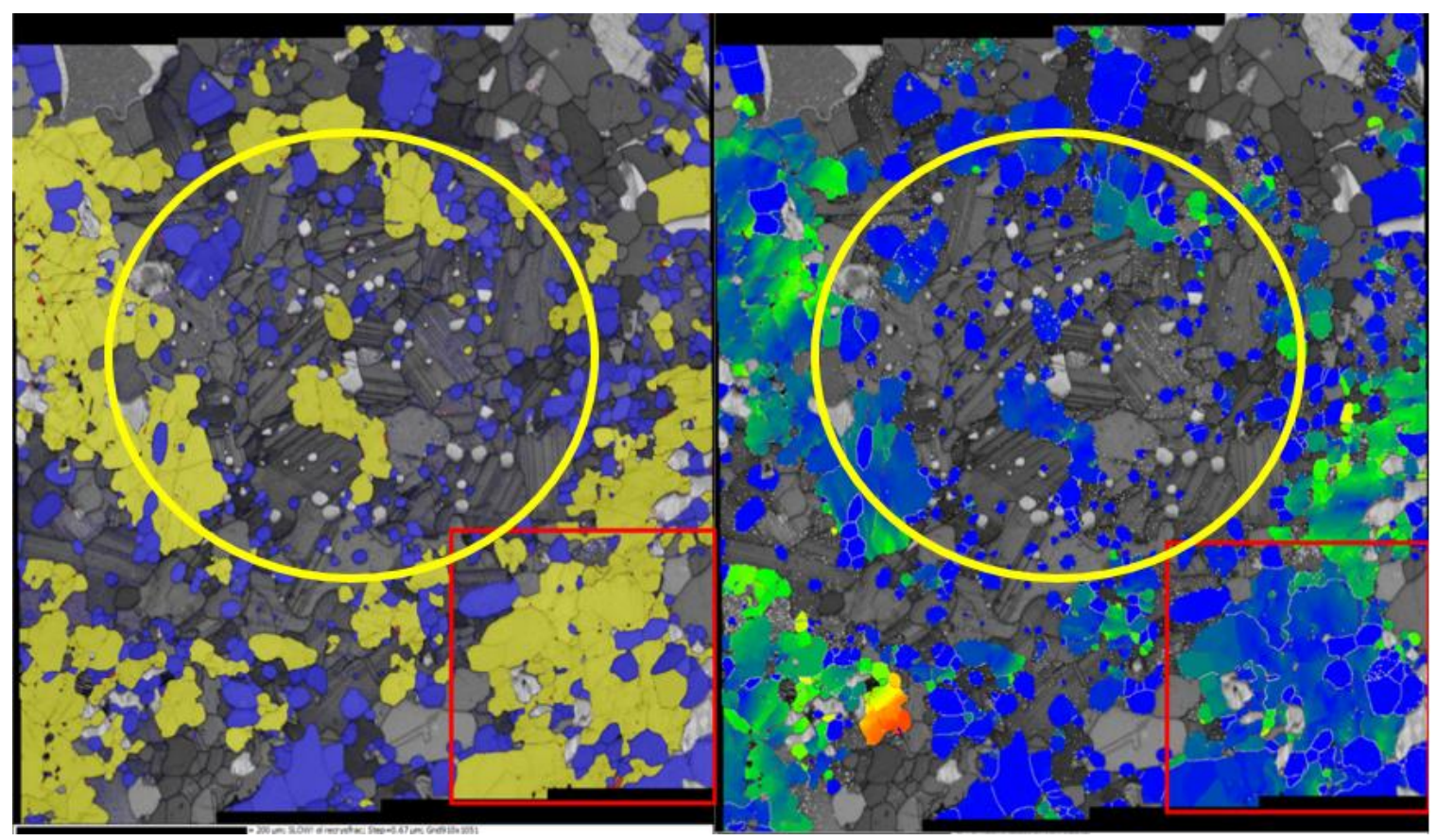

Figure 22: Recrystallization map, Spade 1. The map on the left (Spade TM1) shows the recrystallization of the olivine. Inside the red box the blue grains are the recrystallized grains, while yellow denotes structured grains. The map on the right (Spade TM1) shows the GROD angle20 map. Inside the red box the dark blue grains are grains that have not been deformed, while the green-blue grains have been deformed. The yellow circle highlights the Feldspathic Chromite Assemblage in this map. 

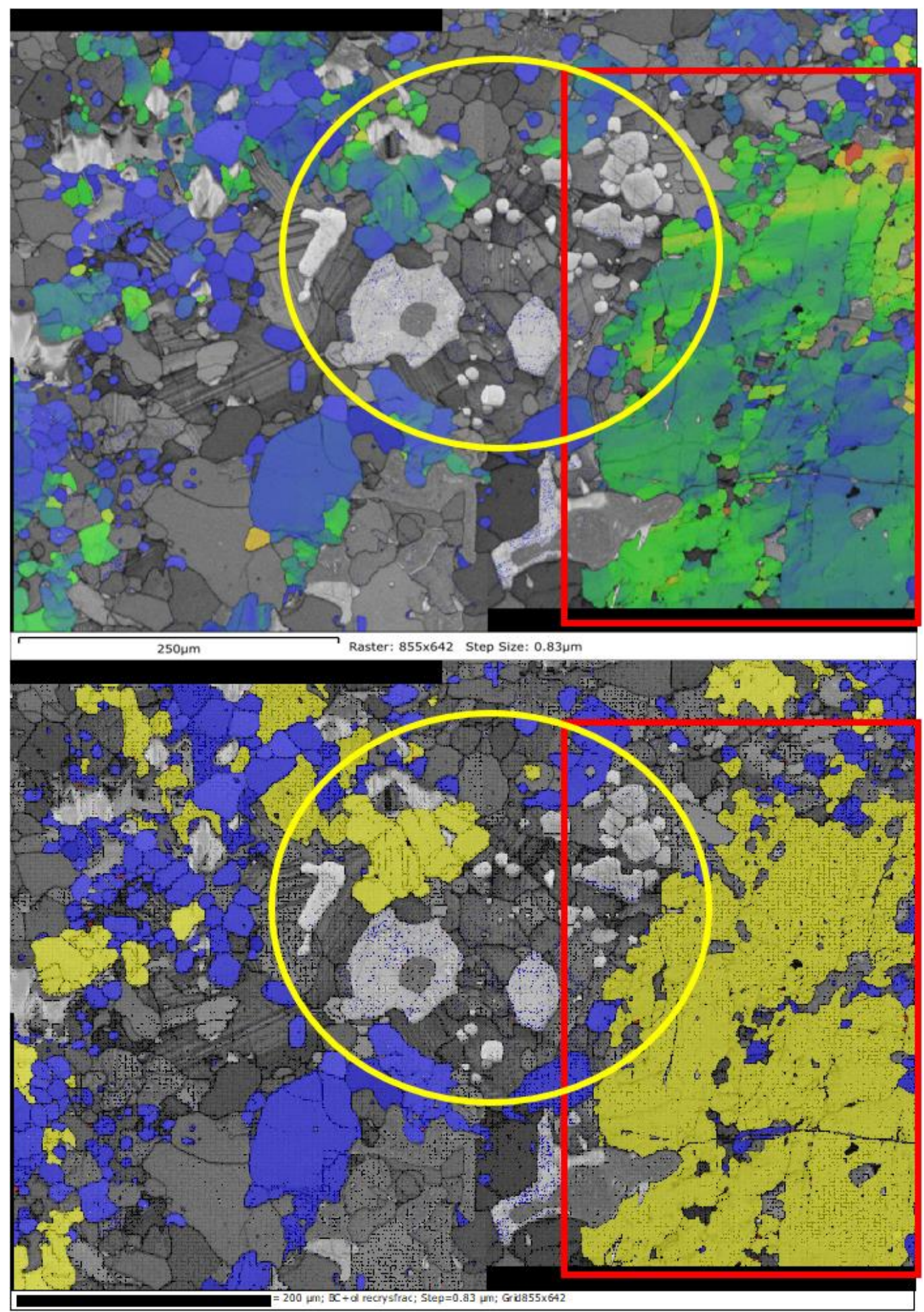

Figure 23: Recrystallization map, Spade 2. The map on the top (Spade TM1) shows the GROD angle20 map. Inside the red box at the top, dark blue grains are grains that have not been deformed, while the greenblue grains have been deformed. The map on the bottom (Spade TM1) shows the recrystallization of the olivine. Inside the red box at the bottom, the blue grains are the recrystallized grains, while yellow denotes structured grains. The yellow circle highlights the Feldspathic Chromite Assemblage in this map. 
Figures 22 and 23 show two targeted maps taken from Spade, TM1 and TM2.

Both figures are olivine maps, that show the recrystallization that Spade experienced. The left side map in Figure 22 shows a recrystallization map derived using Channel5 data. The blue grains are the recrystallized grains, meaning they are largely undeformed grains, while the yellow represents the structured grains that have been deformed, with sub-grain boundaries. The blue grains could represent the recrystallization of previously deformed grains, or grains that were never deformed in the first place. The bottom map in Figure 23 is the same as stated previous. The association of weakly-deformed grains, shown in the GROD angle 20 maps accompanying the recrystallization maps, with heavily deformed grains indicates either that olivine was recrystallized or that it was crystallized from a melt. This will be further discussed later in this Thesis.

\subsection{LAM \& Mini-LAM Data}

The meteorites chosen for this study appear to vary significantly in deformation and thermal history. Data for olivine based on OM and EBSD Large Area Maps are shown in Table 6 and Figure 24. Alfianello and NWA 13533 fit well into the group 3, type 6 meteorites as defined by Ruzicka \& Hugo (2018) and Hugo et al. (2019), which have high shock stage (S4-S5), low $\mathrm{R}_{2-10}$ values, and low $\mathrm{Sk}_{\mathrm{d}>50}$ values. These were interpreted to have been strongly shocked while cold initially, and quickly cooled after shock (Ruzicka and Hugo, 2018; Hugo et al., 2019). Spade is shown to have an elevated rotation parameter $\left(\mathrm{R}_{2-10}\right)$ but a low skewness parameter $\left(\mathrm{Sk}_{\mathrm{d}>50}\right)$ (Table 6$)$. In this regard it resembles St. Severin (LL6), which was interpreted to have been shocked while hot, but which cooled quickly afterwards (Hugo et al. 2019). Estacado has an $\mathrm{R}_{2-10}$ value between that of Spade and Alfianello and NWA 13533, as well as a higher $\mathrm{Sk}_{\mathrm{d}>50}$ value 
(Table 7, Fig. 24). Based on Ruzicka and Hugo (2018) and Hugo et al. (2019), this could indicate that Estacado experienced deformation at an elevated temperature followed by a significant amount of post-shock annealing (A. Ruzicka, personal communication). More details on the apparent deformation and thermal histories for the four meteorites are given in the Discussion.

Table 7: Olivine data including shock stage (weighted and conventional), and the EBSD parameters $\mathrm{R}_{2-10}$ and $\mathrm{Sk}_{\mathrm{d}>50}$ based on Large Area Maps. The implied thermal history based on the EBSD parameters is shown following Ruzicka and Hugo (2018). Shock stage data for Spade, Estacado, and Alfianello after Friedrich et al. (2017).

\begin{tabular}{|c|c|c|c|c|c|c|c|}
\hline Meteorite & Map & $\begin{array}{l}\text { Step Size } \\
(\mu \mathrm{m})\end{array}$ & $\begin{array}{c}\text { Weighted } \\
\text { Shock Stage }\end{array}$ & $\begin{array}{l}\text { Conventional } \\
\text { Shock Stage }\end{array}$ & $\mathrm{R}_{2-10}$ & $\mathrm{Sk}_{\mathrm{d}>50}$ & $\begin{array}{l}\text { Thermal } \\
\text { History* }\end{array}$ \\
\hline \multirow{2}{*}{$\begin{array}{c}\text { Spade } \\
(0269-1 \mathrm{~A})\end{array}$} & $\begin{array}{l}\text { mini } \\
\text { LAM }\end{array}$ & 2.5 & \multirow{2}{*}{2.39} & \multirow{2}{*}{$\mathrm{S} 4$} & 0.748 & 1.065 & $\begin{array}{l}\text { high temp, low } \\
\text { annealing }\end{array}$ \\
\hline & LAM & 4 & & & 0.695 & 1.062 & $\begin{array}{l}\text { high temp, low } \\
\text { annealing }\end{array}$ \\
\hline $\begin{array}{c}\text { Estacado } \\
(0295-3 C)\end{array}$ & LAM & 4 & 1.28 & S1 & 0.605 & 1.451 & $\begin{array}{c}\text { high temp, } \\
\text { high annealing }\end{array}$ \\
\hline $\begin{array}{l}\text { Alfianello } \\
\text { (0496-1A) }\end{array}$ & LAM & 4 & 4.18 & S5 & 0.383 & 1.082 & $\begin{array}{c}\text { low temp, low } \\
\text { annealing }\end{array}$ \\
\hline $\begin{array}{c}\text { NWA } 13533 \\
(0995-1)\end{array}$ & LAM & 4.5 & 3.73 & S4 & 0.357 & 1.100 & $\begin{array}{c}\text { low temp, low } \\
\text { annealing }\end{array}$ \\
\hline
\end{tabular}

$*$ Temp $=$ temperature



Figure 24: Temperature $\left(\mathrm{R}_{2-10}\right.$ parameter $)$ vs. Annealing $\left(\mathrm{Sk}_{\mathrm{d}>50}\right.$ parameter $)$. 
Tables 8 and 9 and Figures 25 and 26 present data for GOS in the 3 major phases highlighted for this study, olivine, chromite, plagioclase. No GOS data were obtained for chromite in the LAM dataset for Spade, because in this dataset metal grains were often mis-indexed as chromite. Figures 27, 28, 29, and 30 show GOS maps for olivine in the mini-LAM for Spade and the three LAMs for Alfianello, Estacado, and NWA 13533, using a uniform false color scale for GOS.

The GOS maps show that most olivine grains in Estacado are weakly deformed (dominantly blue colors, Fig. 28), whereas many olivine grains in Alfianello (Fig. 29) and NWA 13533 (Fig. 30) are significantly deformed (dominantly green colors). A few of the grains in Estacado have higher GOS values (green, yellow in Fig. 28). In Spade, many olivine grains are significantly deformed (green) and many others are weakly deformed (blue) (Fig. 27).

Mean GOS values in olivine and chromite for the coarsest grains $(\mathrm{d}>50 \mu \mathrm{m})$ are similar in Estacado and Alfianello but tend to be higher for olivine than chromite in Spade and NWA 13533 (Fig. 25). In comparing coarse (d>50 $\mu$ m) grains of olivine and plagioclase in Spade and Estacado, mean GOS values appear to be higher in olivine (Table 9) but there are too few data for plagioclase to be sure.

For moderately small $(\mathrm{d}=5-15 \mu \mathrm{m})$ grains, the mean GOS values in Spade and Estacado for olivine and chromite are similar, but in Alfianello and NWA 13533 the GOS values are significantly lower in olivine than in chromite (Fig. 26). When comparing moderately small grains of olivine and plagioclase in Spade and Estacado, the mean GOS values are notably lower in olivine than in plagioclase (Table 9). 
Table 8: Mean Grain Orientation Spread (GOS) values for equivalent grain sizes greater than $50 \mu \mathrm{m}$ and for equivalent grain sizes of 5-15 $\mu \mathrm{m}$ for olivine and chromite, based on LAM and mini-LAM data.

\begin{tabular}{|c|c|c|c|c|c|}
\hline Meteorite & Map & $\begin{array}{c}\text { Mean GOS } \\
\text { olivine }(\mathrm{d}>50)\end{array}$ & $\begin{array}{c}\text { Mean GOS } \\
\text { olivine (d5-15) }\end{array}$ & $\begin{array}{c}\text { Mean GOS } \\
\text { chromite (d }>50)\end{array}$ & $\begin{array}{c}\text { Mean GOS } \\
\text { chromite (d5-15) }\end{array}$ \\
\hline $\begin{array}{c}\text { Spade } \\
(0269-1 \mathrm{~A})\end{array}$ & mini LAM & 2.76 & 0.55 & $1.2 \mathrm{x}$ & 0.37 \\
\cline { 2 - 6 } & LAM & 2.75 & 0.90 & -- & -- \\
\hline $\begin{array}{c}\text { Estacado } \\
(0295-3 \mathrm{C})\end{array}$ & LAM & 0.70 & 0.53 & 0.75 & 0.55 \\
\hline $\begin{array}{c}\text { Alfianello } \\
(0496-1 \mathrm{~A})\end{array}$ & LAM & 4.36 & 3.23 & 4.18 & 1.62 \\
\hline $\begin{array}{c}\text { NWA 13533 } \\
(0995-1)\end{array}$ & LAM & 4.71 & 3.46 & 3.16 & 1.97 \\
\hline
\end{tabular}

\section{Mean GOS (olivine) d $>50$ vs. Mean GOS (chromite)}

$$
\mathrm{d}>50
$$

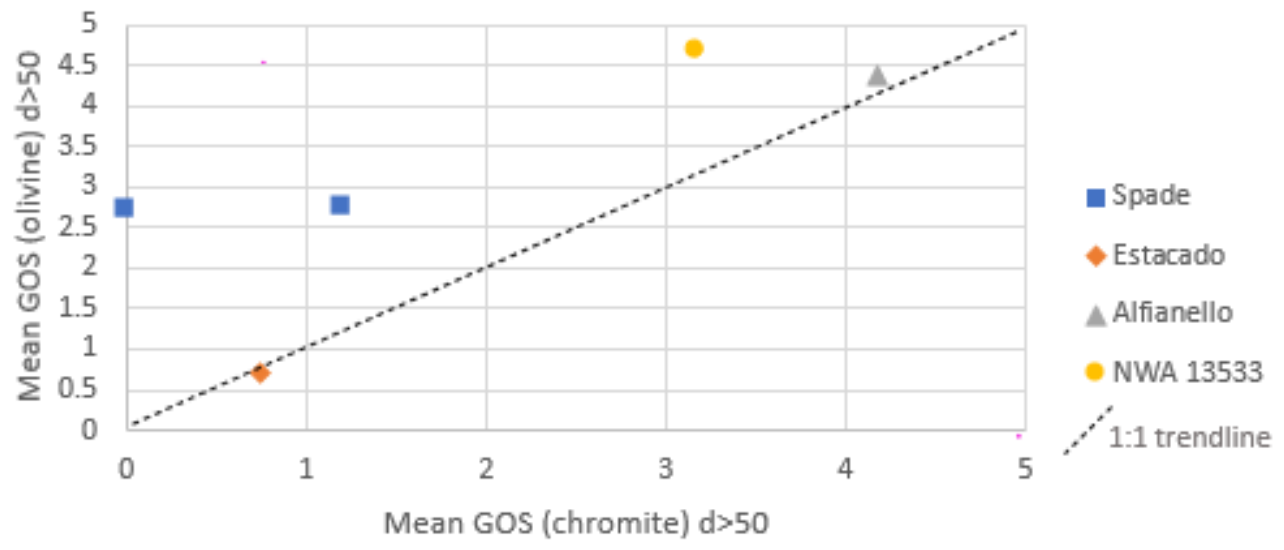

Figure 25: Mean Grain Orientation Spread (GOS) of grain sizes (d) greater than 50 for olivine versus chromite in all four samples Large Area Maps (LAM). The zero-GOS value for the Spade point is an artifact, as metal was mis-indexed as chromite and the GOS value for chromite was arbitrarily set to zero. 


\section{Mean GOS (olivine) d5-15 vs. Mean GOS (chromite) d5-15}

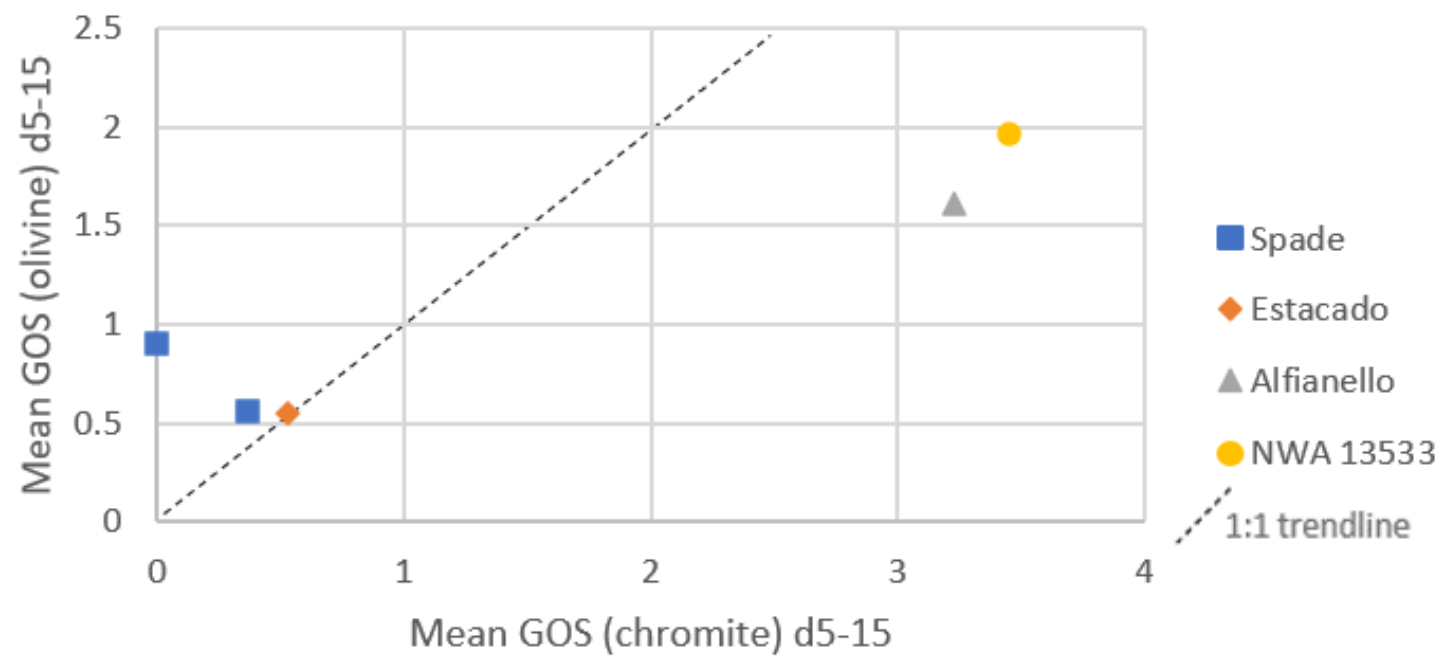

Figure 26: Mean Grain Orientation Spread (GOS) of grain sizes (d) 5-15 for olivine verses chromite in all four samples Large Area Maps (LAM). The zero-GOS value for the Spade point is an artifact, as metal was mis-indexed as chromite and the GOS value for chromite was arbitrarily set to zero. 
Table 9: Mean GOS table for all Targeted Maps and Large Area Maps. Shows the grain size (d>50 \& d515) and standard deviation of GOS for Olivine, Chromite, and Plagioclase.

\begin{tabular}{|c|c|c|c|c|c|c|c|}
\hline Meteorite & Map & $\begin{array}{c}\text { olivine } \\
(d>50)+/- \text { St } \\
\text { Dev }\end{array}$ & $\begin{array}{c}\text { olivine (d5-15) } \\
\text { +/- St Dev }\end{array}$ & $\begin{array}{l}\operatorname{chr}(d>50) \\
+/- \text { St Dev }\end{array}$ & $\begin{array}{l}\text { chr (d5-15) } \\
\text { +/-St Dev }\end{array}$ & $\begin{array}{l}\text { plag }(d>50) \\
+/- \text { St Dev }\end{array}$ & $\begin{array}{l}\text { plag (d5-15) } \\
\text { +/-St Dev }\end{array}$ \\
\hline \multirow{5}{*}{$\begin{array}{c}\text { Spade } \\
(0269-1 A)\end{array}$} & TM1A & $3.06+/-1.84$ & $0.40+/-1.75$ & -- & $0.18+/-0.04$ & $1.72+/-1.49$ & $0.69+/-0.62$ \\
\hline & TM2A & $2.69+/-1.51$ & $0.49+/-0.80$ & -- & $0.22+/-0.20$ & $0.49+/-n / a$ & $0.90+/-0.54$ \\
\hline & TM3A & $4.08+/-2.71$ & $0.49+/-0.76$ & -- & $0.23+/-0.14$ & $1.91+/-\mathrm{n} / \mathrm{a}$ & $0.69+/-0.45$ \\
\hline & $\begin{array}{l}\text { mini } \\
\text { LAM }\end{array}$ & $2.76+/-1.68$ & $0.55+/-0.61$ & $1.2+/-0.65$ & $0.37+/-0.45$ & $1.15+/-0.98$ & $0.94+/-0.56$ \\
\hline & LAM & $2.75+/-1.57$ & $0.88+/-0.91$ & -- & -- & $0.84+/-0.14$ & $0.93+/-0.55$ \\
\hline \multirow{6}{*}{$\begin{array}{l}\text { Estacado } \\
(0295-3 C)\end{array}$} & TM1B & -- & $0.43+/-0.13$ & -- & -- & -- & $0.64+/-0.16$ \\
\hline & TM2B & $0.38+/-0.14$ & $0.39+/-0.10$ & -- & $1.47+/-0.21$ & -- & $0.85+/-0.62$ \\
\hline & TM3B & -- & $0.31+/-0.10$ & -- & -- & -- & $0.89+/-0.34$ \\
\hline & TM4B & -- & -- & -- & -- & -- & $0.82+/-0.44$ \\
\hline & TM5B & -- & $0.68+/-0.85$ & -- & $0.58+/-\mathrm{n} / \mathrm{a}$ & $0.75+/-n / a$ & $0.61+/-0.36$ \\
\hline & LAM & $0.697+/-0.73$ & $0.53+/-0.35$ & $0.75+/-0.49$ & $0.55+/-0.39$ & $1.15+/-0.53$ & $1.11+/-0.75$ \\
\hline \multirow{7}{*}{$\begin{array}{l}\text { Alfianello } \\
\text { (0496-1A) }\end{array}$} & TM1C & $5.34+/-0.38$ & $3.61+/-2.55$ & -- & $1.97+/-1.49$ & maskelynite & maskelynite \\
\hline & TM2C & $4.12+/-n / a$ & $3.27+/-1.99$ & -- & $2.04+/-1.65$ & maskelynite & maskelynite \\
\hline & TM3C & -- & $4.44+/-1.52$ & -- & -- & maskelynite & maskelynite \\
\hline & TM4C & $3.73+/-n / a$ & $2.34+/-0.91$ & -- & $2.46+/-n / a$ & maskelynite & $2.77+/-n / a$ \\
\hline & TM5C & -- & $4.53+/-2.64$ & -- & $2.83+/-\mathrm{n} / \mathrm{a}$ & maskelynite & $1.13+/-\mathrm{n} / \mathrm{a}$ \\
\hline & TM6C & $2.54+/-1.10$ & $4.1+/-2.15$ & -- & $3.14+/-2.24$ & maskelynite & maskelynite \\
\hline & LAM & $4.36+/-1.74$ & $3.23+/-2.13$ & $4.18+/-2.21$ & $1.62+/-1.81$ & -- & $1.64+/-0.77$ \\
\hline \multirow{5}{*}{$\begin{array}{c}\text { NWA } \\
13533 \\
(0995-1)\end{array}$} & TM1D & $3.23+/-0.62$ & $1.93+/-1.12$ & -- & $1.45+/-1.05$ & maskelynite & $6.83+/-n / a$ \\
\hline & TM4D & -- & $2.19+/-0.99$ & -- & $2.04+/-0.81$ & maskelynite & maskelynite \\
\hline & TM5D & $3.84+/-n / a$ & $2.94+/-1.73$ & -- & $1.09+/-0.63$ & maskelynite & maskelynite \\
\hline & TM6D & $4.07+/-2.04$ & $3.52+/-1.74$ & -- & $2.37+/-1.53$ & maskelynite & $0.94+/-0.25$ \\
\hline & LAM & $4.71+/-1.97$ & $3.46+/-2.07$ & $3.16+/-1.11$ & $1.97+/-1.89$ & -- & $1.56+/-0.73$ \\
\hline
\end{tabular}






Figure 27: Spade mini-LAM GOS15 map. Olivine (colors) and band contrast (monochrome).

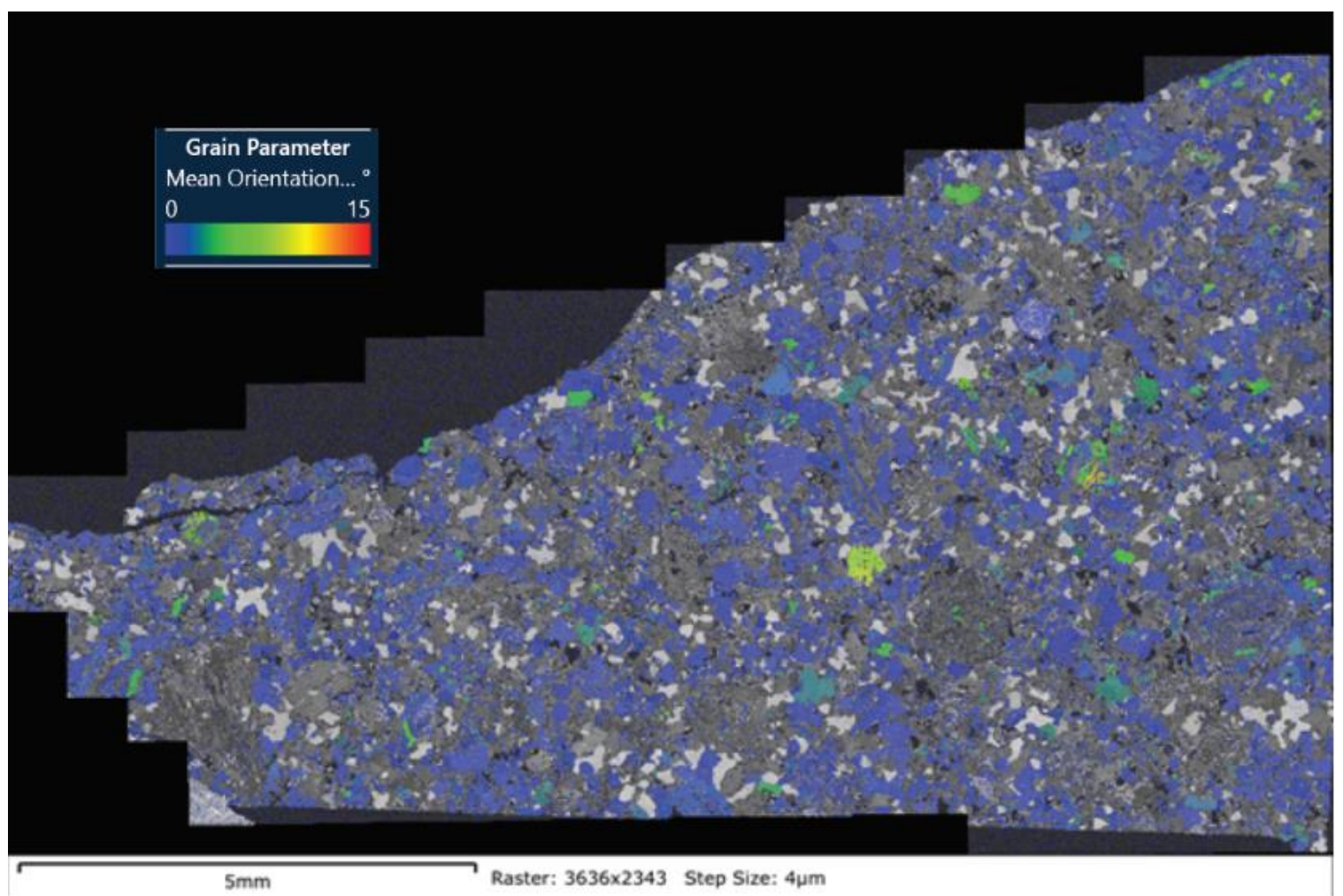

Figure 28: Estacado LAM GOS15 map. Olivine (colors) with band contrast (monochrome). 


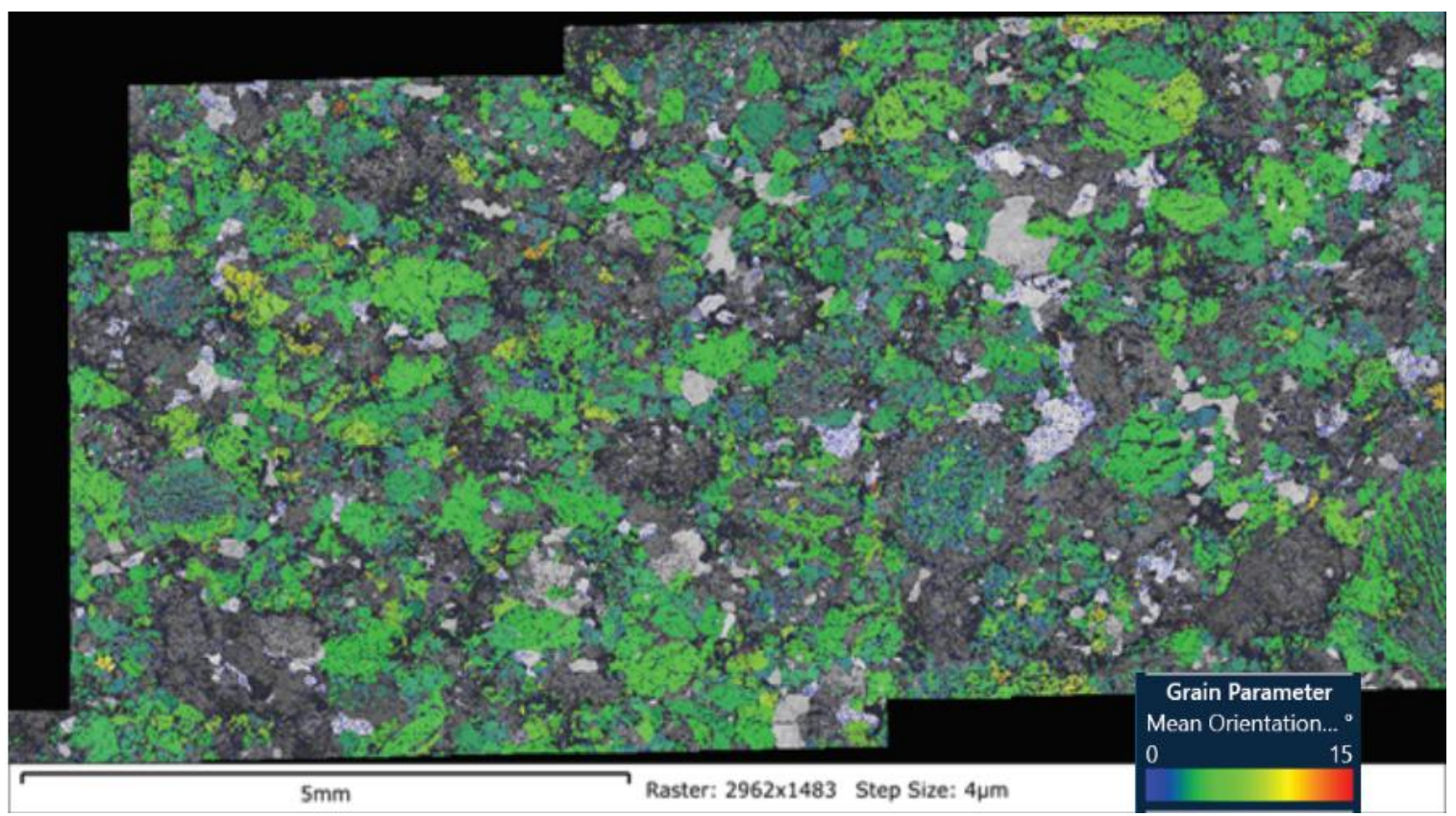

Figure 29: Alfianello LAM GOS15 map. Olivine (colors) and band contrast (monochrome). 




Figure 30: NWA 13533 LAM GOS15 map for olivine. 


\section{4) DISCUSSION}

\subsection{General Meteorites (Deformation-Thermal History)}

Olivine LAM data suggest that the four meteorites can be grouped into three different categories for shock and thermal histories (Table 6). 1) Spade was deformed at high temperatures and did not experience much post-shock annealing afterwards. Like St. Severin (Hugo et al., 2019), Spade may have been excavated from an interior portion of the parent body while it was experiencing thermal metamorphism and placed near the top surface of the body. The histories for Spade and St. Severin could have been generally similar but they represent different parent bodies (H for Spade, LL for St. Severin). 2) Alfianello and NWA 13533 were deformed at low temperatures and did not experience much post-shock annealing. Like Leedey, Bruderheim, and Morrow County for the Lgroup (Ruzicka and Hugo, 2018) and Elbert for the LL group, Alfianello and NWA 13533 could have been shocked while the L parent body was cold. 3) Like Spade, Estacado could have been shocked while the parent body was undergoing thermal metamorphism, but unlike Spade, Estacado was annealed after shock. This could indicate that the source materials for Estacado remained buried in a warm body after deformation. 4.2 Spade

Spade gives the impression of a strongly shocked meteorite that caused localized melting that created the FCAs that are found there. The olivine adjacent to the FCAs appears to be recrystallized, not annealed after deformation as has been previously proposed for Spade overall (Rubin and Jones, 2003). This indicates intense deformation, as olivine recrystallization is associated with shock stage S6 (Stöffler et al. 1991, 2018; Fritz et al., 2017). Figure 16 is strong evidence for Spade having not been annealed, 
given that its annealing parameter $\left(\mathrm{Skd}_{50}\right)$ is relatively low ( 1.06-1.07 for both LAM and mini LAM, Table 6). The small ( $\mathrm{d}=5-15)$ chromite grains in Spade have low mean GOS $\left(<0.4^{\circ}\right)$ and have especially low mean GOS values $(\sim 0.18-0.23)$ in the three FCAs examined (Table 8, Fig. 14). These GOS values are the lowest in the meteorites examined for this grain size range. Similarly, the smallest $(d<5)$ grains in FCAs from Spade have the lowest GOS values among any assemblage examined (Fig. 15). Given that Spade was evidently strongly shocked and not significantly annealed, low GOS values for the smaller chromites including those in FCAs could indicate that the small chromites formed by crystallization from melts, and that the FCAs in Spade formed at least in part by crystallization from melt pockets. This is consistent with the plagioclase normal $\mathrm{Na}-\mathrm{Ca}$ zoning (Ca-rich cores, Na-rich rims) that was found in the EDS maps of these FCAs. For larger (d>50) grains, Spade shows a much higher mean GOS in olivine compared to chromite, but for smaller (d=5-15) grains, GOS values in olivine and chromite are similar (Fig. 25, 26, Table 8). This may indicate that the larger olivines in Spade often have relict deformation, but that the smaller olivine grains could have either been recrystallized, as shown by some olivine adjacent FCAs, or crystallized from a melt, as in the FCAs themselves (Fig. 22, 23).

\subsection{NWA 13533 \& Alfianello}

Both NWA 13533 and Alfianello appear to have been strongly shocked from a cold initial state and quickly cooled afterwards. They give the impression of strongly shocked meteorites with FCAs created by localized melting. The presence of maskelynite, which only appears in strongly shocked meteorites (Stöffler et al., 1991), and which could have crystallized from melts (Chen and El Goresy, 2000) and is 
concentrated in FCAs, supports this idea. Within the maskelynite is the presence of ragged plagioclase patches, which appear to represent relict plagioclase grains. The presence of relict plagioclase indicates that at least some portion of the FCAs was not melted.

GOS values in olivine and chromite grains of different sizes in NWA 13535 and Alfianello are the highest in the four meteorites examined (Table 7; Fig. 25, 26). This includes elevated GOS values in chromite for the FCAs themselves (Table 8). Although the high GOS values generally support the idea that NWA 13533 and Alfianello were strongly shocked, elevated GOS in FCA chromite raises the question of whether all the chromite in these assemblages crystallized from a melt. It would seem either that some of the chromite in the FCAs from these meteorites is also relict, or that chromite in FCAs was deformed after it crystallized from a melt.

\subsection{Estacado}

Estacado shows evidence of a shock followed by annealing. If the FCAs found in this meteorite formed by shock melting, this was followed by the crystallization of plagioclase from these melts (as proposed here for Spade) or was followed by the crystallization of plagioclase from maskelynite. The plagioclase grains found in the FCAs are fairly coarse, which suggests that the plagioclase crystallized out of the melts. However, normal zoning was not observed for plagioclase in EDS maps. Such normal zoning could have been obliterated during annealing, so the lack of such zoning is not necessarily an argument against melt crystallization. Estacado has consistently low GOS values in minerals (though not as low as Spade), which could have been lowered during the annealing event. This is called 'recovery', when the GOS values are lowered by the 
movement of dislocations within crystals, a process proposed for some type 6 ordinary chondrites (Ruzicka and Hugo, 2018). Mean GOS values are similar between olivine, chromite, and plagioclase in Estacado (Table 8), although somewhat higher in plagioclase compared to the other two minerals based on the Large Area Map. This could indicate that annealing lowered the GOS values in all these minerals in Estacado, especially for olivine and chromite.

\subsection{FCA Comparison Across all Meteorites}

There are five main parameters that were used to characterize the assemblages utilized in this study. These parameters help to craft the origin story of these objects, here we will talk about each textural type in terms of these parameters. In the four meteorites chosen, eighteen targeted maps were acquired and further analyzed. Altogether, the data suggest that there are two main types of chromite-rich assemblages in type 6 chondrites, fine clumped chromite (FCC) and coarse clumped chromite (CCC), with chromite-poor (CP) forming a third, smaller, group. Below is the comparison of the parameters for the three assemblage types (LPO, Chromite Coarseness Ratio, and Clump Density), as well as the parameters that do not seem to factor into assemblage origin (Area Fraction of Chromite, and GOS).

\section{FCC:}

A model for the origin of Fine Clumped Chromites relies heavily on three of the five parameters, specifically the LPO, clump density, and grain coarseness ratio. GOS parameters give information on how the assemblages were processed and is discussed after the other parameters. 
Most of the FCC assemblages have a high (>5) chromite LPO number. This leads to one of two conclusions, 1) the subsets taken in these assemblages are pseudomorphs that exsolved from a high pressure precursor phase, or 2) they represent single grains of chromite that are spongy. This means that the grains are connected in 3 dimensions with a good amount of space between the grains. If the second possibility is correct, then the chromite would have to be extremely spongy, with more non-chromite than chromite in any given slice of the meteorite. However, the apparent euhedral shapes of some of the chromite grains is strong evidence against the grains being spongy. Available evidence therefore supports the suggestions of Ramdohr $(1967,1973)$ that some chromite assemblages, including the FCC type described here, formed by the decomposition of unstable precursor grains. Ramdohr $(1967,1973)$ suggested that the precursor phase could be a pyroxene rich in the kosmochlor $\left(\mathrm{NaCrSi}_{2} \mathrm{O}_{6}\right)$ component. Brearley et al. (1991) studied a chromite-rich inclusion in an L6 chondrite (Los Martinez) that has fine oriented chromite set in plagioclase, similar to FCC, and on the basis of preferred orientation and other features suggested that fine chromite and plagioclase exsolved from an unknown metastable phase that itself had crystallized from a melt.

The FCCs used for this study have a high clump density, especially in those examples with high LPOs. This suggests these assemblages are the product of precipitation from a melt that did so in such a way that the result is many chromite grains in one concentrated space such as is seen in the targeted maps. Conversely, this could also imply that the inferred precursor grain was so loaded with normative chromite, that the grains produced were small enough to allow many grains to be packed closely together in a fairly compact area. 
The FCC assemblages are not resolved by the area fraction of said assemblages. They have a variety of chromite area fractions, as well as a variety of GOS. GOS seems to mostly relate to the host meteorite and can indicate that this assemblage is not distinguished by GOS, but by the history experienced by the host meteorite.

\section{CCC:}

The origin of Coarse Clumped Chromites, much like the FCCs, relies on the same three of the five parameters. CCCs are most likely some sort of aggregates of pre-existing grains, or grain clumps that crystallized from a melt that was enriched in normative chromite. The low clump density of the CCC group could be attributed to their potential aggregate origin, as they have fewer, but larger, grains to 'clump'. Clump density is found using the area of an assemblage divided by the number of chromite grains found in that assemblage. CCCs tend to have fewer, but larger, chromite grains and are concentrated closer together, as there is usually little to no space between chromite grains.

Much like the FCCs, the CCCs are not resolved by the area fraction. They trend towards a high to moderate area fraction which leads to two possible conclusions, 1) these were pre-existing chromite grains that were clumped together as a result of shock or 2) they could also be crystallized from a melt after shock and then clumped together.

\section{CP:}

The origins of the Chromite Poor assemblages are less clear. Both $\mathrm{CP}$ assemblages were found to be typically low in almost all parameters. The LPO of these assemblages is the lowest off all 18 Targeted Maps. However, they overlap with the CCC and FCC groups in terms of the grain coarseness ratio and GOS. These assemblages were 
found in Spade and NWA 13533, which points to theses assemblages being crystallized from a melt.

\section{GOS:}

LPO \# vs. Mean GOS (chromite, all d)

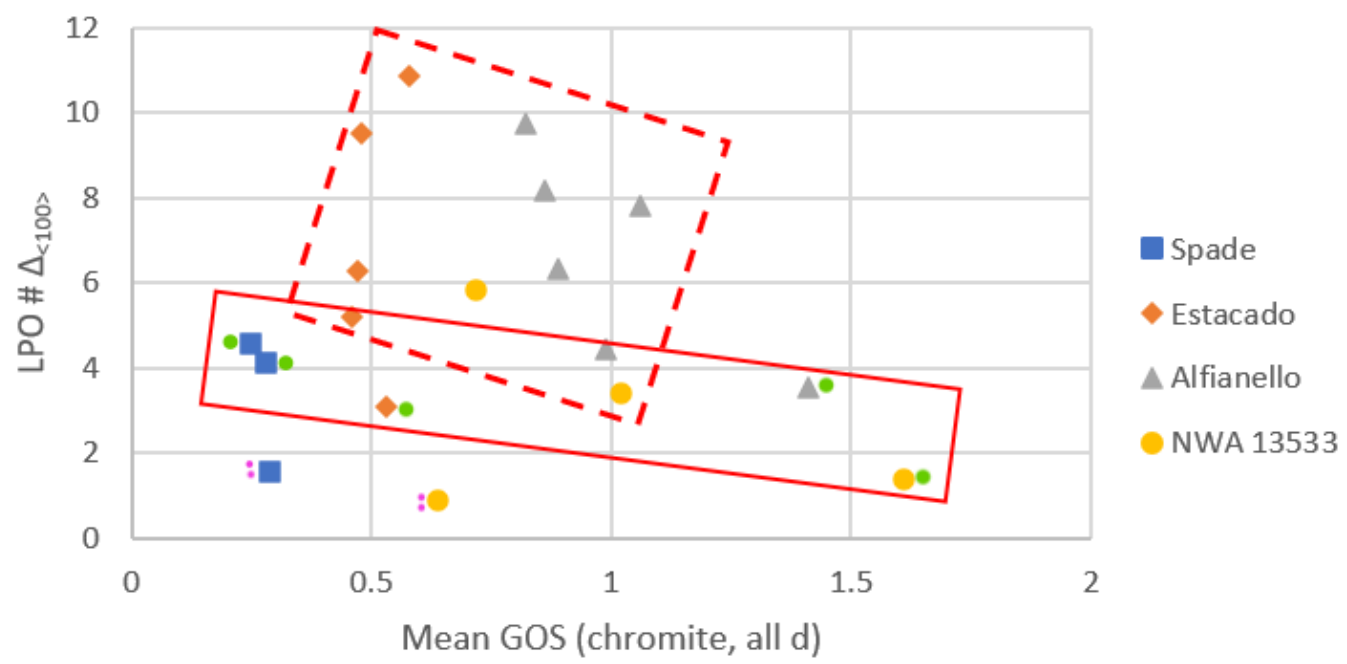

Figure 31: LPO \# vs. Mean GOS of chromite, all d. $d=$ equivalent grain diameter in microns $(\mu)$. Green dots next to symbol for meteorite denote CCC, pink double dots denote CP, lack of dots denote FCC. Solid line box shows CCC trend, while dotted line box shows FCC trend.

This parameter is the only one that does not strongly relate to assemblage type. The GOS data taken for these assemblages appears to have more of a correlation to the shock stage and thermal history of the meteorites host body. This implies that the chromites crystallized from a shock melt due to the deformation that the host body experienced. This could mean that there was more of an aggregational origin for these assemblages, but this doesn't line up well with the FCC group. There is always the possibility of a second shock event having happened, but this is not a model that works for Spade. With the FCCs not fitting into an aggregational origin, therefore we gravitate to the idea that these assemblages were created due to exsolution from a precursor phase. 
Figures 7, 8, and 31 compare mean GOS (all d) for chromite against chromite coarseness ratio, clump density, and LPO \#. Figures 7 and 8 show that texture (grain size and clumping) of the FCC objects didn't change much during the annealing process. This could mean that the chromite grains couldn't grow due to already being encased in plagioclase. Interpretation of the data for CCCs are hampered by having studied relatively few assemblages of this type. However, the CCC assemblages in Spade and Estacado are notably coarser than in Alfianello and NWA 13533 (Fig. 7). Clump densities in Estacado are similar to those of Alfianello and NWA 13533, whereas that in Spade is somewhat lower. This implies that annealing could have caused grain coarsening in Alfianello CCCs without much changing the clump density, by adding to coarser grains from the smaller, possibly similar to an Ostwald ripening process. Spade CCCs may have formed differently, by crystallization from a melt, leading to both coarser grains and a lower clump density. If correct this would imply two origins for CCCs, namely crystallization in Spade, and aggregation ion the other three meteorites.

With Figures $7 \& 8$ showing the comparisons of GOS against two of the three main parameters in determining the assemblage types of the FCAs, there is one important parameter unaccounted for. Figure 31 shows GOS versus LPO, the FCC group shows no significant difference between Estacado, Alfianello, and NWA 13533. Meaning that once more, the annealing that Estacado experienced didn't make much of a difference in FCC LPO. This is likely for the reason that the chromite was encased in feldspathic material, implying that the plagioclase crystallized from maskelynite (if that's what it was originally), and annealing couldn't change the orientation of the chromite. The CCC 
group shows higher LPO in Spade than in Alfianello and NWA 13533. This could imply that crystallization allowed the chromite crystals to attach and become more crystallographically oriented, by one chromite growing on top of another, in a process called topotactic growth. Once more, this implies that there are two different origins for the CCC group, one being crystallization (seen in Spade), and the other being aggregation of pre-existing grains (seen in Alfianello and NWA 13533).

The GOS data shows that Spade and Estacado were deformed during their shock events, while the parent body interiors were being metamorphosed. Meanwhile Alfianello and NWA 13533 were deformed after the parent body interiors were metamorphosed. The high $\mathrm{Skd}_{>50}$ value for Estacado suggests that the post deformation annealing brought down the overall GOS value for the olivine.

4.6 What is the Bigger Picture?

The bigger picture that we can see with these four meteorites, while they are very different meteorites with their own unique origin, is the characteristic that they share. The obvious difference in high and low shock meteorites is the GOS in chromite. For our low shock meteorites (Spade and Estacado) we see evidence that either 1) annealing removed signs of deformation and healed the cracks made via shock (which is likely in Estacado), or 2) the grains crystallized from a melt after most deformation had already happened (which is likely in Spade). For our high shock meteorites (NWA 13533 and Alfianello), the FCAs were likely produced as a result of the strong shock these meteorites experienced, with no complications of post-shock annealing, although localized melting during strong shock might still be involved. 
If these FCA objects are formed by shock melting, as was inferred by Rubin (2003), then what differences do we see between the high and low shock meteorites? There appears to be no difference in many of the measured parameters (chromite coarseness ratio, LPO, area fraction of chromite, and clump density) between the high and the low shocked meteorites. There are some real differences between assemblage types, but aside from those, there is no differences (outside of GOS) between the high and low shock meteorites. The large difference that we do see between the high and low shock meteorites studied for this paper is their GOS values. The mean GOS values tend to be higher for the high shock meteorites, and lower for the low shock meteorites.

Rubin (2003) states that these FCAs form under high shock conditions, and Alfianello and NWA 13533 fit this model. It is likely that Estacado was annealed, and despite this, the FCAs found within the sample were not destroyed in the process. The chromite in Estacado appears to not have been largely affected at all by annealing, the GOS value for chromite was lowered, but other than that there appears to be no other changes. Annealing changed the GOS values of olivine, lowered them from what they were pre-annealing, but that was the only real change due to annealing. Spade does not fit this model. It was shocked at high temperatures but shows no evidence of annealing. The plagioclase in Spade is zoned, which means it could not have been completely equilibrated, which is a side effect of annealing. The chromite in Spade is also somewhat zoned, but not completely equilibrated. Both of these instances point to annealing not being a factor for Spade. In Spade, it appears that both chromite-poor (CP) and coarse clumped chromite (CCC) assemblages were able to form by crystallization from local melt pockets. 
The conclusion that can be made from this study is that Rubin's (2003) model is supported by our findings for most meteorites, but not all. Of the four meteorites used in this study, three of them fit Rubin's model (Estacado, Alfianello, and NWA 13533), with Spade being an outlier. 


\section{References}

Bischoff, A., and Keil, K., (1984), Al-rich objects in ordinary chondrites: Related origin of carbonaceous and ordinary chondrites and their constituents: v. 48, p. 693-709.

Brearley A.J., Casanova I., Miller M.L., and Keil K. (1991), Mineralogy and possible origin of an unusual Cr-rich inclusion in the Los Martinez (L6) chondrite:

Meteoritics \& Planetary Science, v. 26, p. 287-300.

Friedrich J.M., A. Ruzicka, R.J. Macke, J.O. Thostenson, R.A. Rudolph, M.L. Rivers and D.S. Ebel (2017), Relationships among physical properties as indicators of high temperature deformation or post-shock thermal annealing in ordinary chondrite: Geochimica et Cosmochimica Acta, v. 203, p. 157-174.

Fritz, J., Greshake, A., and Fernandes, V.A. (2017), Revising the shock classification of meteorites: Meteoritics \& Planetary Science, v. 52, p. 1216-1232.

Jamsja, N., and Ruzicka, A., (2010), Shock and thermal history of Northwest Africa 4859, an annealed impact-melt breccia of LL chondrite parentage containing unusual igneous features and pentlandite: Meteoritics and Planetary Science, v. 45, p. 828-849, doi:10.1111/j.1945-5100.2010.01056.x.

Hugo, R.C., Ruzicka, A.M. and Rubin, A.E., (2019), Mesoscale and microscale shock effects in the LL 6 S4 chondrites Saint-Séverin and Elbert: A tale of two breccias: Meteoritics \& Planetary Science. doi 10.1111/maps.13304

Krot A. and M.A. Ivanova (1992), Cr-rich chondrules and inclusions in ordinary chondrites: Lunar and Planet Science Conference XXIII, p. 729-730.

Krot, A.N., and Rubin, A.E., (1993), Chromite-Rich Mafic Silicate Chondrules in Ordinary Chondrites: Formation by Impact Melting: Lunar and Planetary Science Conference XXIV, p. 827-828.

Prior, D.J., Mariani, E. and Wheeler, J., (2009), EBSD in the earth sciences: applications, common practice, and challenges: Electron backscatter diffraction in materials science, p. 345-36). Springer, Boston, MA.

Ramdohr, P., (1967), Chromite and chromite chondrules in meteorites-I: v. 31, p. 19611967.

Ramdohr, P. (1973), The Opaque Minerals in Stony Meteorites: Elsevier Publishing Co, Amsterdam, p. 245. 
Rubin, A.E., (2003), Chromite-plagioclase assemblages as a new shock indicator; Implications for the shock and thermal histories of ordinary chondrites: Geochimica et Cosmochimica Acta, v. 67, p. 2695-2709, doi:10.1016/S0016-7037(03)00107-8.

Rubin, A.E., (2004), Postshock annealing and postannealing shock in equilibrated ordinary chondrites: Implications for the thermal and shock histories of chondritic asteroids: Geochimica et Cosmochimica Acta, v. 68, p. 673-689, doi:10.1016/S0016-7037(00)00452-6.

Rubin, A.E., and Jones R.H. (2003), Spade: An H-chondrite impact-melt breccia that experienced post-shock annealing: Meteoritics \& Planetary Sciences, v. 38, p. 15071520.

Ruzicka, A.M., and Hugo, R.C., (2018), Electron backscatter diffraction (EBSD) study of seven heavily metamorphosed chondrites: Deformation systematics and variations in pre-shock temperature and post-shock annealing: Geochimica et Cosmochimica Acta, v. 234, p. 115-147, doi:10.1016/j.gca.2018.05.014.

Stöffler, D., Keil, K., and Edward R.D, S., (1991), Shock metamorphism of ordinary chondrites: Geochimica et Cosmochimica Acta, v. 55, p. 3845-3867, doi:10.1016/0016-7037(91)90078-J.

Stöffler D., Hamann C., and Metzler K., (2018), Shock metamorphism of planetary silicate rocks and sediments: Proposal for an updated classification system. Meteoritics \& Planetary Science 53: p. 5-49.

Stöffler D., Hamann C., and Metzler K., (2019), Addendum to "Stöffler, D., Hamann, C., and Metzler, K., Shock metamorphism of planetary silicate rocks and sediments: Proposal for an updated classification system": Meteoritics \& Planetary Science 53, 5-49, 2018. Meteoritics \& Planetary Science 54: p. 946-949. 


\section{Appendix A: Optical Microscopy}

Table A-1: All thin section samples investigated for this study. Those with an * were chosen for further analysis, with bolded samples being the four chosen for this study.

\begin{tabular}{|c|c|c|c|c|}
\hline CML \# & Meteorite Name & Classification & $\begin{array}{c}\text { Conventional } \\
\text { Shock Stage }\end{array}$ & $\begin{array}{c}\text { FCA Present? } \\
\text { Y/N }\end{array}$ \\
\hline $0018-2 *$ & -- & unclassified & -- & $\mathrm{Y}$ \\
\hline 158 & -- & unclassified & -- & $\mathrm{Y}$ \\
\hline 0269-1A* & Spade & H6 & S4 & $\mathbf{Y}$ \\
\hline 0295-3C* & Estacado & H6 & S1 & $\mathbf{Y}$ \\
\hline 0414* & Jungo 001 & & S1 & $\mathrm{Y}$ \\
\hline 0417 & NWA 5962 & & -- & $\mathrm{Y}$ \\
\hline 0496-1A* & Alfianello & L6 & S5 & $\mathbf{Y}$ \\
\hline 0594-4A* & -- & unclassified & -- & $\mathrm{Y}$ \\
\hline 0646-1-1* & Tamdakht & H5 & S3 & $\mathrm{Y}$ \\
\hline 0649* & Jungo 004 & & S3 & $\mathrm{Y}$ \\
\hline 788 & Yucca 050 & H3-6 & S3 & $\mathrm{Y}$ \\
\hline 789 & -- & unclassified & -- & $\mathrm{N}$ \\
\hline 800 & NWA 8645 & L5 & S4 & $\mathrm{Y}$ \\
\hline 802 & -- & unclassified & -- & $\mathrm{Y}$ \\
\hline $803-3 A^{*}$ & -- & unclassified & -- & $\bar{Y}$ \\
\hline 804 & NWA 11229 & L6 & S4 & $\mathrm{Y}$ \\
\hline 805 & NWA 10312 & H5 & S3 & $\mathrm{N}$ \\
\hline 806 & Trapeang Ronoas & $\mathrm{H} 4$ & S1 & $\mathrm{N}$ \\
\hline 811 & -- & unclassified & -- & $\mathrm{N}$ \\
\hline 812 & NWA 11913 & H5 & $\mathrm{S} 2$ & $\mathrm{~N}$ \\
\hline 813 & NWA 11914 & H5 & $\mathrm{S} 2$ & $\mathrm{~N}$ \\
\hline 815 & NWA 10458 & L5 & S3 & $\mathrm{N}$ \\
\hline 817 & NWA 11915 & LL4-6 & $\mathrm{S} 2$ & $\mathrm{~N}$ \\
\hline 823 & - & unclassified & -- & $\mathrm{N}$ \\
\hline 824 & -- & unclassified & -- & $\mathrm{Y}$ \\
\hline 825 & -- & unclassified & -- & $\mathrm{Y}$ \\
\hline 826 & -- & unclassified & -- & $\mathrm{N}$ \\
\hline 830 & -- & unclassified & -- & $\mathrm{N}$ \\
\hline 835 & Bison & LL6 & -- & $\mathrm{Y}$ \\
\hline 841 & -- & unclassified & -- & $\mathrm{N}$ \\
\hline 842 & -- & unclassified & -- & $\mathrm{Y}$ \\
\hline 843 & -- & unclassified & -- & $\mathrm{Y}$ \\
\hline 844 & -- & unclassified & -- & $\mathrm{N}$ \\
\hline 845 & -- & unclassified & -- & $\mathrm{Y}$ \\
\hline 846 & NWA 10313 & L6 & S4 & $\mathrm{Y}$ \\
\hline 847 & Yucca 043 & H3-6 & S4 & $\mathrm{N}$ \\
\hline
\end{tabular}




\begin{tabular}{|c|c|c|c|c|}
\hline 848 & NWA 11230 & L6 & $\mathrm{S} 4$ & $\mathrm{Y}$ \\
\hline 853 & NWA 10816 & LL5 & S3 & $\mathrm{N}$ \\
\hline 854 & NWA 10828 & $\mathrm{H} 4$ & -- & $\mathrm{Y}$ \\
\hline 864 & -- & unclassified & -- & $\mathrm{N}$ \\
\hline 866 & -- & unclassified & -- & $\mathrm{Y}$ \\
\hline 867 & -- & unclassified & -- & $\mathrm{Y}$ \\
\hline 869 & -- & unclassified & -- & $\mathrm{Y}$ \\
\hline 870 & -- & unclassified & -- & $\mathrm{Y}$ \\
\hline 871 & -- & unclassified & -- & $\mathrm{Y}$ \\
\hline 872 & -- & unclassified & -- & $\mathrm{Y}$ \\
\hline 873 & -- & unclassified & -- & $\mathrm{Y}$ \\
\hline 891 & -- & unclassified & -- & $\mathrm{Y}$ \\
\hline 896 & -- & unclassified & -- & $\mathrm{Y}$ \\
\hline 897 & -- & unclassified & -- & $\mathrm{Y}$ \\
\hline 900 & -- & unclassified & -- & $\mathrm{Y}$ \\
\hline 901 & -- & unclassified & -- & $\mathrm{Y}$ \\
\hline 902 & -- & unclassified & -- & $\mathrm{Y}$ \\
\hline 912 & -- & unclassified & -- & $\mathrm{N}$ \\
\hline 921 & -- & unclassified & -- & $\mathrm{Y}$ \\
\hline 939 & -- & unclassified & -- & $\mathrm{N}$ \\
\hline 940 & NWA 12431 & LL3 & -- & $\mathrm{N}$ \\
\hline 941 & NWA 12432 & H5 & -- & $\mathrm{Y}$ \\
\hline 942 & -- & unclassified & -- & $\mathrm{Y}$ \\
\hline 944 & -- & unclassified & -- & $\mathrm{Y}$ \\
\hline 945 & -- & unclassified & -- & $\mathrm{Y}$ \\
\hline 946 & -- & unclassified & -- & $\mathrm{Y}$ \\
\hline 947 & -- & unclassified & -- & $\mathrm{Y}$ \\
\hline 953 & NWA 5421 & LL3.7 & -- & $\mathrm{Y}$ \\
\hline 956 & -- & unclassified & -- & $\mathrm{N}$ \\
\hline 967 & -- & unclassified & -- & $\mathrm{Y}$ \\
\hline 974 & -- & unclassified & -- & $\mathrm{Y}$ \\
\hline 978 & NWA 11905 & LL3 & S3 & $\mathrm{Y}$ \\
\hline 983 & NWA 11291 & LL3 & -- & $\mathrm{Y}$ \\
\hline 984 & NWA 10220 & LL3 & $\mathrm{S} 1$ & $\mathrm{Y}$ \\
\hline 985 & NWA 8575 & L/LL3 & $\mathrm{S} 1$ & $\mathrm{Y}$ \\
\hline 995-1* & NWA 13533 & L6 & S4 & $\mathbf{Y}$ \\
\hline 997 & Bluff (a) & L5 & $\mathrm{S} 4$ & $\mathrm{Y}$ \\
\hline 1001 & NWA 12434 & L3 & $\mathrm{S} 4$ & $\mathrm{Y}$ \\
\hline 1004 & NWA 12380 & L3 & $\mathrm{S} 2$ & $\mathrm{~N}$ \\
\hline 1014 & Bovedy & L3 & -- & $\mathrm{Y}$ \\
\hline $1016-1^{*}$ & Ber-Gheluai & $\mathrm{H} 5$ & -- & $\mathrm{Y}$ \\
\hline 1019-1* & Dalgety Downs & L4 & -- & $\mathrm{Y}$ \\
\hline
\end{tabular}




\begin{tabular}{|l|c|c|c|c|}
\cline { 3 - 4 } 1070 & Selma & H4 & -- & $\mathrm{N}$ \\
\hline 1071 & Broken Hill & L6 & -- & $\mathrm{N}$ \\
\hline 1117 & -- & unclassified & -- & $\mathrm{Y}$ \\
\hline 1118 & -- & unclassified & -- & $\mathrm{N}$ \\
\hline 1119 & -- & unclassified & -- & $\mathrm{Y}$ \\
\hline
\end{tabular}




\section{Appendix B: EDS-EBSD}

Below are false color maps of each targeted map (TM). Each image is a composite map with different colors attached to different elements (obtained by EDS, color bar shown below), and a band contrast EBSD image shown in monochrome. In these maps, feldspathic material shows as dark purple, chromite as pink, olivine as bright green, lowCa pyroxene as dark green to tan, high-Ca pyroxene as brown-red, low-Ni metal as light blue, high-Ni metal as dark blue, troilite as yellow-green, phosphate as orange, and holes as black.
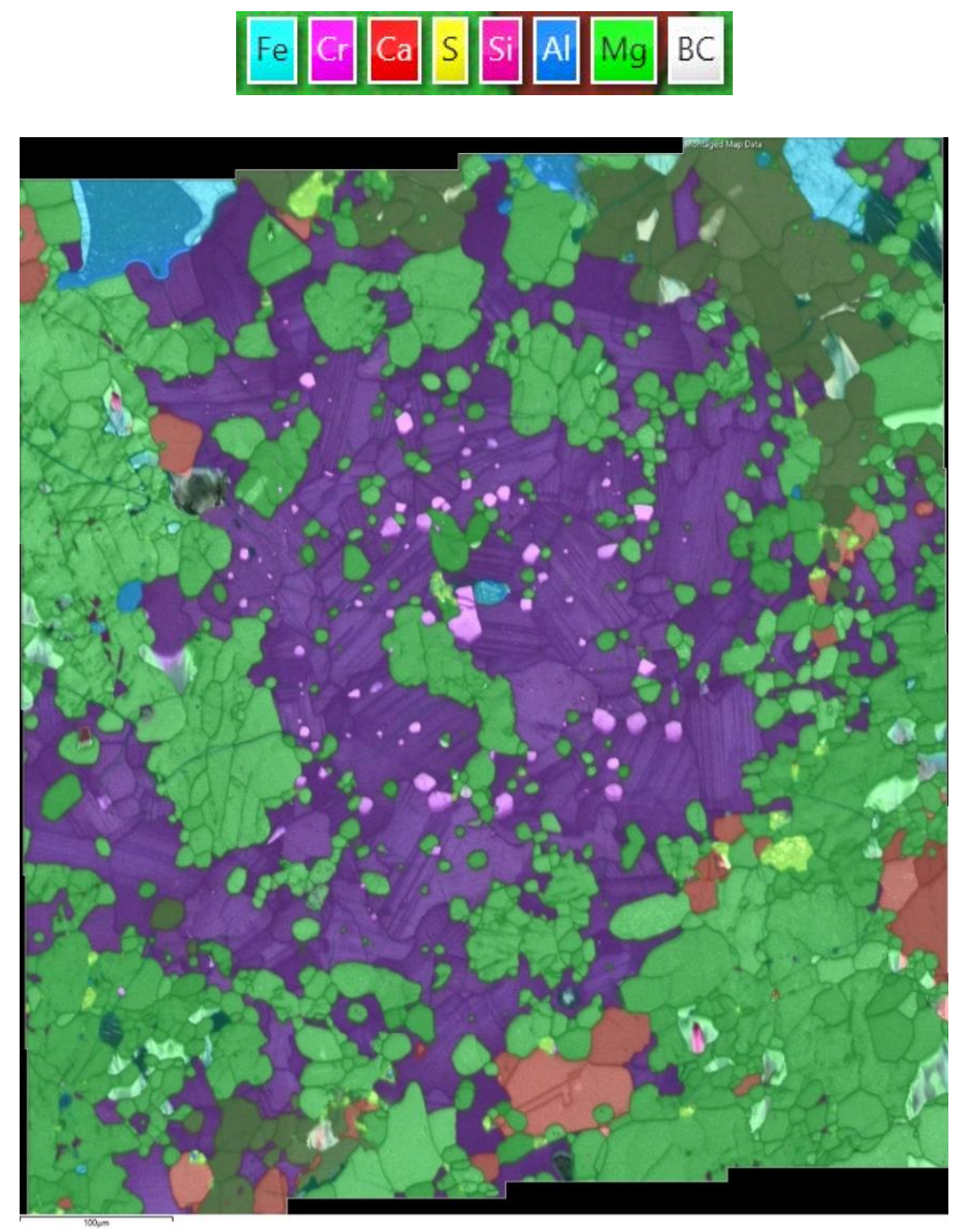

Spade TM1 


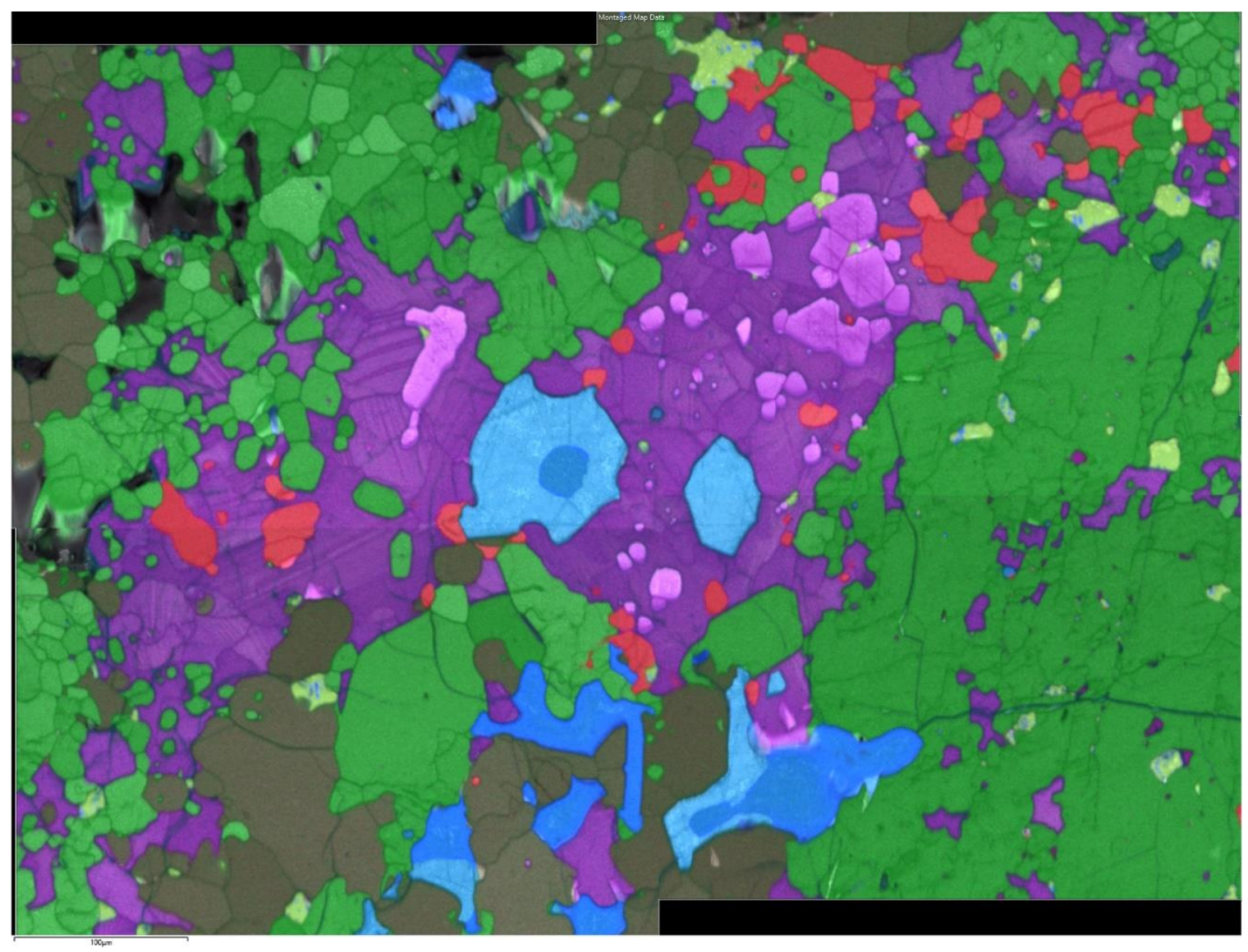

Spade TM2 


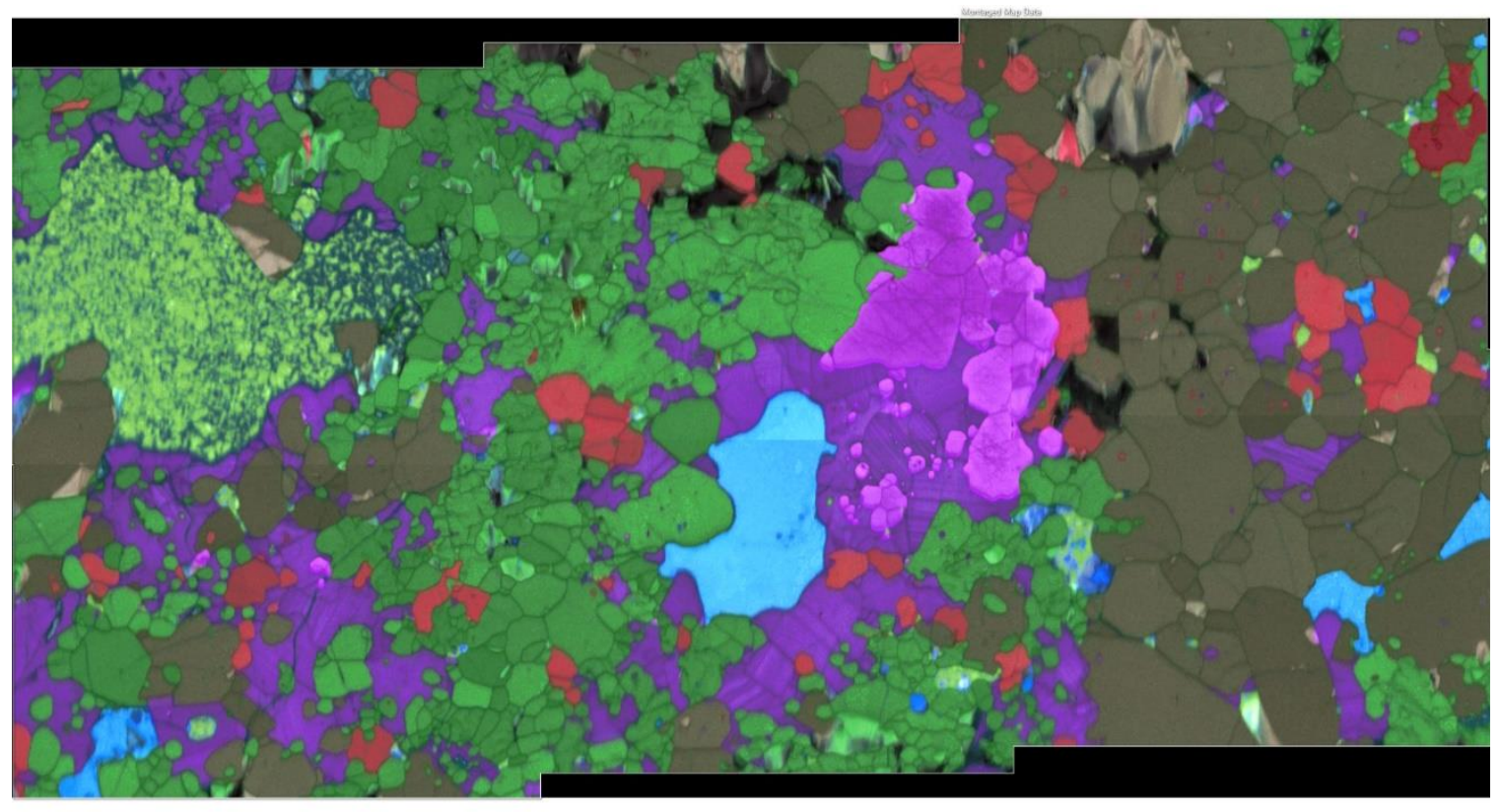

Spade TM3 


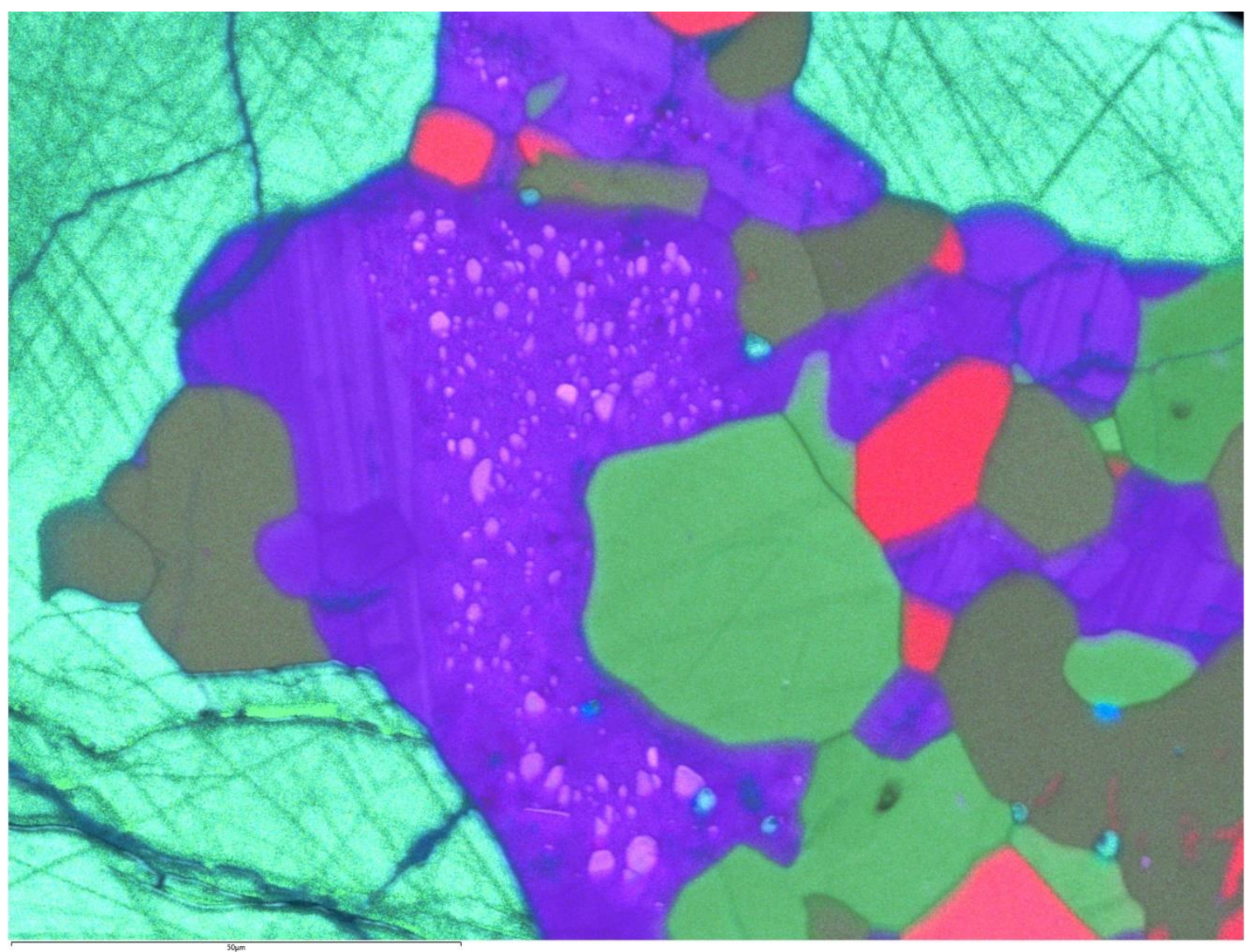

Estacado TM1 


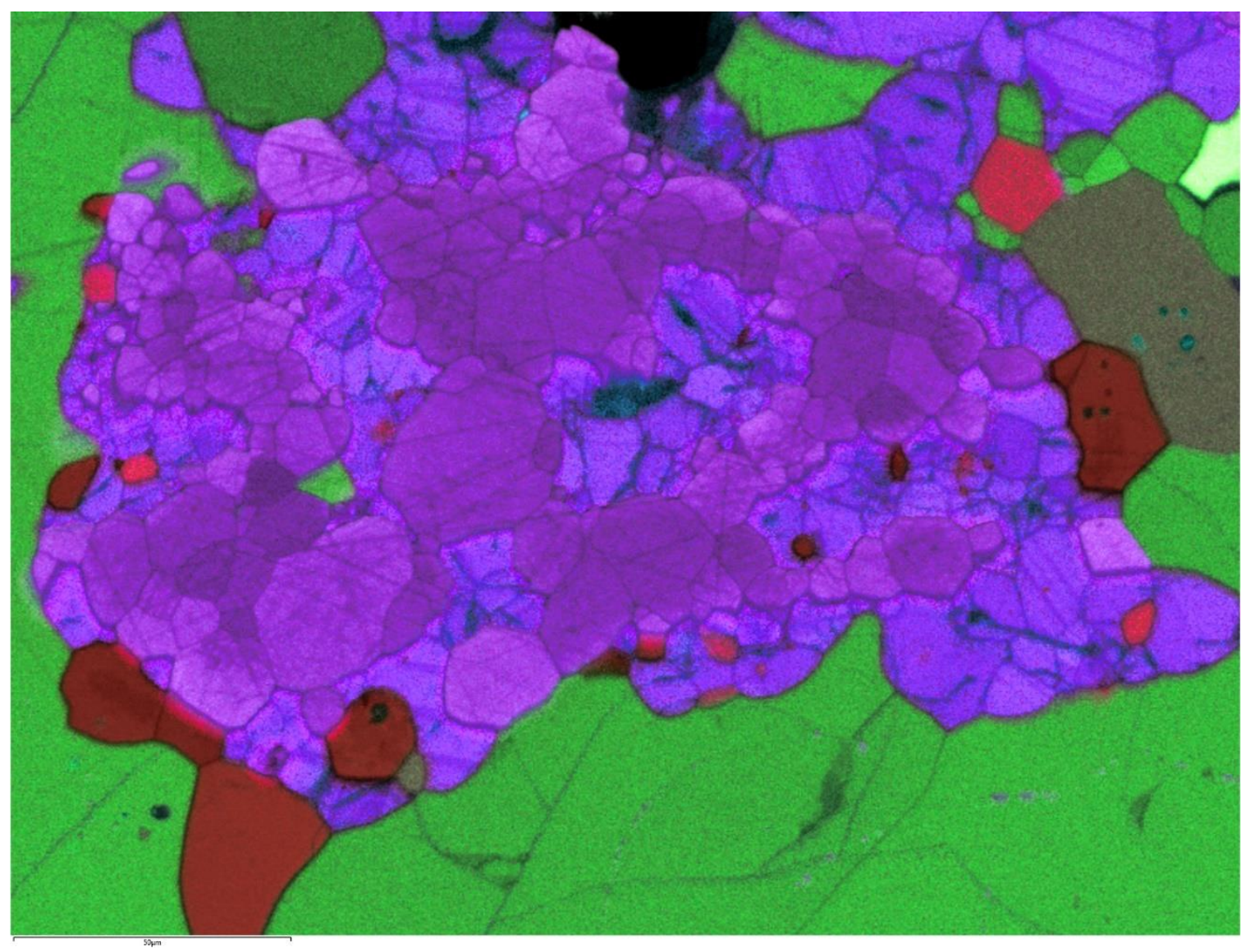

Estacado TM2 


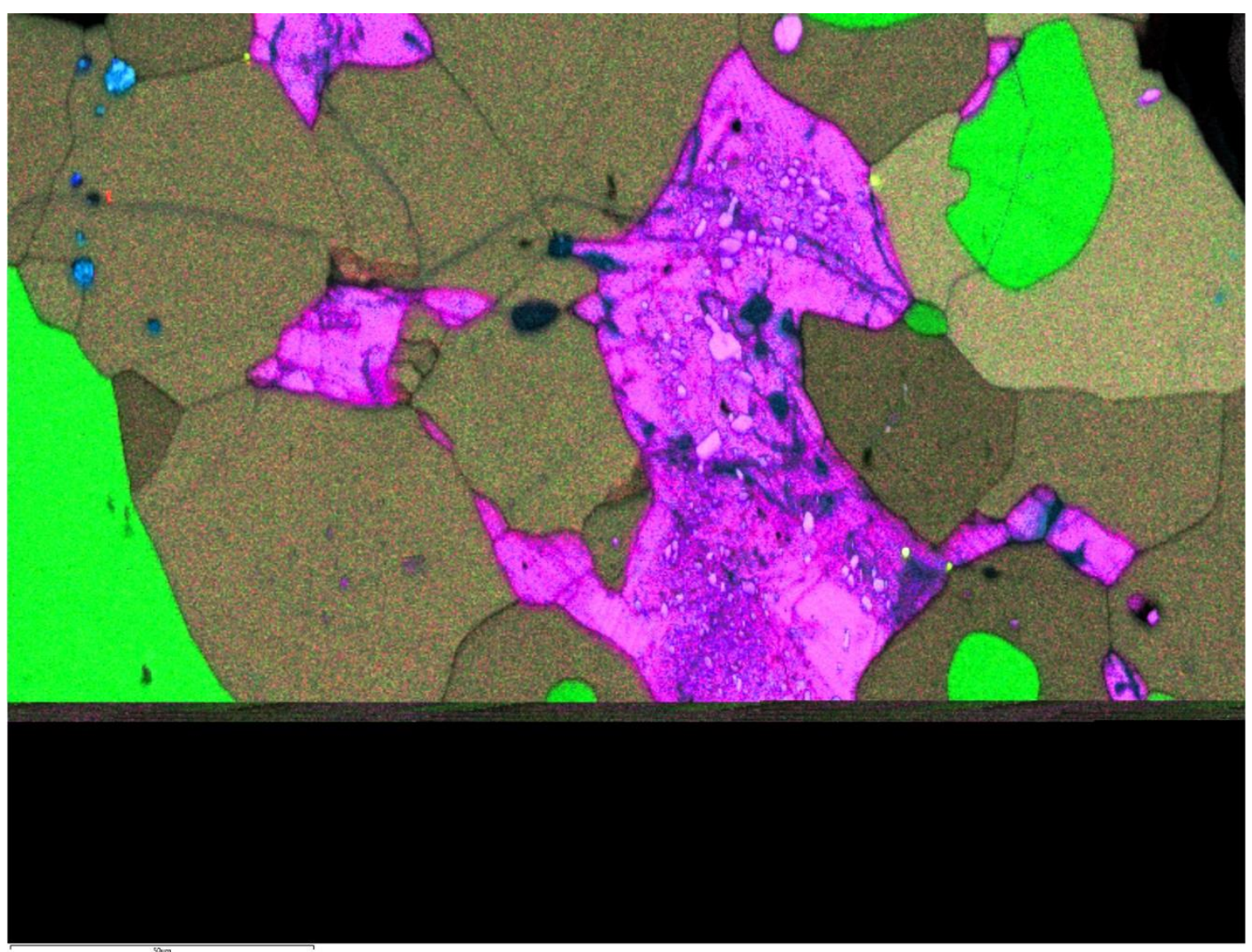

Estacado TM3 


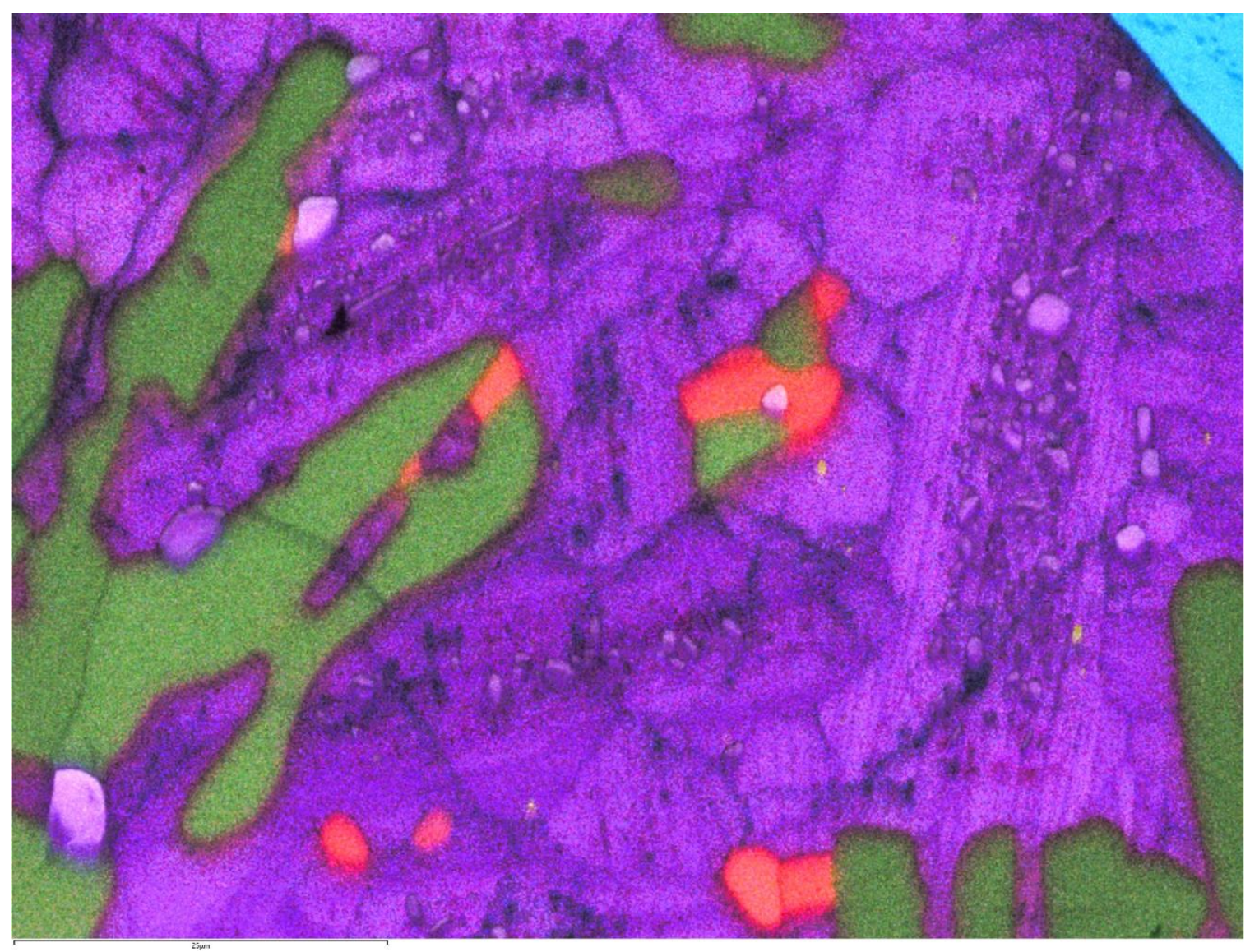

Estacado TM4 


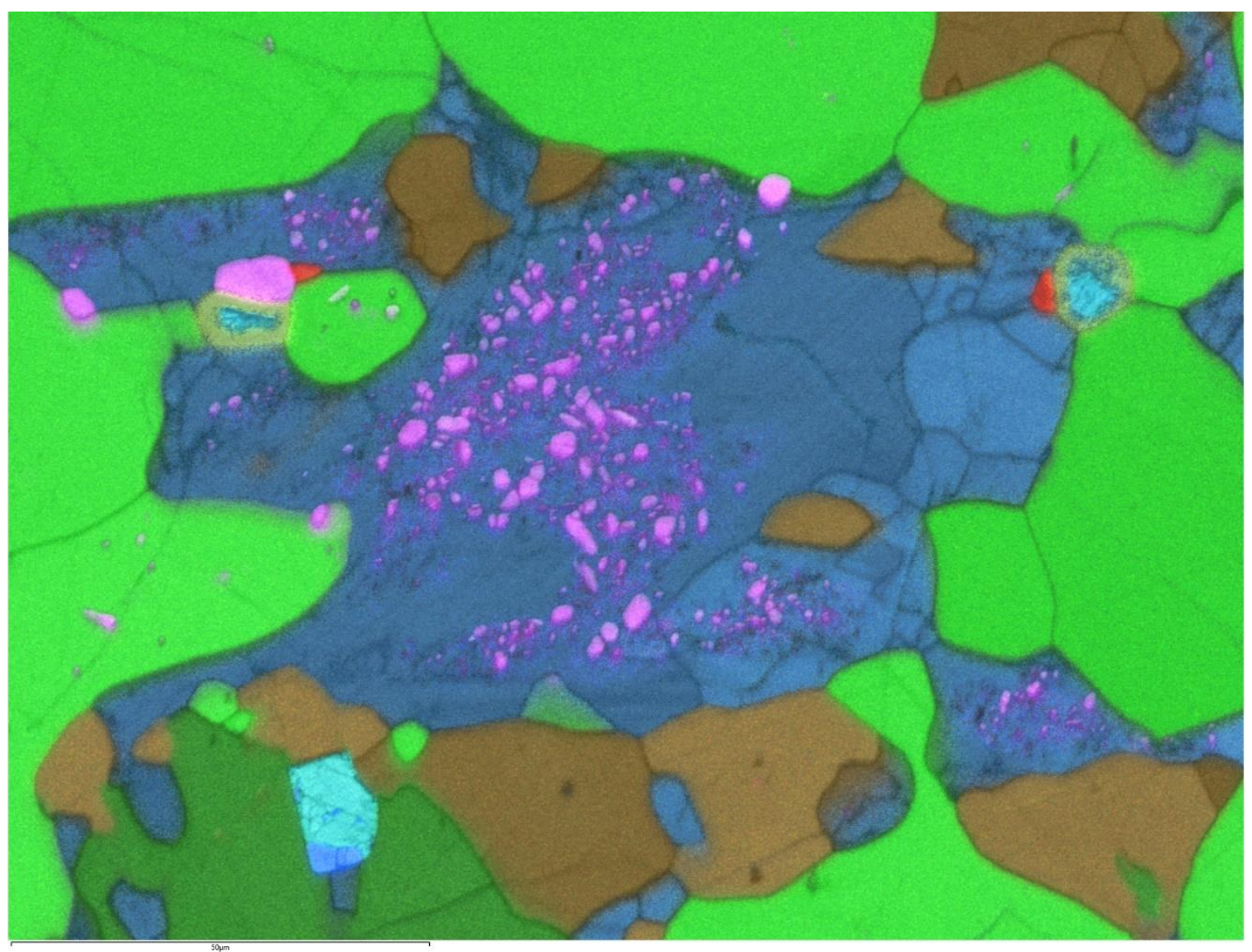

Estacado TM 5 


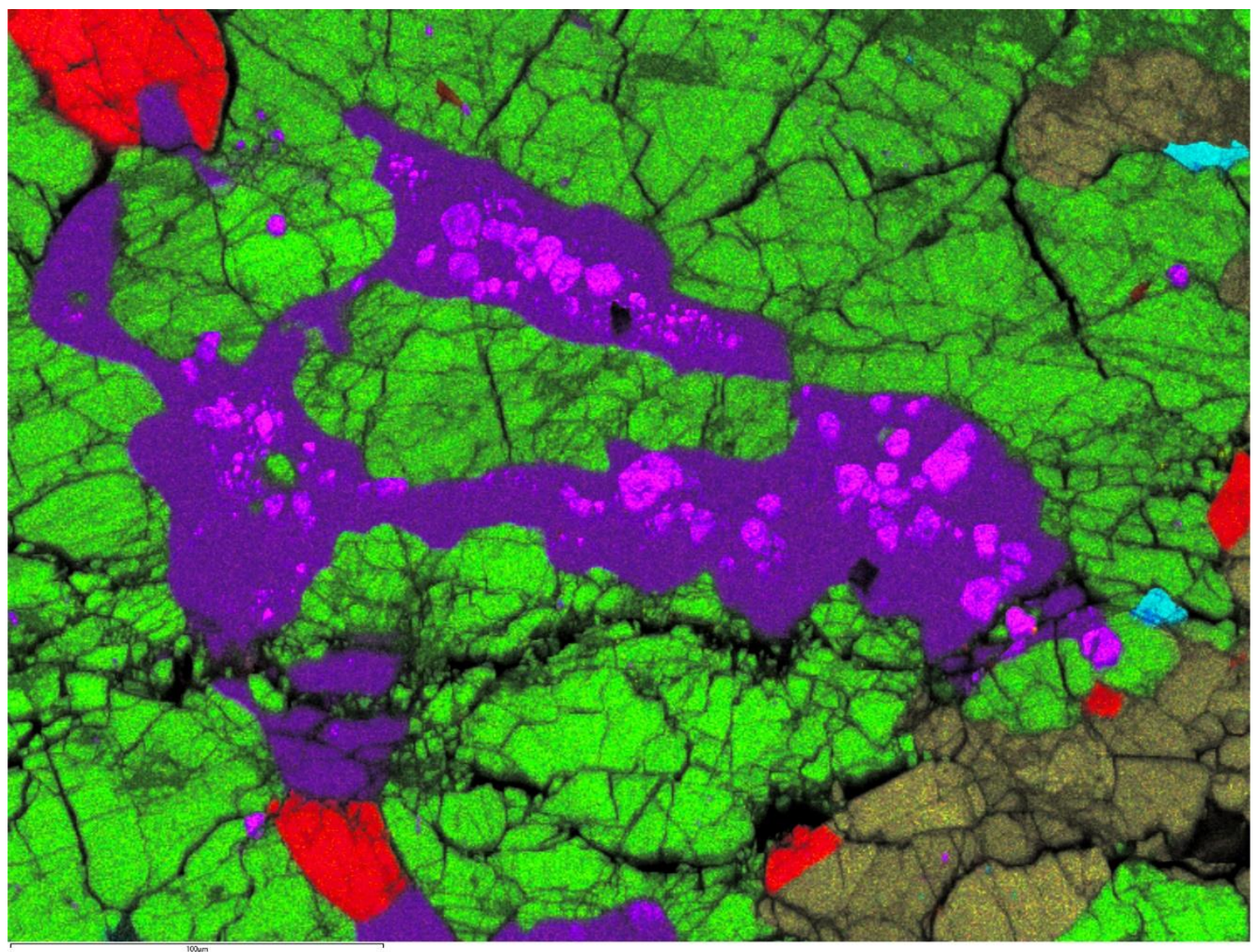

Alfianello TM1 


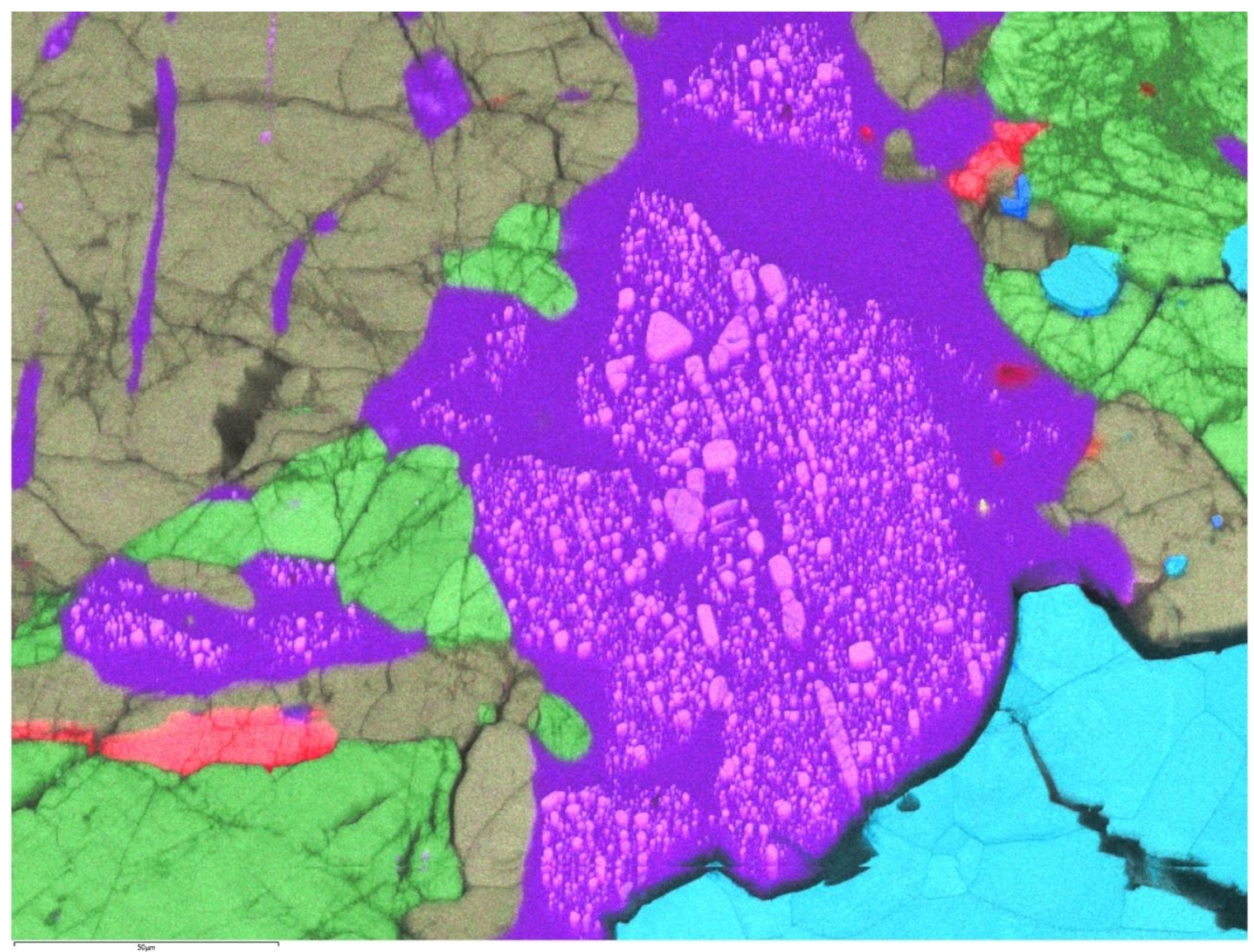

Alfianello TM2 


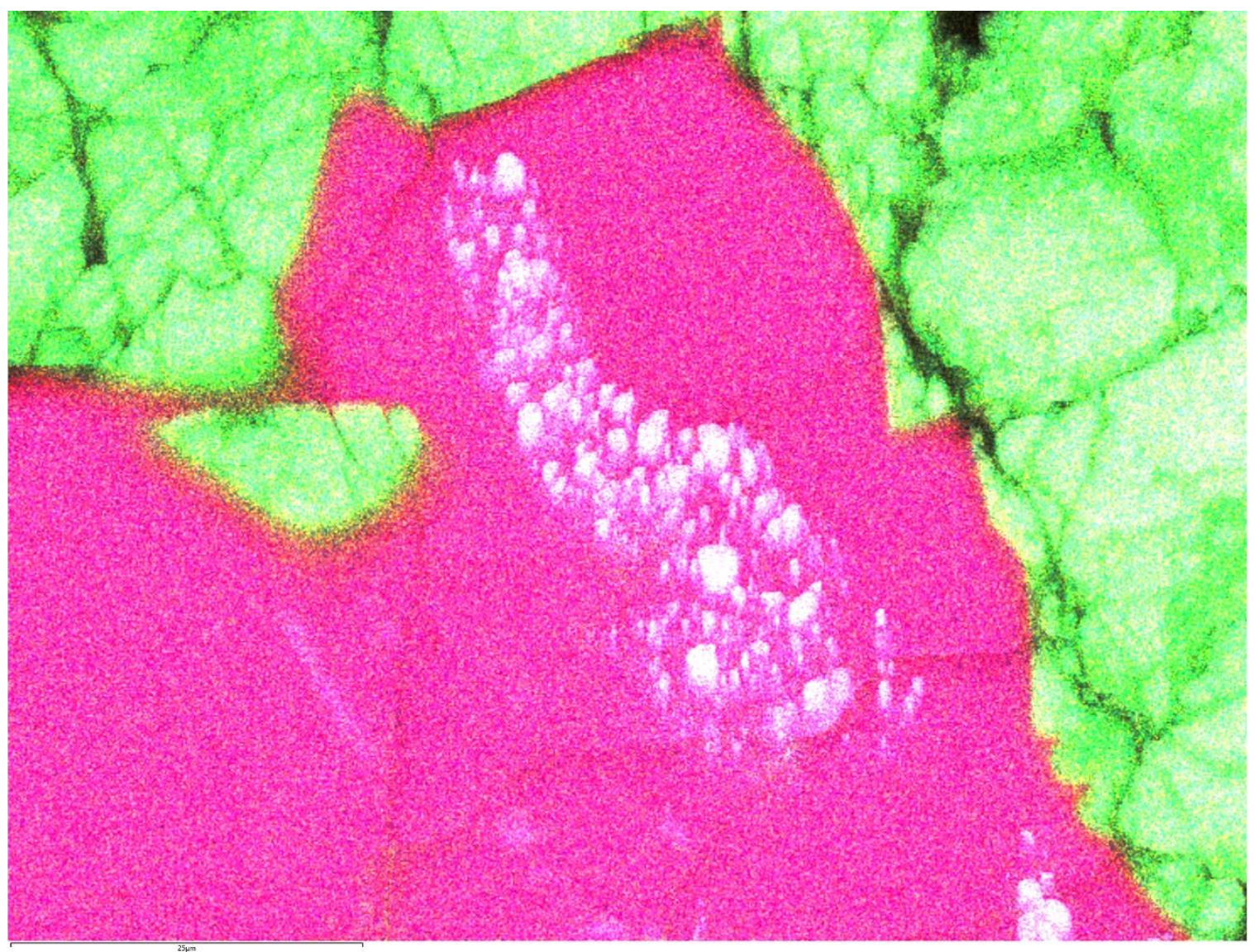

Alfianello TM3 


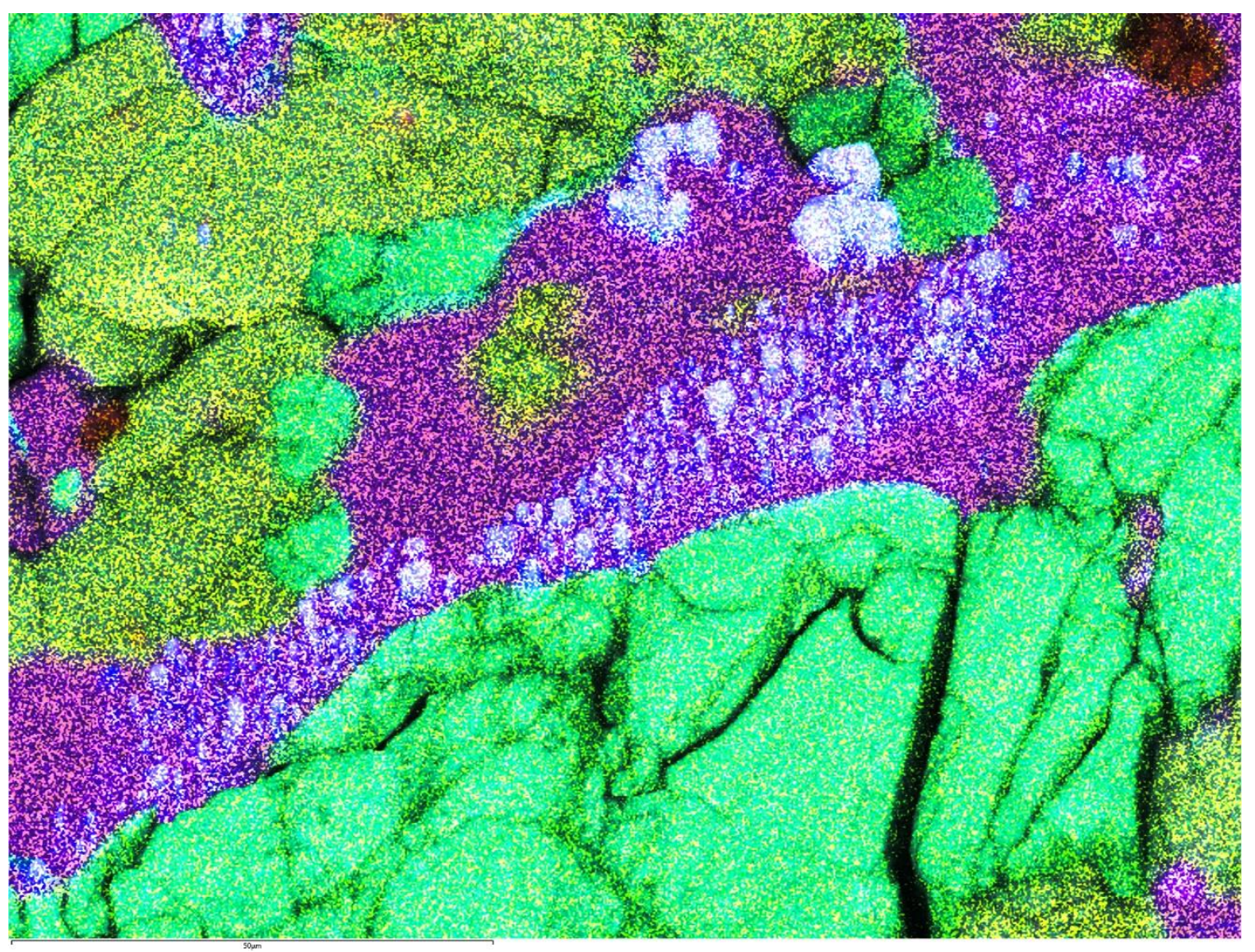

Alfianello TM4 




Alfianello TM5 


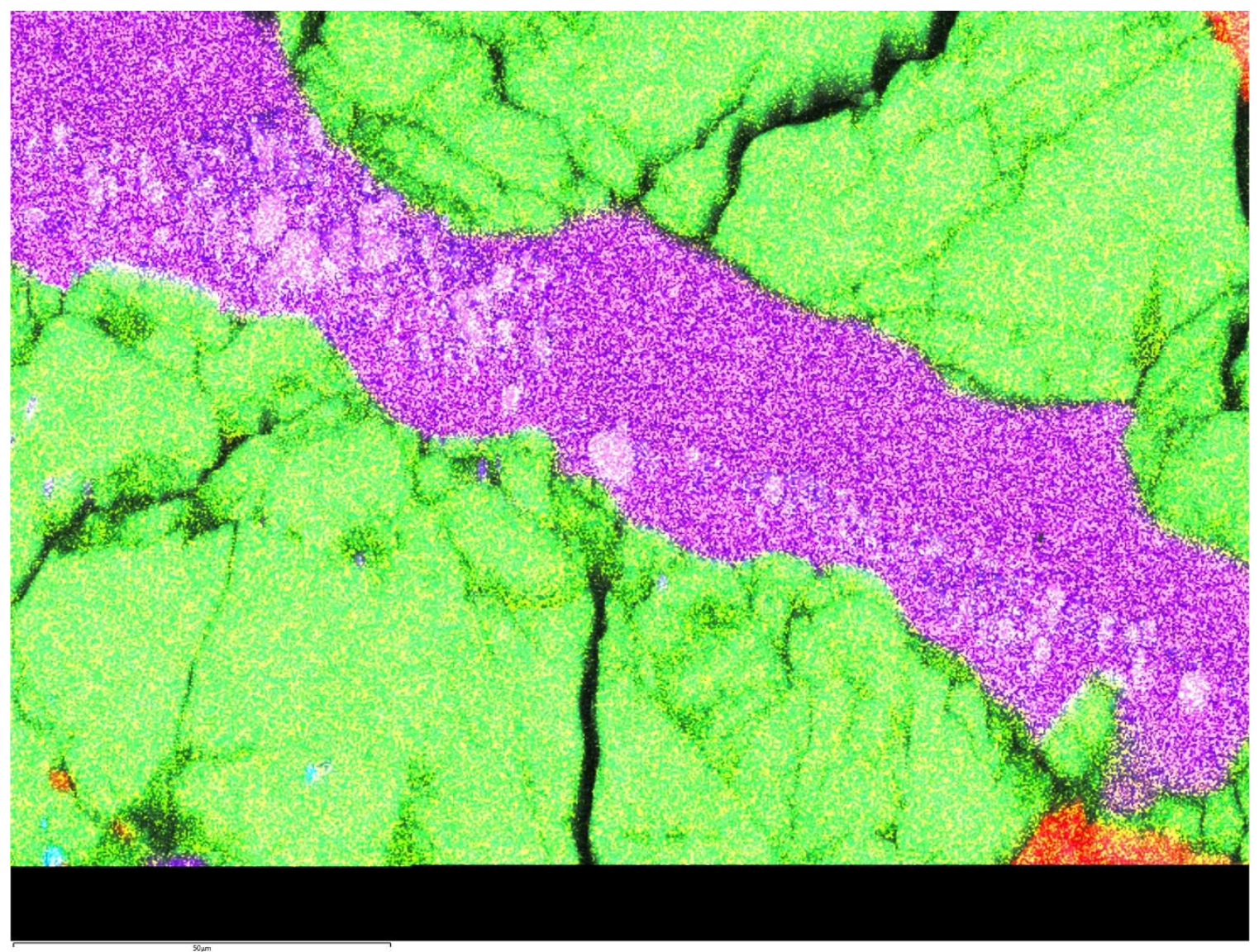

Alfianello TM6 


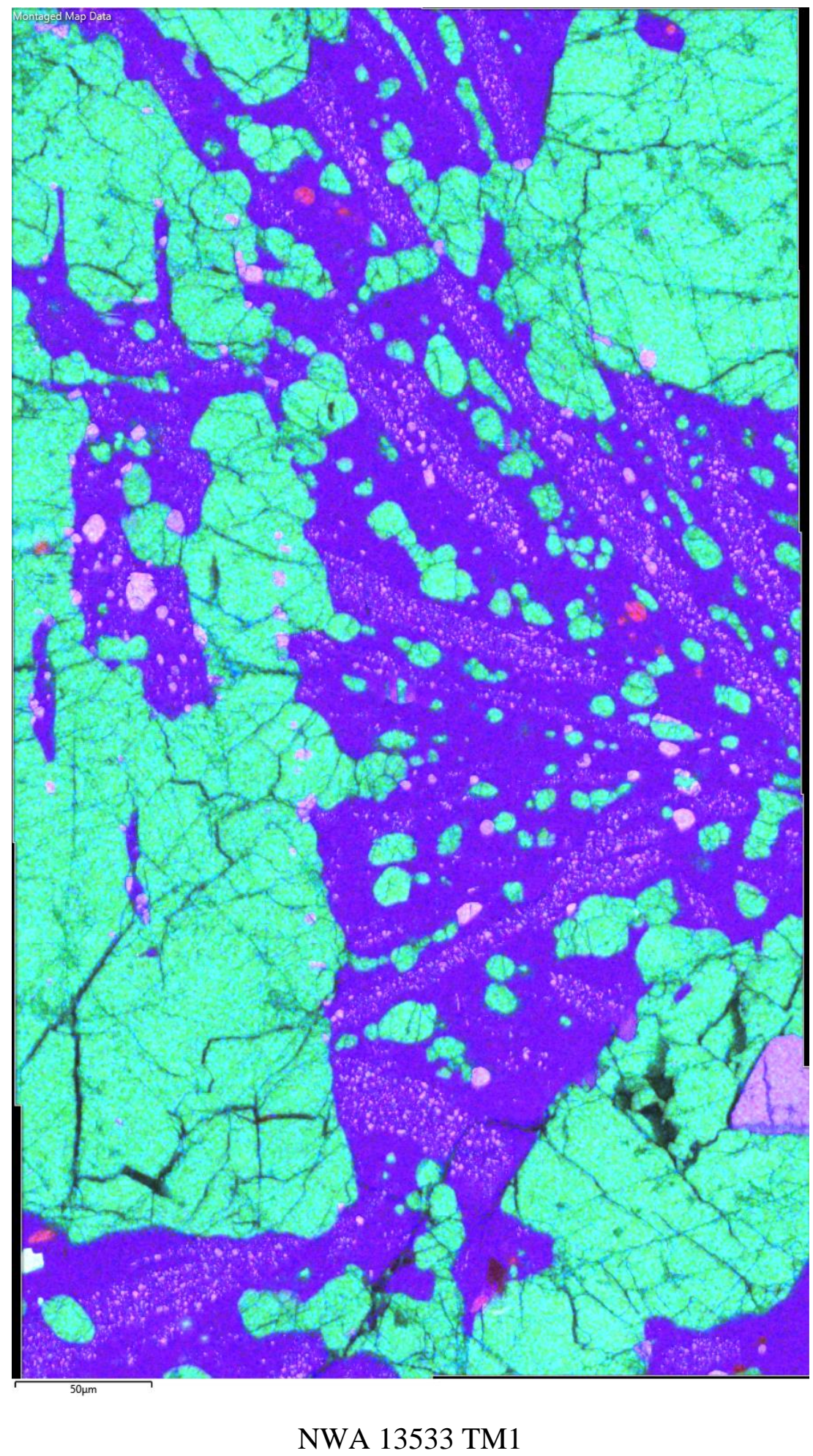




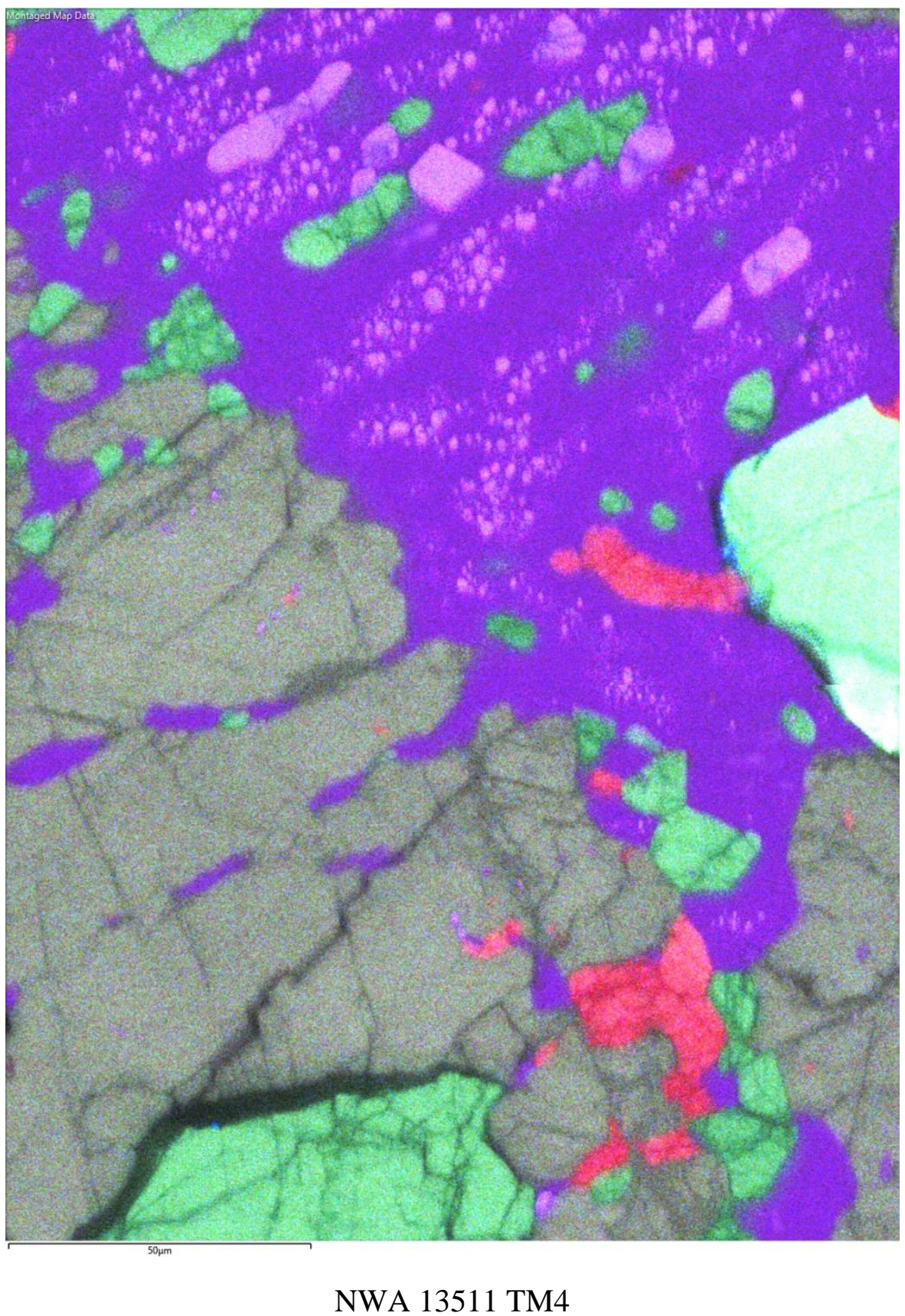




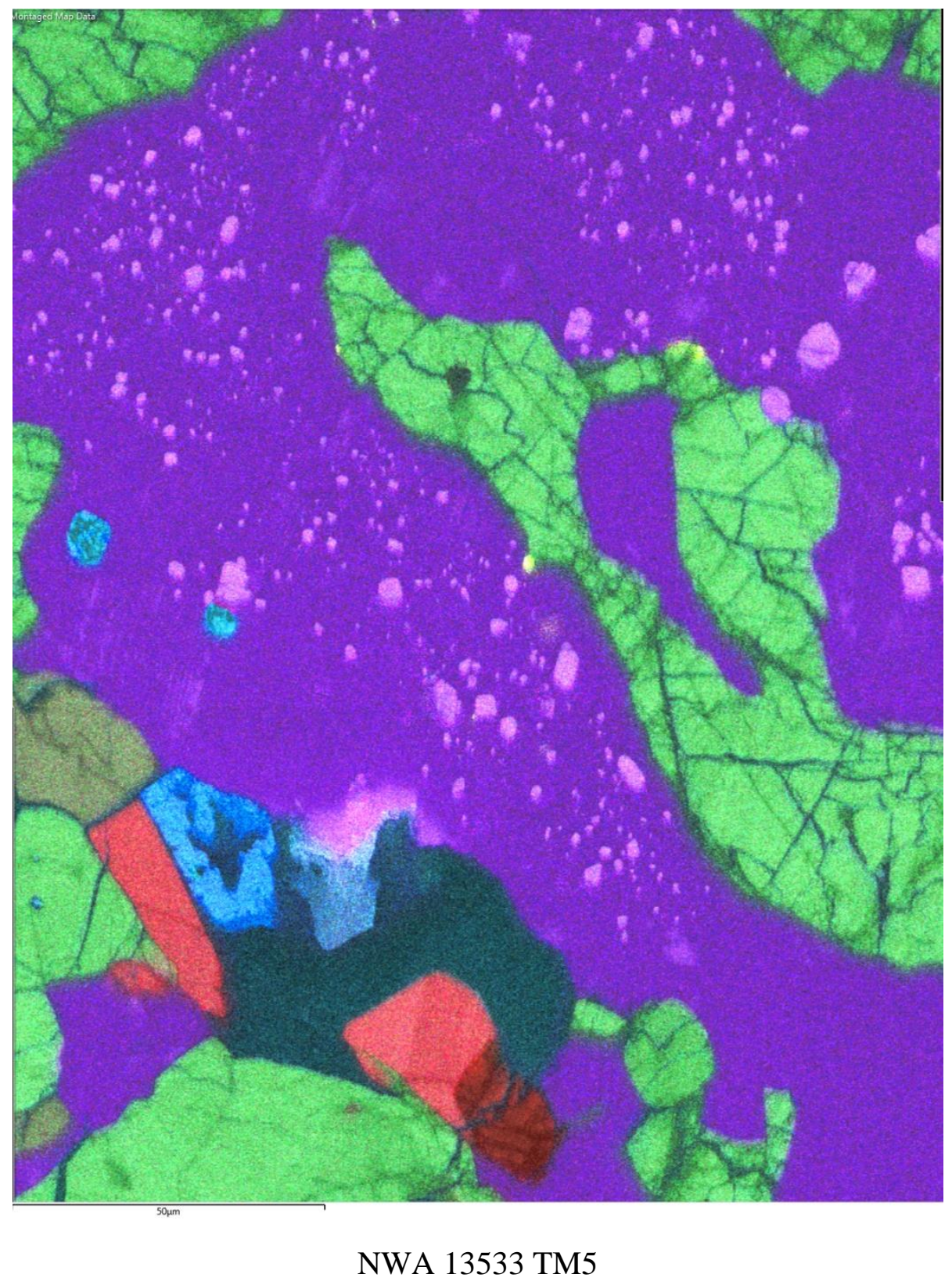




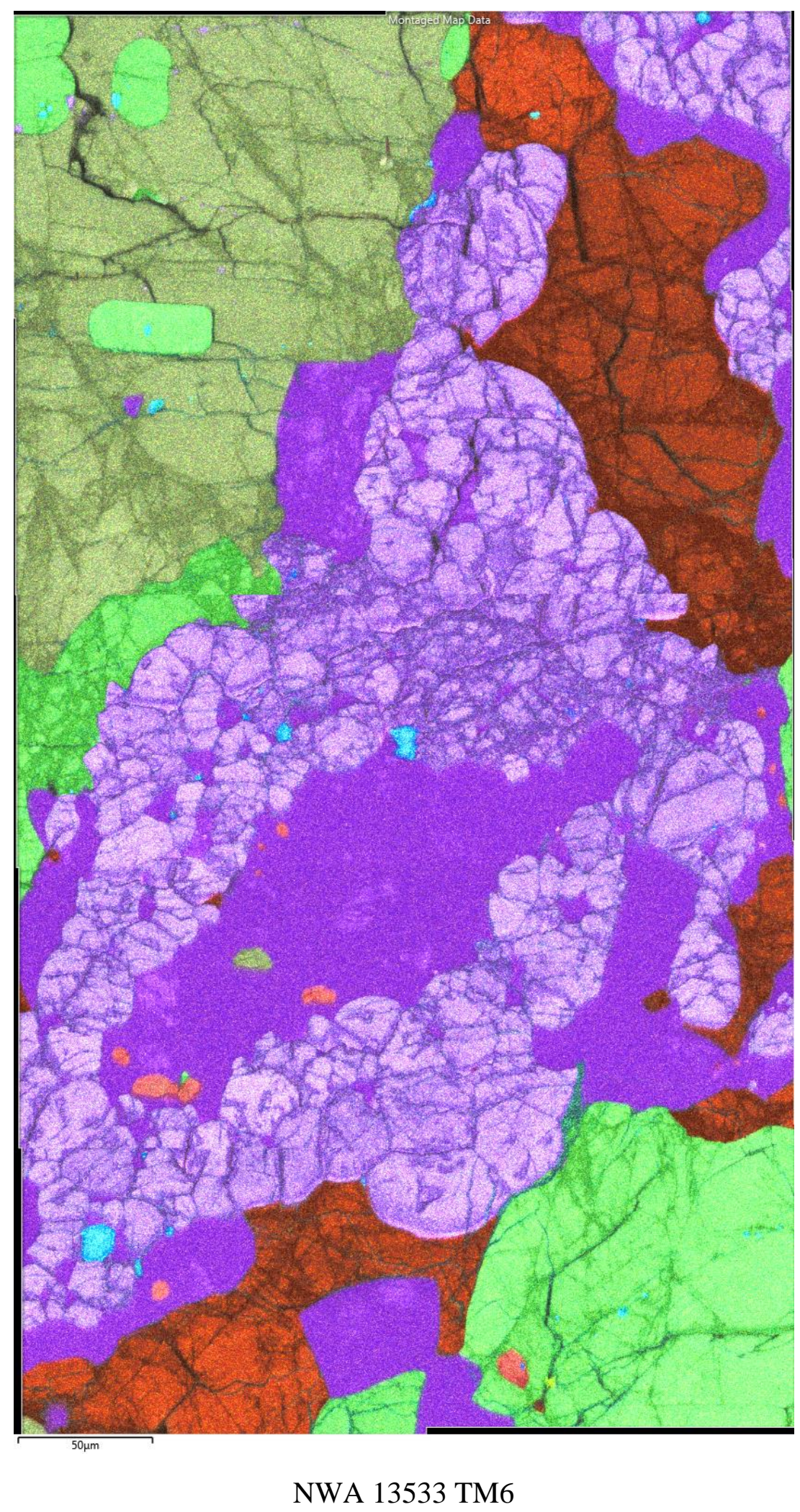


Appendix C: Subsets and other data

SPADE (0269-1A)

\begin{tabular}{|c|c|c|c|c|c|c|c|c|}
\hline \multirow{2}{*}{ TM1 } & \multicolumn{2}{|c|}{$\begin{array}{l}\text { Density of } \\
\text { Chromite }\end{array}$} & \multicolumn{2}{|c|}{ Area of subset } & \multicolumn{2}{|c|}{ Grain Data } & \multirow[b]{2}{*}{$\begin{array}{c}\text { Area } \\
\text { Fraction } \\
\text { of chr }\end{array}$} & \multirow[b]{2}{*}{$\begin{array}{c}\text { LPO \# } \\
\Delta<100>\end{array}$} \\
\hline & $\mu \mathrm{m}^{2}$ & $\mathbf{m m}^{2}$ & $\mu \mathrm{m}^{2}$ & $\mathbf{m m}^{2}$ & Average & $\begin{array}{c}\text { Std } \\
\text { Deviation }\end{array}$ & & \\
\hline $\begin{array}{l}\text { Subset } 1 \\
\text { (All) }\end{array}$ & 0.002 & 1616.2 & 67448.1 & 0.067 & 5.42 & 3.67 & 0.054 & 1.67 \\
\hline
\end{tabular}

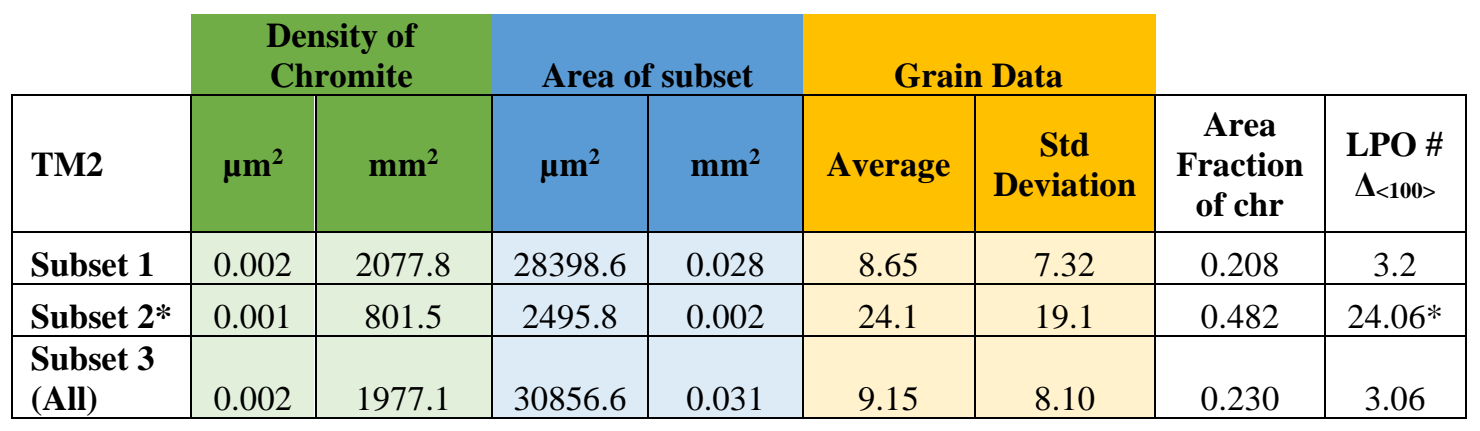

\begin{tabular}{|l|c|c|c|c|c|c|c|c|}
\multicolumn{9}{c}{$\begin{array}{c}\text { Density of } \\
\text { Chromite }\end{array}$} \\
\hline TM3 & $\boldsymbol{\mu m}^{2}$ & $\mathbf{m m}^{2}$ & $\boldsymbol{\mu \mathbf { m } ^ { 2 }}$ & $\mathbf{m m}^{\mathbf{2}}$ & Average & $\begin{array}{c}\text { Std } \\
\text { Deviation }\end{array}$ & $\begin{array}{c}\text { Area } \\
\text { Fraction } \\
\text { of chr }\end{array}$ & $\begin{array}{c}\text { LPO \# } \\
\boldsymbol{\Delta}<\mathbf{1 0 0 >}\end{array}$ \\
\hline $\begin{array}{l}\text { Subset 1 } \\
\text { (All) }\end{array}$ & 0.004 & 3989.3 & 30080.5 & 0.0301 & 7.32 & 9.47 & 0.446 & 10.92 \\
\hline
\end{tabular}

ESTACADO (0295-3C)

\begin{tabular}{|c|c|c|c|c|c|c|c|c|}
\hline & & $\begin{array}{l}\text { sity of } \\
\text { omite }\end{array}$ & Area & subset & Gra & Data & & \\
\hline TM1 & $\mu \mathbf{m}^{2}$ & $\mathbf{m m}^{2}$ & $\mu \mathbf{m}^{2}$ & $\mathrm{~mm}^{2}$ & Average & $\begin{array}{c}\text { Std } \\
\text { Deviation }\end{array}$ & $\begin{array}{c}\text { Area } \\
\text { Fraction } \\
\text { of chr }\end{array}$ & $\begin{array}{c}\text { LPO \# } \\
\Delta<100>\end{array}$ \\
\hline Subset 1 & 0.19 & 188328.4 & 1263.7 & 0.001264 & 1.06 & 0.62 & 0.237 & 11.69 \\
\hline Subset 2 & 0.24 & 242190.9 & 185.8 & 0.000186 & 0.86 & 0.46 & 0.130 & 13.15 \\
\hline $\begin{array}{l}\text { Subset } \\
3 *\end{array}$ & 0.19 & 192284.9 & 46.8 & 0.000047 & 0.70 & 0.30 & 0.085 & 10.48 \\
\hline $\begin{array}{l}\text { Subset } \\
4 *\end{array}$ & 0.24 & 235014.9 & 34.0 & 0.000034 & 0.87 & 0.42 & 0.166 & 12.52 \\
\hline Subset 5 & 0.18 & 179899.9 & 1717.6 & 0.001718 & 1.06 & 0.66 & 0.218 & 10.43 \\
\hline $\begin{array}{l}\text { Subset } \\
6^{*}\end{array}$ & 0.16 & 162702.6 & 36.9 & 0.000037 & 0.83 & 0.28 & 0.096 & 11.23 \\
\hline $\begin{array}{l}\text { Subset } 7 \\
\text { (All) }\end{array}$ & 0.18 & 180892.4 & 1835.3 & 0.001835 & 1.04 & 0.64 & 0.212 & 9.74 \\
\hline
\end{tabular}




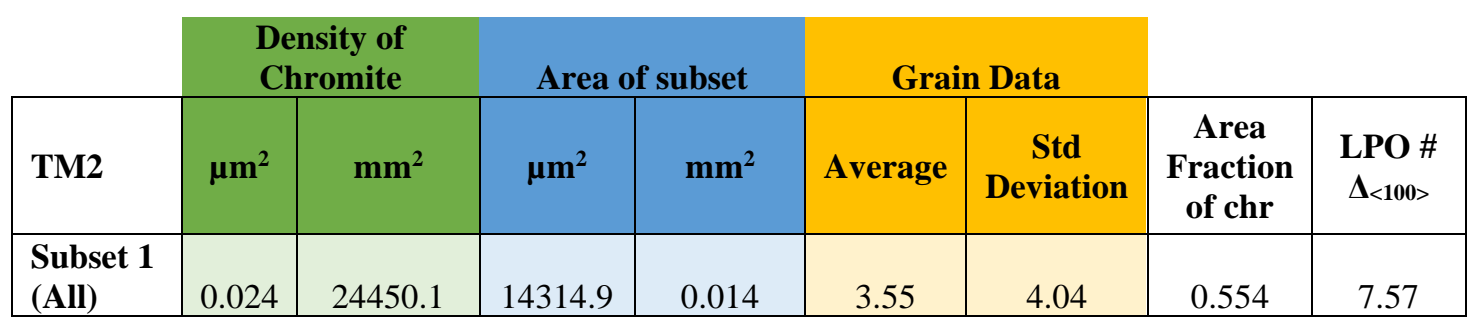

\begin{tabular}{|c|c|c|c|c|c|c|c|c|}
\hline \multirow{2}{*}{ TM3 } & \multicolumn{2}{|c|}{$\begin{array}{l}\text { Density of } \\
\text { Chromite }\end{array}$} & \multicolumn{2}{|c|}{ Area of subset } & \multicolumn{2}{|c|}{ Grain Data } & \multirow[b]{2}{*}{$\begin{array}{c}\text { Area } \\
\text { Fraction } \\
\text { of chr }\end{array}$} & \multirow[b]{2}{*}{$\begin{array}{c}\text { LPO \# } \\
\Delta<100>\end{array}$} \\
\hline & $\mu \mathbf{m}^{2}$ & $\mathbf{m m}^{2}$ & $\mu \mathbf{m}^{2}$ & $\mathbf{m m}^{2}$ & Average & $\begin{array}{c}\text { Std } \\
\text { Deviation }\end{array}$ & & \\
\hline $\begin{array}{l}\text { Subset } 1 \\
\text { (All) }\end{array}$ & 0.073 & 72754.7 & 2309.1 & 0.002 & 1.29 & 0.62 & 0.116 & 6.65 \\
\hline
\end{tabular}

\begin{tabular}{|c|c|c|c|c|c|c|c|c|}
\hline & & $\begin{array}{l}\text { ty of } \\
\text { mite }\end{array}$ & Area & subset & Gra & Data & & \\
\hline TM4 & $\mu \mathbf{m}^{2}$ & $\mathbf{m m}^{2}$ & $\mu \mathbf{m}^{2}$ & $\mathbf{m m}^{2}$ & Average & $\begin{array}{c}\text { Std } \\
\text { Deviation }\end{array}$ & $\begin{array}{c}\text { Area } \\
\text { Fraction } \\
\text { of chr }\end{array}$ & $\begin{array}{c}\text { LPO \# } \\
\Delta<100>\end{array}$ \\
\hline Subset 1 & 0.364 & 364371.3 & 279.9 & 0.00028 & 0.62 & 0.34 & 0.144 & 8.16 \\
\hline Subset 2 & 0.210 & 209859.4 & 81.0 & 0.00008 & 0.79 & 0.41 & 0.129 & 23.58 \\
\hline Subset 3 & 0.310 & 309885.9 & 109.7 & 0.00011 & 0.74 & 0.37 & 0.165 & 11.21 \\
\hline Subset 4 & 0.232 & 232197.4 & 86.1 & 0.00009 & 0.70 & 0.48 & 0.130 & 14.86 \\
\hline Subset 5 & 0.295 & 294611.7 & 465.0 & 0.00047 & 0.68 & 0.43 & 0.151 & 8.09 \\
\hline Subset 6 & 0.185 & 184630.8 & 211.2 & 0.00021 & 0.83 & 0.72 & 0.172 & 14.84 \\
\hline $\begin{array}{l}\text { Subset } \\
7 *\end{array}$ & 0.075 & 75017.6 & 26.7 & 0.00003 & 2.30 & 2.40 & 0.480 & 26.03 \\
\hline $\begin{array}{l}\text { Subset } 8 \\
\text { (All) }\end{array}$ & 0.003 & 2579.9 & 89918.8 & 0.08993 & 0.73 & 0.53 & 0.165 & 5.77 \\
\hline
\end{tabular}

\begin{tabular}{|c|c|c|c|c|c|c|c|c|}
\hline \multirow{2}{*}{ TM5 } & \multicolumn{2}{|c|}{$\begin{array}{l}\text { Density of } \\
\text { Chromite }\end{array}$} & \multicolumn{2}{|c|}{ Area of subset } & \multicolumn{2}{|c|}{ Grain Data } & \multirow[b]{2}{*}{$\begin{array}{c}\text { Area } \\
\text { Fraction } \\
\text { of chr }\end{array}$} & \multirow[b]{2}{*}{$\begin{array}{c}\text { LPO \# } \\
\Delta<100>\end{array}$} \\
\hline & $\mu \mathbf{m}^{2}$ & $\mathbf{m m}^{2}$ & $\mu \mathrm{m}^{2}$ & $\mathbf{m m}^{2}$ & Average & $\begin{array}{c}\text { Std } \\
\text { Deviation }\end{array}$ & & \\
\hline Subset 1 & 0.199 & 199343.3 & 85.3 & 0.00009 & 1.02 & 0.53 & 0.205 & 14.48 \\
\hline Subset 2 & 0.158 & 157905.0 & 1646.6 & 0.00165 & 1.10 & 0.70 & 0.210 & 13.54 \\
\hline Subset 3 & 0.214 & 213810.6 & 126.3 & 0.00013 & 0.89 & 0.44 & 0.163 & 9.67 \\
\hline Subset 4 & 0.149 & 148530.3 & 127.9 & 0.00013 & 0.60 & 0.24 & 0.040 & 12.29 \\
\hline Subset 5 & 0.143 & 142708.9 & 77.1 & 0.00008 & 0.83 & 0.92 & 0.162 & 11.54 \\
\hline Subset 6 & 0.226 & 225835.6 & 44.3 & 0.00004 & 0.85 & 0.41 & 0.158 & 15.76 \\
\hline $\begin{array}{l}\text { Subset } 7 \\
\text { (All) }\end{array}$ & 0.159 & 158771.8 & 2210.8 & 0.00221 & 1.05 & 0.75 & 0.208 & 11.67 \\
\hline
\end{tabular}


ALFIANELLO (0496-1A)

\begin{tabular}{|l|c|c|c|c|c|c|c|c|}
\multicolumn{9}{c}{$\begin{array}{c}\text { Density of } \\
\text { Chromite }\end{array}$} \\
\hline TM1 & $\boldsymbol{\mu} \mathbf{m}^{2}$ & $\mathbf{m m}^{2}$ & $\boldsymbol{\mu m}^{2}$ & $\mathbf{m m}^{2}$ & Average & $\begin{array}{c}\text { Std } \\
\text { Deviation }\end{array}$ & $\begin{array}{c}\text { Area } \\
\text { Fraction } \\
\text { of chr }\end{array}$ & $\begin{array}{c}\text { LPO \# } \\
\Delta<100>\end{array}$ \\
\hline Subset 1 & 0.030 & 29749.7 & 2319.3 & 0.0023 & 2.83 & 2.31 & 0.310 & 6.71 \\
\hline Subset 2 & 0.012 & 11857.9 & 3120.3 & 0.0031 & 4.82 & 3.07 & 0.302 & 2.57 \\
\hline Subset 3 & 0.020 & 20450.2 & 1760.4 & 0.0018 & 2.94 & 2.78 & 0.259 & 4.59 \\
\hline Subset 4 & 0.025 & 25184.8 & 2144.1 & 0.0021 & 2.55 & 1.69 & 0.184 & 5.30 \\
\hline $\begin{array}{l}\text { Subset 5 } \\
\text { (All) }\end{array}$ & 0.021 & 20975.7 & 9344.1 & 0.0093 & 3.15 & 2.54 & 0.269 & 4.02 \\
\hline
\end{tabular}

\begin{tabular}{|c|c|c|c|c|c|c|c|c|}
\hline \multirow{2}{*}{ TM2 } & \multicolumn{2}{|c|}{$\begin{array}{l}\text { Density of } \\
\text { Chromite }\end{array}$} & \multicolumn{2}{|c|}{ Area of subset } & \multicolumn{2}{|c|}{ Grain Data } & \multirow[b]{2}{*}{$\begin{array}{c}\text { Area } \\
\text { Fraction } \\
\text { of chr }\end{array}$} & \multirow[b]{2}{*}{$\begin{array}{c}\text { LPO \# } \\
\Delta<100>\end{array}$} \\
\hline & $\mu \mathbf{m}^{2}$ & $\mathbf{m m}^{2}$ & $\mu \mathrm{m}^{2}$ & $\mathbf{m m}^{2}$ & Average & $\begin{array}{c}\text { Std } \\
\text { Deviation }\end{array}$ & & \\
\hline Subset 1 & 0.20 & 200565.5 & 304.3 & 0.00030 & 1.25 & 0.62 & 0.307 & 12.67 \\
\hline Subset 2 & 0.19 & 185378.3 & 172.7 & 0.00017 & 1.07 & 0.50 & 0.202 & 12.34 \\
\hline Subset 3 & 0.25 & 254368.5 & 90.5 & 0.00009 & 1.12 & 0.44 & 0.287 & 12.87 \\
\hline Subset 4 & 0.24 & 241708.3 & 625.1 & 0.00062 & 1.15 & 0.53 & 0.304 & 12.47 \\
\hline Subset 5 & 0.22 & 218918.6 & 1682.1 & 0.00168 & 1.14 & 0.59 & 0.283 & 11.17 \\
\hline Subset 6 & 0.24 & 241066.5 & 892.4 & 0.00089 & 1.05 & 0.47 & 0.250 & 10.22 \\
\hline Subset 7 & 0.21 & 211573.0 & 378.4 & 0.00038 & 1.15 & 0.49 & 0.259 & 9.49 \\
\hline Subset 8 & 0.21 & 210740.1 & 522.3 & 0.00052 & 1.21 & 0.57 & 0.293 & 9.18 \\
\hline Subset 9 & 0.23 & 227560.8 & 2541.6 & 0.00254 & 1.10 & 0.55 & 0.273 & 13.04 \\
\hline Subset 10 & 0.22 & 220987.1 & 448.3 & 0.00045 & 1.04 & 0.47 & 0.225 & 12.99 \\
\hline Subset 11 & 0.21 & 207918.6 & 226.2 & 0.00023 & 1.15 & 0.59 & 0.258 & 8.79 \\
\hline Subset 12 & 0.04 & 38889.6 & 1003.5 & 0.00100 & 2.39 & 1.93 & 0.285 & 8.26 \\
\hline Subset 13 & 0.18 & 177273.8 & 9894.9 & 0.00989 & 1.17 & 0.74 & 0.267 & 7.38 \\
\hline $\begin{array}{l}\text { Subset } 14 \\
\text { (All) }\end{array}$ & 0.18 & 181044.2 & 11136.9 & 0.01113 & 1.17 & 0.72 & 0.266 & 6.61 \\
\hline
\end{tabular}

\begin{tabular}{|l|c|c|c|c|c|c|c|c|}
\multicolumn{4}{c}{$\begin{array}{c}\text { Density of } \\
\text { Chromite }\end{array}$} \\
\hline TM3 & $\boldsymbol{\mu} \mathbf{m}^{2}$ & $\mathbf{m m}^{2}$ & $\boldsymbol{\mu m}^{2}$ & $\mathbf{m m}^{2}$ & Average & $\begin{array}{c}\text { Std } \\
\text { Deviation }\end{array}$ & $\begin{array}{c}\text { Area } \\
\text { Fraction } \\
\text { of chr }\end{array}$ & $\begin{array}{c}\text { LPO \# } \\
\Delta<100>\end{array}$ \\
\hline Subset 1 & 0.35 & 351507.8 & 631.3 & 0.000629 & 0.86 & 0.61 & 0.303 & 7 \\
\hline Subset 2* & 0.18 & 178359.1 & 33.8 & 0.000034 & 0.87 & 0.50 & 0.135 & 12.87 \\
\hline
\end{tabular}




\begin{tabular}{|l|c|c|c|c|c|c|c|c|}
\begin{tabular}{|l|l|l|} 
Subset 3 \\
(All)
\end{tabular} & 0.34 & 343014.3 & 664.5 & 0.000662 & 0.86 & 0.60 & 0.295 & 6.96 \\
\hline
\end{tabular}

\begin{tabular}{|c|c|c|c|c|c|c|c|c|}
\hline \multirow[b]{2}{*}{ TM5 } & \multicolumn{2}{|c|}{$\begin{array}{l}\text { Density of } \\
\text { Chromite }\end{array}$} & \multicolumn{2}{|c|}{ Area of subset } & \multicolumn{2}{|c|}{ Grain Data } & \multirow[b]{2}{*}{$\begin{array}{c}\text { Area } \\
\text { Fraction } \\
\text { of chr }\end{array}$} & \multirow[b]{2}{*}{$\begin{array}{c}\text { LPO \# } \\
\Delta<100>\end{array}$} \\
\hline & $\mu \mathbf{m}^{2}$ & $\mathbf{m m}^{2}$ & $\mu \mathrm{m}^{2}$ & $\mathbf{m m}^{2}$ & Average & $\begin{array}{c}\text { Std } \\
\text { Deviation }\end{array}$ & & \\
\hline Subset 1 & 0.27 & 266509.7 & 611.1 & 0.00061 & 1.04 & 0.72 & 0.337 & 9.07 \\
\hline Subset 2 & 0.29 & 284788.9 & 536.8 & 0.00054 & 1.02 & 0.77 & 0.364 & 12.39 \\
\hline Subset 3 & 0.25 & 251070.7 & 67.7 & 0.00007 & 1.08 & 0.46 & 0.266 & 16.12 \\
\hline Subset 4 & 0.30 & 296767.4 & 471.4 & 0.00047 & 0.97 & 0.59 & 0.302 & 12.69 \\
\hline Subset 5* & 0.12 & 117508.8 & 25.5 & 0.00003 & 1.77 & 0.58 & 0.306 & 23.1 \\
\hline $\begin{array}{l}\text { Subset } 6 \\
\text { (All) }\end{array}$ & 0.29 & 291646.6 & 1808.9 & 0.00181 & 1.06 & 0.76 & 0.388 & 7.8 \\
\hline
\end{tabular}

\begin{tabular}{|c|c|c|c|c|c|c|c|c|}
\hline \multirow[b]{2}{*}{$\begin{array}{l}\text { 0496-1A } \\
\text { TM6 }\end{array}$} & \multicolumn{2}{|c|}{$\begin{array}{l}\text { Density of } \\
\text { Chromite }\end{array}$} & \multicolumn{2}{|c|}{ Area of subset } & \multicolumn{2}{|c|}{ Grain Data } & \multirow[b]{2}{*}{$\begin{array}{c}\text { Area } \\
\text { Fraction } \\
\text { of chr }\end{array}$} & \multirow[b]{2}{*}{$\begin{array}{c}\text { LPO \# } \\
\Delta<100>\end{array}$} \\
\hline & $\mu \mathbf{m}^{2}$ & $\mathbf{m m}^{2}$ & $\mu \mathbf{m}^{2}$ & $\mathbf{m m}^{2}$ & Average & $\begin{array}{c}\text { Std } \\
\text { Deviation }\end{array}$ & & \\
\hline Subset 1 & 0.10 & 99789.3 & 630.6 & 0.00063 & 1.61 & 1.18 & 0.310 & 8.3 \\
\hline Subset 2 & 0.13 & 128188.7 & 545.4 & 0.00055 & 1.41 & 0.91 & 0.283 & 6.58 \\
\hline Subset 3 & 0.15 & 153329.2 & 612.3 & 0.00061 & 1.23 & 0.70 & 0.241 & 4.99 \\
\hline Subset 4* & 0.00 & 0.0 & 141.9 & 0.00014 & -- & -- & \#VALUE! & 23.65 \\
\hline Subset 5* & 0.06 & 63155.2 & 79.1 & 0.00008 & 1.03 & 0.35 & 0.058 & 13.13 \\
\hline Subset 6* & 0.08 & 78817.7 & 50.7 & 0.00005 & 1.79 & 1.84 & 0.355 & 10.52 \\
\hline Subset 7* & 0.10 & 101048.4 & 79.1 & 0.00008 & 1.58 & 0.97 & 0.265 & 9.71 \\
\hline $\begin{array}{l}\text { Subset } 8 \\
\text { (All) }\end{array}$ & 0.10 & 104790.9 & 2135.0 & 0.00214 & 1.40 & 0.94 & 0.253 & 4.6 \\
\hline
\end{tabular}


NWA 13533 (0995-1)

\begin{tabular}{|c|c|c|c|c|c|c|c|c|}
\hline & Density & Chromite & Area & subset & Gra & in Data & & \\
\hline $\begin{array}{l}\text { 0995-1 } \\
\text { TM1 }\end{array}$ & $\mu \mathbf{m}^{2}$ & $\mathbf{m m}^{2}$ & $\mu \mathbf{m}^{2}$ & $\mathbf{m m}^{2}$ & Mean & $\begin{array}{c}\text { Std } \\
\text { Deviation }\end{array}$ & $\begin{array}{c}\text { Area } \\
\text { Fraction } \\
\text { of } \\
\text { chromite }\end{array}$ & $\begin{array}{c}\text { LPO } \\
\# \\
\Delta<100>\end{array}$ \\
\hline Subset 1 & 0.073 & 72837.3 & 1427.8 & 0.0014 & 1.38 & 0.41 & 0.118 & 10.41 \\
\hline Subset 2 & 0.049 & 49194.2 & 426.9 & 0.0004 & 1.41 & 0.47 & 0.085 & 11.67 \\
\hline Subset 3 & 0.091 & 90579.7 & 309.1 & 0.0003 & 1.29 & 0.41 & 0.130 & 19.77 \\
\hline Subset 4 & 0.066 & 65833.7 & 1427.8 & 0.0014 & 1.37 & 0.47 & 0.109 & 9.49 \\
\hline Subset 5 & 0.086 & 86462.5 & 323.8 & 0.0003 & 1.33 & 0.34 & 0.127 & 11.46 \\
\hline Subset 6* & 0.049 & 49407.1 & 161.9 & 0.0002 & 1.17 & 0.27 & 0.055 & 17.3 \\
\hline Subset 7 & 0.075 & 74728.3 & 294.4 & 0.0003 & 1.38 & 0.41 & 0.122 & 9.73 \\
\hline Subset 8 & 0.051 & 51297.7 & 721.3 & 0.0007 & 1.28 & 0.35 & 0.071 & 9.85 \\
\hline Subset 9 & 0.072 & 72257.9 & 1619.2 & 0.0016 & 1.37 & 0.40 & 0.116 & 11.52 \\
\hline Subset 10 & 0.087 & 87429.1 & 1692.8 & 0.0017 & 1.43 & 0.49 & 0.157 & 10.94 \\
\hline Subset 11 & 0.107 & 107265.4 & 279.7 & 0.0003 & 1.38 & 0.36 & 0.168 & 13.23 \\
\hline Subset 12 & 0.079 & 79088.3 & 986.2 & 0.0010 & 1.40 & 0.49 & 0.137 & 9.52 \\
\hline Subset 13 & 0.088 & 88315.2 & 294.4 & 0.0003 & 1.31 & 0.35 & 0.126 & 12.95 \\
\hline Subset $14 *$ & 0.044 & 43672.4 & 206.1 & 0.0002 & 1.26 & 0.25 & 0.056 & 12.63 \\
\hline Subset $15^{*}$ & 0.026 & 26128.8 & 191.4 & 0.0002 & 1.17 & 0.27 & 0.030 & 11.83 \\
\hline Subset 16 & 0.045 & 45289.9 & 485.8 & 0.0005 & 1.39 & 0.42 & 0.073 & 8.58 \\
\hline Subset 17 & 0.082 & 81521.7 & 2723.2 & 0.0027 & 1.42 & 0.57 & 0.149 & 9.52 \\
\hline Subset 18 & 0.073 & 73326.4 & 927.4 & 0.0009 & 1.34 & 0.40 & 0.114 & 13.86 \\
\hline Subset 19 & 0.074 & 73596.0 & 176.6 & 0.0002 & 1.17 & 0.20 & 0.085 & 8.37 \\
\hline Subset 20 & 0.048 & 47954.0 & 250.2 & 0.0003 & 1.29 & 0.30 & 0.066 & 10.58 \\
\hline Subset 21 & 0.082 & 81921.4 & 500.5 & 0.0005 & 1.39 & 0.39 & 0.132 & 13.87 \\
\hline Subset 22 & 0.074 & 74404.8 & 618.2 & 0.0006 & 1.21 & 0.26 & 0.089 & 12.64 \\
\hline Subset 23 & 0.079 & 79113.9 & 1162.9 & 0.0012 & 1.42 & 0.45 & 0.138 & 6 \\
\hline $\begin{array}{l}\text { Subset } 24 \\
\text { (All) }\end{array}$ & 0.074 & 73862.4 & 17207.6 & 0.0172 & 1.37 & 0.45 & 0.121 & 4.25 \\
\hline
\end{tabular}

Density of Chromite Area of subset _ Grain Data 


\begin{tabular}{|c|c|c|c|c|c|c|c|c|}
\hline TM4 & $\mu \mathrm{m}^{2}$ & $\mathrm{~mm}^{2}$ & $\mu \mathrm{m}^{2}$ & $\mathbf{m m}^{2}$ & Mean & $\begin{array}{c}\text { Std } \\
\text { Deviation }\end{array}$ & $\begin{array}{c}\text { Area } \\
\text { Fraction } \\
\text { of } \\
\text { chromite }\end{array}$ & $\begin{array}{c}\text { LPO \# } \\
\Delta<100>\end{array}$ \\
\hline Subset 1 & 0.21 & 209399.0 & 334.2 & 0.00033 & 1.21 & 0.61 & 0.302 & 12.04 \\
\hline Subset 2 & 0.17 & 171415.0 & 653.3 & 0.00065 & 1.09 & 0.46 & 0.187 & 8.82 \\
\hline Subset 3 & 0.16 & 159220.5 & 94.2 & 0.00009 & 1.18 & 0.64 & 0.221 & 11.41 \\
\hline Subset 4* & 0.14 & 141023.8 & 63.8 & 0.00006 & 1.17 & 0.40 & 0.169 & 13.11 \\
\hline Subset 5 & 0.15 & 151121.8 & 410.2 & 0.00041 & 1.24 & 0.70 & 0.242 & 8.88 \\
\hline Subset 6 & 0.16 & 158434.2 & 492.2 & 0.00049 & 1.33 & 0.74 & 0.286 & 9.54 \\
\hline Subset 7 & 0.14 & 142938.2 & 671.5 & 0.00067 & 1.25 & 0.61 & 0.217 & 8.75 \\
\hline Subset 8 & 0.18 & 176279.8 & 255.2 & 0.00026 & 1.13 & 0.67 & 0.231 & 9.93 \\
\hline Subset 9 & 0.17 & 171479.7 & 215.7 & 0.00022 & 1.04 & 0.45 & 0.168 & 8.68 \\
\hline Subset 10 & 0.19 & 191949.1 & 72.9 & 0.00007 & 0.95 & 0.57 & 0.181 & 16.35 \\
\hline Subset 11 & 0.10 & 103591.6 & 164.1 & 0.00016 & 1.04 & 0.47 & 0.106 & 16.11 \\
\hline Subset 12 & 0.12 & 119656.6 & 200.5 & 0.00020 & 0.86 & 0.28 & 0.076 & 10.34 \\
\hline Subset 13 & 0.09 & 92994.0 & 279.5 & 0.00028 & 0.95 & 0.34 & 0.071 & 9.71 \\
\hline Subset 14* & 0.01 & 6093.6 & 164.1 & 0.00016 & 5.42 & -- & 0.142 & 13.12 \\
\hline Subset $15^{*}$ & 0.00 & 0.0 & 164.1 & 0.00016 & -- & -- & \#VALUE! & 26.14 \\
\hline Subset $16^{*}$ & 0.03 & 31338.6 & 63.8 & 0.00006 & 8.88 & 4.79 & 0.647 & 21.68 \\
\hline Subset $17^{*}$ & 0.02 & 20249.6 & 197.5 & 0.00020 & 3.86 & 5.76 & 0.442 & 15.4 \\
\hline Subset $18^{*}$ & 0.01 & 11752.0 & 85.1 & 0.00009 & 0.70 & -- & 0.004 & 26.08 \\
\hline Subset 19 & 0.13 & 134245.9 & 4573.0 & 0.00457 & 1.19 & 0.76 & 0.209 & 6.26 \\
\hline $\begin{array}{l}\text { Subset } 20 \\
\text { (All) }\end{array}$ & 0.09 & 85840.6 & 8316.4 & 0.00832 & 1.22 & 0.95 & 0.156 & 6.05 \\
\hline
\end{tabular}

\begin{tabular}{|c|c|c|c|c|c|c|c|c|}
\hline & Density & Chromite & Area & subset & Gr & in Data & & \\
\hline TM5 & $\mu \mathrm{m}^{2}$ & $\mathbf{m m}^{2}$ & $\mu \mathrm{m}^{2}$ & $\mathbf{m m}^{2}$ & Mean & $\begin{array}{c}\text { Std } \\
\text { Deviation }\end{array}$ & $\begin{array}{c}\text { Area } \\
\text { Fraction } \\
\text { of } \\
\text { chromite }\end{array}$ & $\begin{array}{c}\text { LPO \# } \\
\Delta<100>\end{array}$ \\
\hline Subset 1 & 0.072 & 72150.1 & 180.4 & 0.0002 & 1.86 & 1.19 & 0.267 & 3.77 \\
\hline Subset $2 *$ & 0.014 & 14175.0 & 211.9 & 0.0002 & 2.17 & 2.37 & 0.094 & 10.59 \\
\hline Subset 3 & 0.068 & 67761.7 & 2216.7 & 0.0022 & 1.12 & 0.60 & 0.086 & 2.75 \\
\hline Subset 4 & 0.063 & 62974.2 & 5931.3 & 0.0059 & 1.09 & 0.72 & 0.085 & 0.98 \\
\hline $\begin{array}{l}\text { Subset } 5 \\
\text { (All) }\end{array}$ & 0.063 & 63199.7 & 8540.4 & 0.0085 & 1.13 & 0.73 & 0.089 & 0.78 \\
\hline
\end{tabular}

Density of Chromite Area of subset _ Grain Data




\begin{tabular}{|l|c|c|c|c|c|c|c|c|}
\hline TM6 & $\boldsymbol{\mu \mathbf { m } ^ { 2 }}$ & $\mathbf{m m}^{\mathbf{2}}$ & $\boldsymbol{\mu m}^{\mathbf{2}}$ & $\mathbf{m m}^{\mathbf{2}}$ & Mean & $\begin{array}{c}\text { Std } \\
\text { Deviation }\end{array}$ & $\begin{array}{c}\text { Area } \\
\text { Fraction } \\
\text { of } \\
\text { chromite }\end{array}$ & $\begin{array}{c}\text { LPO \# } \\
\boldsymbol{\Delta}<\mathbf{1 0 0 >}\end{array}$ \\
\hline Subset 1 & 0.025 & 24789.8 & 71444.8 & 0.071 & 2.36 & 3.89 & 0.403 & 1.45 \\
\hline Subset 2 & 0.015 & 15277.9 & 5040.3 & 0.005 & 3.92 & 4.60 & 0.435 & 6.79 \\
\hline $\begin{array}{l}\text { Subset 3 } \\
\text { (All) }\end{array}$ & 0.024 & 24163.0 & 76485.1 & 0.076 & 2.43 & 3.93 & 0.405 & 1.4 \\
\hline
\end{tabular}

SPADE (0269-1A)

\begin{tabular}{|l|c|c|c|c|c|}
\hline TM1 & pixel & $\%$ & $\begin{array}{c}\text { grain } \\
\text { count: }\end{array}$ & $\begin{array}{c}\text { Total \# } \\
\text { of chr } \\
\text { grain } \\
\text { pixels }\end{array}$ & Prevailing Grain Size \\
\hline Subset 1 (All) & 150223 & 0.1571 & 109 & 8150 & $</=13$ \\
\hline
\end{tabular}

\begin{tabular}{|l|c|c|c|c|c|}
\hline TM2 & pixel & \% & $\begin{array}{c}\text { grain } \\
\text { count: }\end{array}$ & $\begin{array}{c}\text { Total \# } \\
\text { of chr } \\
\text { grain } \\
\text { pixels }\end{array}$ & Prevailing Grain Size \\
\hline Subset 1 & 41201 & 0.0751 & 59 & 8573 & $</=15, \sim 31, \sim 33$ \\
\hline Subset 2* & 3614 & 0.0066 & 2 & 1741 & No prevailing \\
\hline Subset 3 (All) & 44815 & 0.0816 & 61 & 10314 & $\sim 22, \sim 33, \sim 38$ \\
\hline
\end{tabular}

\begin{tabular}{|l|c|c|c|c|c|}
\hline & pixel & $\%$ & $\begin{array}{c}\text { grain } \\
\text { count: }\end{array}$ & $\begin{array}{c}\text { Total \# } \\
\text { of chr } \\
\text { grain } \\
\text { pixels }\end{array}$ & Prevailing Grain Size \\
\hline Subset 1 (All) & 43657 & 0.0528 & 120 & 19491 & $24-30,38-46, \sim 74$ \\
\hline
\end{tabular}

ESTACADO (0295-3C)

\begin{tabular}{|l|c|c|c|c|c|}
\hline TM1 & $\begin{array}{c}\text { pixel } \\
\text { (all, } \\
\mu \mathrm{m} 2)\end{array}$ & $\begin{array}{c}\text { chromite } \\
\text { grain \# } \\
\text { density) } \\
\%\end{array}$ & $\begin{array}{c}\text { grain } \\
\text { count: }\end{array}$ & $\begin{array}{c}\text { Total \# } \\
\text { of chr } \\
\text { grain } \\
\text { pixels }\end{array}$ & Prevailing Grain Size \\
\hline
\end{tabular}




\begin{tabular}{|l|c|c|c|c|c|} 
Subset 1 & 74798 & 0.0891 & 238 & 17743 & $</=2.5$ \\
\hline Subset 2 & 10987 & 0.0131 & 45 & 1432 & $</=1, \sim 2.1, \sim 2.5$ \\
\hline Subset 3* & 2774 & 0.0033 & 9 & 237 & No prevailing \\
\hline Subset 4* & 2041 & 0.0024 & 8 & 339 & No prevailing \\
\hline Subset 5 & 101648 & 0.1211 & 309 & 22198 & $</=2.5$ \\
\hline Subset 6* & 2177 & 0.0026 & 6 & 210 & No prevailing \\
\hline Subset 7 (All) & 108640 & 0.1294 & 332 & 22984 & $</=1.7, \sim 2.5$ \\
\hline
\end{tabular}

\begin{tabular}{|l|c|c|c|c|c|}
\hline TM2 & $\begin{array}{c}\text { pixel } \\
\text { (all, } \\
\boldsymbol{\mu m 2} \text { 2) }\end{array}$ & $\begin{array}{c}\text { (chromite } \\
\text { grain \# } \\
\text { density) } \\
\text { \% }\end{array}$ & $\begin{array}{c}\text { grain } \\
\text { count: }\end{array}$ & $\begin{array}{c}\text { Total \# } \\
\text { of chr } \\
\text { grain } \\
\text { pixels }\end{array}$ & Prevailing Grain Size \\
\hline Subset 1 (All) & 159053 & 0.3878 & 350 & 88164 & $</=16$ \\
\hline
\end{tabular}

\begin{tabular}{|l|c|c|c|c|c|}
\hline TM3 & $\begin{array}{c}\text { pixel } \\
\text { (all, } \\
\boldsymbol{\mu m 2} \text { 2) }\end{array}$ & $\begin{array}{c}\text { (chromite } \\
\text { grain \# } \\
\text { density) } \\
\text { \% }\end{array}$ & $\begin{array}{c}\text { grain } \\
\text { count: }\end{array}$ & $\begin{array}{c}\text { Total \# } \\
\text { of chr } \\
\text { grain } \\
\text { pixels }\end{array}$ & Prevailing Grain Size \\
\hline Subset 1 (All) & 30253 & 0.0738 & 168 & 3521 & $</=2.3$ \\
\hline
\end{tabular}

\begin{tabular}{|l|c|c|c|c|c|}
\hline TM4 & $\begin{array}{c}\text { pixel } \\
\text { (all, } \\
\boldsymbol{\mu m} \text { 2) }\end{array}$ & $\begin{array}{c}\text { (chromite } \\
\text { grain \# } \\
\text { density) } \\
\text { \% }\end{array}$ & $\begin{array}{c}\text { grain } \\
\text { count: }\end{array}$ & $\begin{array}{c}\text { Total \# } \\
\text { of chr } \\
\text { grain } \\
\text { pixels }\end{array}$ & Prevailing Grain Size \\
\hline Subset 1 & 22396 & 0.0546 & 102 & 3218 & $</=0.6, \sim 1.5$ \\
\hline Subset 2 & 6497 & 0.0158 & 17 & 838 & No prevailing \\
\hline Subset 3 & 8780 & 0.0214 & 34 & 1445 & No prevailing \\
\hline Subset 4 & 6893 & 0.0168 & 20 & 894 & No prevailing \\
\hline Subset 5 & 37220 & 0.0907 & 137 & 5634 & $</=1.9$ \\
\hline Subset 6 & 16906 & 0.0412 & 39 & 2900 & No prevailing \\
\hline Subset 7* & 2127 & 0.0052 & 2 & 1022 & No prevailing \\
\hline Subset 8 (All) & 71926 & 17.54 & 232 & 11895 & $</=1.6, \sim 2.9$ \\
\hline
\end{tabular}

\begin{tabular}{|l|c|c|c|c|c|}
\hline TM5 & $\begin{array}{c}\text { pixel } \\
\text { (all, } \\
\boldsymbol{\mu m 2} \text { 2) }\end{array}$ & $\begin{array}{c}\text { (chromite } \\
\text { grain \# } \\
\text { density) } \\
\text { \% }\end{array}$ & $\begin{array}{c}\text { grain } \\
\text { count: }\end{array}$ & $\begin{array}{c}\text { Total \# } \\
\text { of chr } \\
\text { grain } \\
\text { pixels }\end{array}$ & Prevailing Grain Size \\
\hline Subset 1 & 3796 & 0.0052 & 17 & 778 & No prevailing \\
\hline Subset 2 & 73177 & 0.1004 & 260 & 15386 & $</=2.6$ \\
\hline Subset 3 & 5639 & 0.0077 & 27 & 919 & $</=1.3, \sim 2.3$ \\
\hline Subset 4 & 5708 & 0.0078 & 19 & 227 & No prevailing \\
\hline Subset 5 & 3452 & 0.0047 & 11 & 559 & No prevailing \\
\hline
\end{tabular}




\begin{tabular}{|l|c|c|c|c|c|} 
Subset 6 & 1939 & 0.0027 & 10 & 306 & No prevailing \\
\hline Subset 7 (All) & 98232 & 0.1348 & 351 & 20467 & $</=1.6, \sim 7.2$ \\
\hline
\end{tabular}

\section{ALFIANELLO (0496-1A)}

\begin{tabular}{|l|c|c|c|c|c|}
\hline TM1 & $\begin{array}{c}\text { pixel } \\
\text { (all, } \\
\boldsymbol{\mu m 2} \text { 2) }\end{array}$ & $\begin{array}{c}\text { (chromite } \\
\text { grain \# } \\
\text { density) } \\
\mathbf{\%}\end{array}$ & $\begin{array}{c}\text { grain } \\
\text { count: }\end{array}$ & $\begin{array}{c}\text { Total \# } \\
\text { of chr } \\
\text { grain } \\
\text { pixels }\end{array}$ & Prevailing Grain Size \\
\hline Subset 1 & 11440 & 0.0278 & 69 & 3549 & $\sim 8.1, \sim 9.3$ \\
\hline Subset 2 & 15415 & 0.0374 & 37 & 4648 & $\sim 6-8, \sim 13.5$ \\
\hline Subset 3 & 8692 & 0.0211 & 36 & 2249 & No prevailing \\
\hline Subset 4 & 10594 & 0.0257 & 54 & 1948 & $</=5.6, \sim 7.3$ \\
\hline Subset 5 (All) & 46141 & 0.112 & 196 & 12394 & $</=8.5$ \\
\hline
\end{tabular}

\begin{tabular}{|l|c|c|c|c|c|}
\hline TM2 & $\begin{array}{c}\text { pixel } \\
\text { (all, } \\
\text { Mm2) }\end{array}$ & $\begin{array}{c}\text { (chromite } \\
\text { grain \# } \\
\text { density) } \\
\text { \% }\end{array}$ & $\begin{array}{c}\text { grain } \\
\text { count: }\end{array}$ & $\begin{array}{c}\text { Total \# } \\
\text { of chr } \\
\text { grain } \\
\text { pixels }\end{array}$ & Prevailing Grain Size \\
\hline Subset 1 & 4863 & 0.0074 & 61 & 1491 & $\sim 1.9, \sim 2.4, \sim 3.2$ \\
\hline Subset 2 & 2768 & 0.0042 & 32 & 559 & $\sim 1.6$ \\
\hline Subset 3 & 1448 & 0.0022 & 23 & 415 & $\sim 1.2, \sim 1.8$ \\
\hline Subset 4 & 9978 & 0.0152 & 151 & 3035 & $</=1.9$ \\
\hline Subset 5 & 26935 & 0.0409 & 368 & 7633 & $</=2$ \\
\hline Subset 6 & 14279 & 0.0217 & 215 & 3565 & $</=1.5$ \\
\hline Subset 7 & 6058 & 0.0092 & 80 & 1566 & $</=1.8, \sim 2.8$ \\
\hline Subset 8 & 8368 & 0.0127 & 110 & 2455 & $</=2.3$ \\
\hline Subset 9 & 40642 & 0.0618 & 578 & 11075 & $</=2.2$ \\
\hline Subset 10 & 7203 & 0.0109 & 99 & 1622 & $</=1.1, \sim 2.1$ \\
\hline Subset 11 & 3598 & 0.0055 & 47 & 928 & $</=1.2, \sim 2.3$ \\
\hline Subset 12 & 16045 & 0.0244 & 39 & 4580 & $</=5.9$ \\
\hline Subset 13 & 158343 & 0.2406 & 1753 & 42348 & $</=2$ \\
\hline $\begin{array}{l}\text { Subset 14 } \\
\text { (All) }\end{array}$ & 178214 & 0.2708 & 2015 & 47431 & $</=2$ \\
\hline
\end{tabular}

\begin{tabular}{|l|c|c|c|c|c|}
\hline TM3 & $\begin{array}{c}\text { pixel } \\
\text { (all, } \\
\boldsymbol{\mu m 2} \text { 2) }\end{array}$ & $\begin{array}{c}\text { (chromite } \\
\text { grain \# } \\
\text { density) } \\
\text { \% }\end{array}$ & $\begin{array}{c}\text { grain } \\
\text { count: }\end{array}$ & $\begin{array}{c}\text { Total \# } \\
\text { of chr } \\
\text { grain } \\
\text { pixels }\end{array}$ & Prevailing Grain Size \\
\hline Subset 1 & 43823 & 0.1084 & 221 & 13291 & $</=1.1, \sim 2.5$ \\
\hline Subset 2* & 2334 & 0.0058 & 6 & 314 & No prevailing \\
\hline
\end{tabular}




\begin{tabular}{|c|c|c|c|c|c|}
\hline Subset 3 (All) & 46157 & 0.1141 & 227 & 13605 & $</=1.8, \sim 2.6$ \\
\hline TM4 & $\begin{array}{c}\text { pixel } \\
\text { (all, } \\
\mu \mathrm{m} 2)\end{array}$ & $\begin{array}{c}\text { (chromite } \\
\text { grain \# } \\
\text { density) } \\
\%\end{array}$ & $\begin{array}{l}\text { grain } \\
\text { count: }\end{array}$ & $\begin{array}{c}\text { Total \# } \\
\text { of chr } \\
\text { grain } \\
\text { pixels }\end{array}$ & Prevailing Grain Size \\
\hline Subset 1 & 2366 & 0.0059 & 13 & 278 & $\sim 1.1, \sim 1.24, \sim 1.35$ \\
\hline Subset 2 & 12916 & 0.0319 & 106 & 3107 & $</=1.1,</=1.5$ \\
\hline Subset 3 & 10536 & 0.0261 & 75 & 3174 & $</=1.3, \sim 3.2$ \\
\hline Subset 4 & 15435 & 3.82 & 98 & 5929 & $</=2.3, \sim 3.6, \sim 5$ \\
\hline Subset 5 & 25849 & 0.0639 & 174 & 9419 & $</=1.5,</=2.3, \sim 3.6$ \\
\hline Subset 6 & 4231 & 0.0105 & 10 & 1541 & No prevailing \\
\hline Subset 7 & 4668 & 0.0115 & 10 & 2945 & No prevailing \\
\hline Subset $8^{*}$ & 1743 & 0.0043 & 7 & 642 & No prevailing \\
\hline Subset 9 & 3693 & 0.0091 & 13 & 722 & No prevailing \\
\hline $\begin{array}{l}\text { Subset } 10 \\
\text { (All) }\end{array}$ & 56411 & 0.1395 & 336 & 18761 & $</=1.4,>/=2.2$ \\
\hline
\end{tabular}

\begin{tabular}{|l|c|c|c|c|c|}
\hline TM5 & $\begin{array}{c}\text { pixel } \\
\text { (all, } \\
\boldsymbol{\mu m 2} \text { 2) }\end{array}$ & $\begin{array}{c}\text { (chromite } \\
\text { grain \# } \\
\text { density) } \\
\text { \% }\end{array}$ & $\begin{array}{c}\text { grain } \\
\text { count: }\end{array}$ & $\begin{array}{c}\text { Total \# } \\
\text { of chr } \\
\text { grain } \\
\text { pixels }\end{array}$ & Prevailing Grain Size \\
\hline Subset 1 & 22296 & 0.0551 & 163 & 7505 & $</=2, \sim 5.2$ \\
\hline Subset 2 & 19580 & 0.0484 & 153 & 7125 & $</=2.5, \sim 4.7$ \\
\hline Subset 3 & 2473 & 0.0061 & 17 & 658 & $\sim 1.1, \sim 1.8, \sim 2$ \\
\hline Subset 4 & 17174 & 0.0425 & 140 & 5188 & $</=1.8, \sim 4.7$ \\
\hline Subset 5* & 939 & 0.0023 & 3 & 287 & No prevailing \\
\hline Subset 6 (All) & 65976 & 0.1631 & 528 & 25595 & $</=1.2, \sim 4.5$ \\
\hline
\end{tabular}

\begin{tabular}{|l|c|c|c|c|c|}
\hline TM6 & $\begin{array}{c}\text { pixel } \\
\text { (all, } \\
\boldsymbol{\mu m 2} \text { 2) }\end{array}$ & $\begin{array}{c}\text { (chromite } \\
\text { grain \# } \\
\text { density) } \\
\text { \% }\end{array}$ & $\begin{array}{c}\text { grain } \\
\text { count: }\end{array}$ & $\begin{array}{c}\text { Total \# } \\
\text { of chr } \\
\text { grain } \\
\text { pixels }\end{array}$ & Prevailing Grain Size \\
\hline Subset 1 & 12582 & 0.0311 & 63 & 3896 & $</=2.6, \sim 6, \sim 7.1$ \\
\hline Subset 2 & 10886 & 0.0269 & 70 & 3076 & $</=2.8, \sim 4.2, \sim 5.8$ \\
\hline Subset 3 & 12226 & 0.0302 & 94 & 2951 & $</=2.7, \sim 3.3, \sim 3.8$ \\
\hline Subset 4* & 2821 & 0.007 & 0 & -- & No prevailing \\
\hline Subset 5* & 1559 & 0.0039 & 5 & 91 & No prevailing \\
\hline Subset 6* & 1009 & 0.0025 & 4 & 358 & No prevailing \\
\hline Subset 7* & 1567 & 0.0039 & 8 & 416 & No prevailing \\
\hline
\end{tabular}


\begin{tabular}{|l|l|l|l|l|l|} 
Subset 8 (All) & 42573 & 0.1053 & 224 & 10788 & $</=2, \sim 4.4$ \\
\hline
\end{tabular}

NWA 13533 (0995-1)

\begin{tabular}{|c|c|c|c|c|c|}
\hline TM1 & $\begin{array}{l}\text { pixel } \\
\text { (all, } \\
\mu \mathrm{m} 2)\end{array}$ & $\begin{array}{c}\text { (chromite } \\
\text { grain \# } \\
\text { density) } \\
\%\end{array}$ & $\begin{array}{l}\text { grain } \\
\text { count: }\end{array}$ & $\begin{array}{l}\text { Total \# } \\
\text { of chr } \\
\text { grain } \\
\text { pixels }\end{array}$ & $\begin{array}{l}\text { Prevailing Grain Size } \\
(\boldsymbol{\mu m})\end{array}$ \\
\hline Subset 1 & 9681 & 0.0097 & 104 & 1144 & $<1.7$ \\
\hline Subset 2 & 2868 & 0.0029 & 21 & 245 & $1.3-1.5, \sim 2.5$ \\
\hline Subset 3 & 2092 & 0.0021 & 28 & 271 & $</=2,2.8$ \\
\hline Subset 4 & 9651 & 0.0097 & 94 & 1051 & $</=1.7$ \\
\hline Subset 5 & 2209 & 0.0022 & 28 & 281 & $</=1.5, \sim 1.9$ \\
\hline Subset 6* & 1101 & 0.0011 & 8 & 61 & No prevailing \\
\hline Subset 7 & 1972 & 0.002 & 22 & 241 & No prevailing \\
\hline Subset 8 & 4872 & 0.0049 & 37 & 346 & No prevailing \\
\hline Subset 9 & 10948 & 0.011 & 117 & 1268 & $</=2$ \\
\hline Subset 10 & 11448 & 0.0115 & 148 & 1794 & $<2.5$ \\
\hline Subset 11 & 1940 & 0.0019 & 30 & 325 & No prevailing \\
\hline Subset 12 & 6632 & 0.0067 & 78 & 910 & $</=2.7$ \\
\hline Subset 13 & 2005 & 0.002 & 26 & 252 & $</=1.05, \sim 1.3, \sim 1.7$ \\
\hline Subset 14* & 1415 & 0.0014 & 9 & 79 & No prevailing \\
\hline Subset $15 *$ & 1261 & 0.0013 & 5 & 38 & No prevailing \\
\hline Subset 16 & 3334 & 0.0033 & 22 & 244 & $</=1.2,</=1.5, \sim 2.7$ \\
\hline Subset 17 & 18472 & 0.0185 & 222 & 2754 & $</=2.6$ \\
\hline Subset 18 & 6240 & 0.0063 & 68 & 710 & $</=1.5, \sim 2.4, \sim 3$ \\
\hline Subset 19 & 1147 & 0.0012 & 13 & 97 & No prevailing \\
\hline Subset 20 & 1696 & 0.0017 & 12 & 112 & No prevailing \\
\hline Subset 21 & 3407 & 0.0034 & 41 & 451 & $</=1.1,</=1.4,</=1.6$ \\
\hline Subset 22 & 4226 & 0.0042 & 46 & 375 & No prevailing \\
\hline Subset 23 & 7901 & 0.0079 & 92 & 1092 & $</=1.6, \sim 2.3$ \\
\hline $\begin{array}{l}\text { Subset } 24 \\
\text { (All) }\end{array}$ & 116518 & 0.1169 & 1271 & 14141 & $</=2$ \\
\hline
\end{tabular}

\begin{tabular}{|l|c|c|c|c|c|}
\hline TM4 & $\begin{array}{c}\text { pixel } \\
\text { (all, } \\
\boldsymbol{\mu m 2} \text { 2) }\end{array}$ & $\begin{array}{c}\text { (chromite } \\
\text { grain \# } \\
\text { density) } \\
\text { \% }\end{array}$ & $\begin{array}{c}\text { grain } \\
\text { count: }\end{array}$ & $\begin{array}{c}\text { Total \# } \\
\text { of chr } \\
\text { grain } \\
\text { pixels }\end{array}$ & Prevailing Grain Size \\
\hline Subset 1 & 10532 & 0.011 & 70 & 3184 & $</=2.7$ \\
\hline Subset 2 & 20482 & 0.0215 & 112 & 3827 & $</=2.1$ \\
\hline Subset 3 & 2971 & 0.0031 & 15 & 658 & $</=1.7, \sim 3.1$ \\
\hline Subset 4* & 1973 & 0.0021 & 9 & 334 & No prevailing \\
\hline
\end{tabular}




\begin{tabular}{|l|c|c|c|c|c|} 
Subset 5 & 12872 & 0.0135 & 62 & 3114 & $\sim 1.3, \sim 3.3, \sim 4.1$ \\
\hline Subset 6 & 15469 & 0.0162 & 78 & 4430 & $</=2.3,2.7$ \\
\hline Subset 7 & 21087 & 0.0221 & 96 & 4566 & $<2, \sim 2.3, \sim 2.5$ \\
\hline Subset 8 & 7998 & 0.0084 & 45 & 1850 & $</=1.3, \sim 2.6, \sim 3.7$ \\
\hline Subset 9 & 6805 & 0.0071 & 37 & 1143 & $\sim 1.2, \sim 1.5,>/=1.7$ \\
\hline Subset 10 & 2270 & 0.0024 & 14 & 412 & $>/=0.4, \sim 2.8$ \\
\hline Subset 11 & 5114 & 0.0054 & 17 & 540 & $\sim 1, \sim 1.4, \sim 1.9$ \\
\hline Subset 12 & 6322 & 0.0066 & 24 & 480 & $</=0.8, \sim 1.3, \sim 1.4$ \\
\hline Subset 13 & 8817 & 0.0092 & 26 & 625 & $</=1.3$ \\
\hline Subset 14* & 5111 & 0.0054 & 1 & 726 & No prevailing \\
\hline Subset 15* & 5113 & 0.0054 & 0 & -- & No prevailing \\
\hline Subset 16* & 2018 & 0.0021 & 2 & 1306 & $\sim 7.4$ \\
\hline Subset 17* & 6199 & 0.0065 & 4 & 2739 & $\sim 10.5$ \\
\hline Subset 18* & 2710 & 0.0028 & 1 & 12 & No prevailing \\
\hline Subset 19 & 143713 & 0.1505 & 614 & 30068 & $</=1,5$ \\
\hline $\begin{array}{l}\text { Subset 20 } \\
\text { (All) }\end{array}$ & 261262 & 0.2737 & 714 & 40867 & $</=2$ \\
\hline
\end{tabular}

\begin{tabular}{|l|c|c|c|c|c|}
\hline TM5 & $\begin{array}{c}\text { pixel } \\
\text { (all, } \\
\boldsymbol{\mu m 2} \text { 2) }\end{array}$ & $\begin{array}{c}\text { (chromite } \\
\text { grain \# } \\
\text { density) } \\
\text { \% }\end{array}$ & $\begin{array}{c}\text { grain } \\
\text { count: }\end{array}$ & $\begin{array}{c}\text { Total \# } \\
\text { of chr } \\
\text { grain } \\
\text { pixels }\end{array}$ & Prevailing Grain Size \\
\hline Subset 1 & 5699 & 0.0063 & 13 & 1524 & No prevailing \\
\hline Subset 2* & 6664 & 0.0074 & 3 & 627 & No prevailing \\
\hline Subset 3 & 69690 & 0.0774 & 150 & 5969 & $</=2.5$ \\
\hline Subset 4 & 186325 & 0.2071 & 373 & 15815 & $</=3.5$ \\
\hline Subset 5 (All) & 268378 & 0.2982 & 539 & 23935 & $</=3.5, \sim 5$ \\
\hline
\end{tabular}

\begin{tabular}{|l|c|c|c|c|c|}
\hline TM6 & $\begin{array}{c}\text { pixel } \\
\text { (all, } \\
\text { Mm2) }\end{array}$ & $\begin{array}{c}\text { (chromite } \\
\text { grain \# } \\
\text { density) } \\
\text { \% }\end{array}$ & $\begin{array}{c}\text { grain } \\
\text { count: }\end{array}$ & $\begin{array}{c}\text { Total \# } \\
\text { of chr } \\
\text { grain } \\
\text { pixels }\end{array}$ & Prevailing Grain Size \\
\hline Subset 1 & 2200166 & 0.4621 & 1771 & 887487 & $5-27$ \\
\hline Subset 2 & 155225 & 0.0326 & 77 & 67469 & $9-29$ \\
\hline Subset 3 (All) & 2355391 & 0.4947 & 1848 & 954956 & $5-27$ \\
\hline
\end{tabular}

